\title{
EFFECTS OF UNIVERSITY PREPARATION AND ENGAGEMENT ON ACHIEVEMENT
}

\author{
BY \\ ELIZABETH MARIE CHINLUND
}

\author{
A thesis \\ submitted to Victoria University of Wellington \\ in partial fulfilment of the requirements for a degree of \\ Master of Education
}

Victoria University of Wellington, New Zealand

2013 

Effects of University Preparation and Engagement on Achievement

Table of Contents

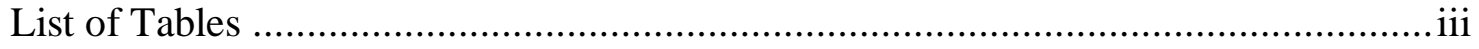

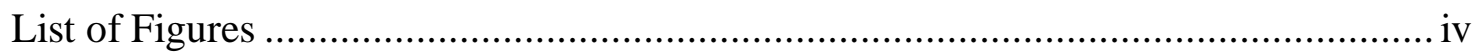

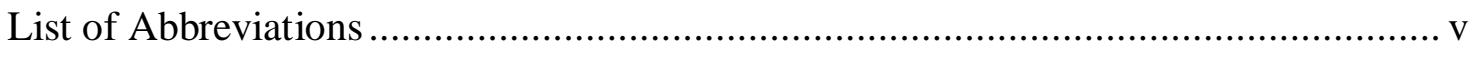

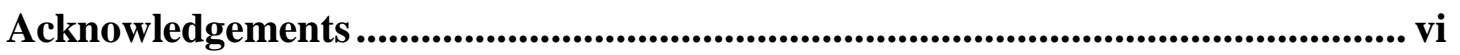

Abstract .................................................................................................................. vii

Effects of University Preparation and Engagement on Achievement ................... 1

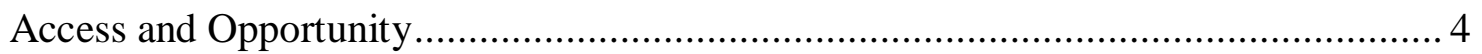

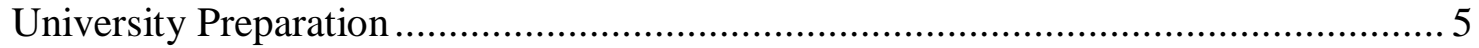

New Zealand Context of Preparation. .................................................................. 7

Diversity and Preparation Programmes. .............................................................. 12

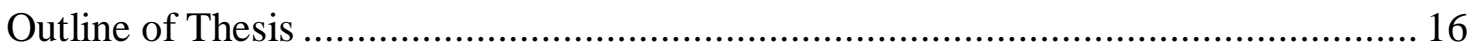

Chapter 2. Literature Review ............................................................................... 17

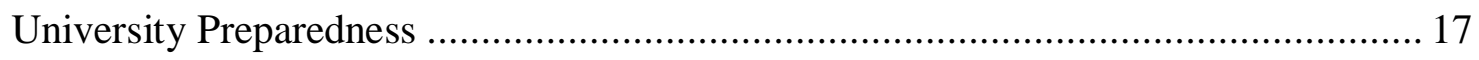

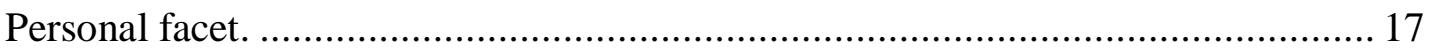

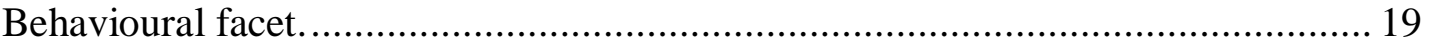

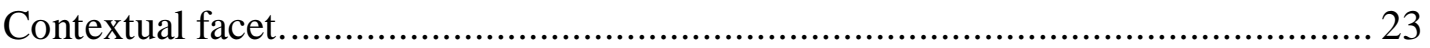

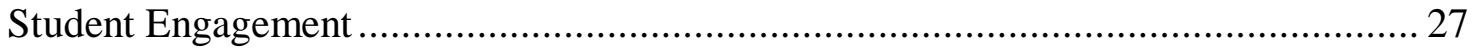

Academic Achievement and Engagement. ...................................................... 31

Chapter 3. Method ...................................................................................... 34

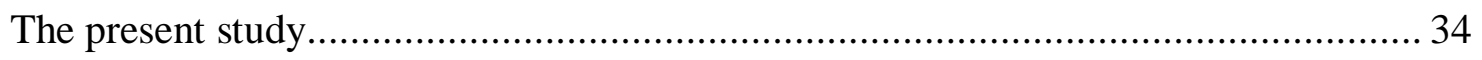

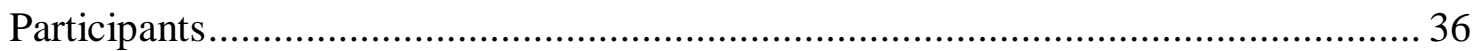

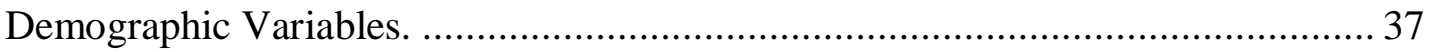

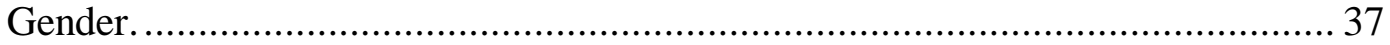

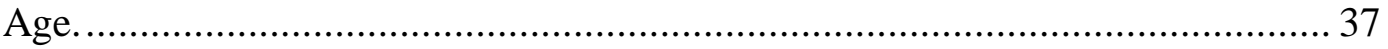

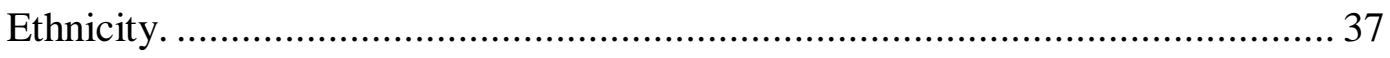

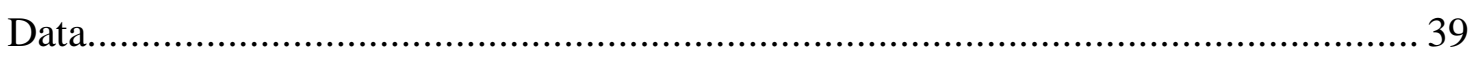

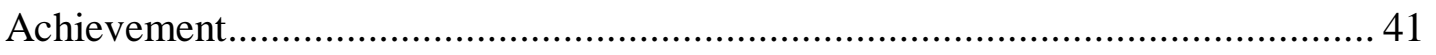

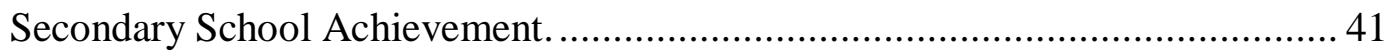

CUP and First-year Degree Level University Achievement............................. 42

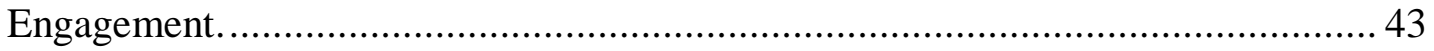

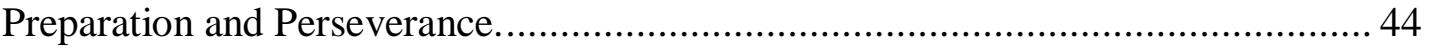

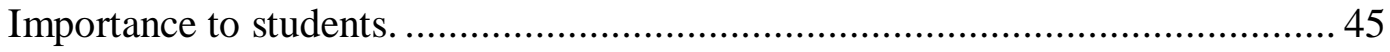

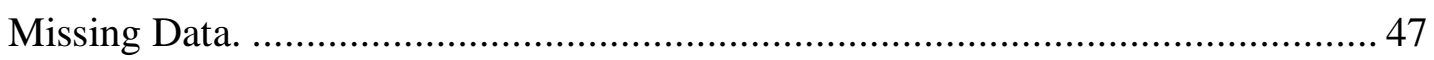

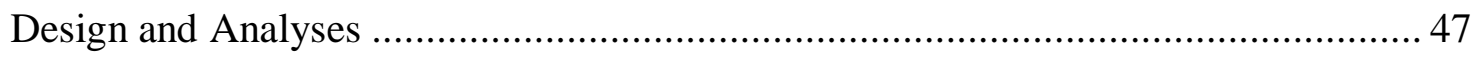

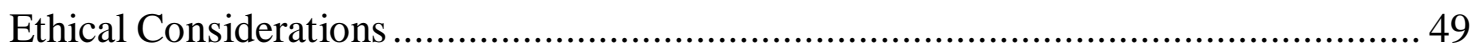




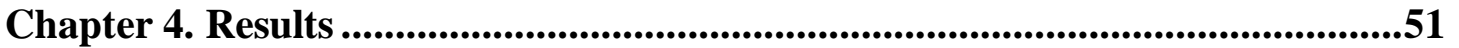

Academic achievement as mediated by CUP and engagement ......................... 51

Controlling for Variables Related to Achievement. ...................................... 54

Predicting university achievement from past achievement .................................. 56

Comparative group by prior achievement. ................................................ 59

Achievement as related to academic perseverance, engagement, and preparation

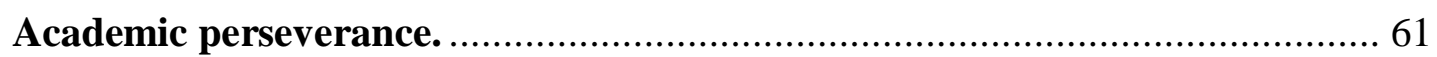

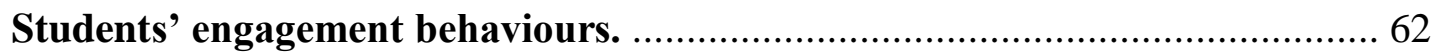

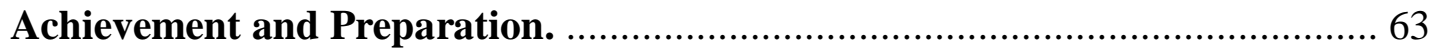

The Value of Engagement Practices and Their Links to Achievement. ..................... 66

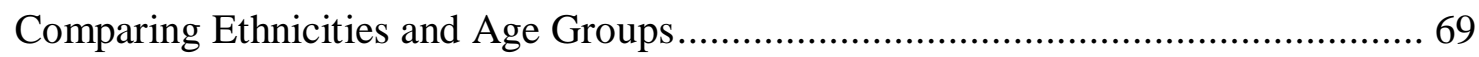

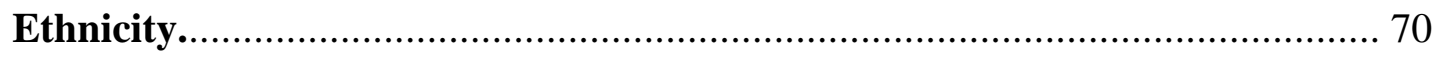

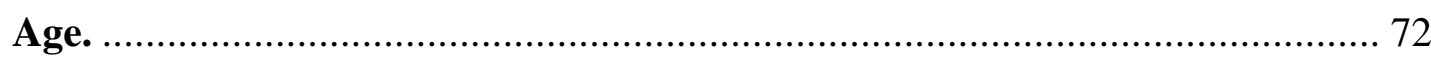

Chapter 5. Discussion and Conclusion ...............................................................75

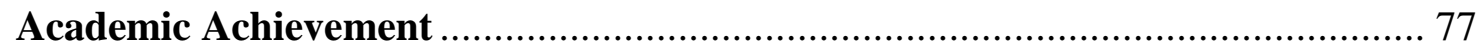

Predicting University Achievement from Secondary School Achievement............. 79

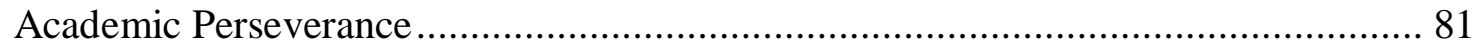

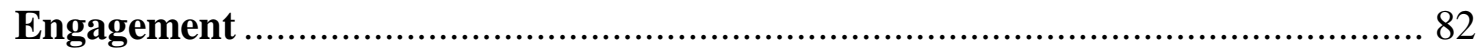

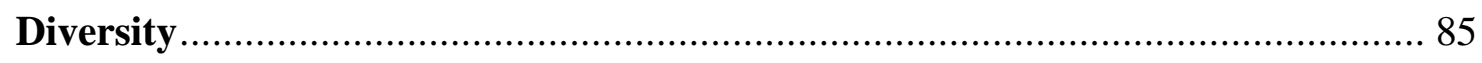

Practices and behaviours related to achievement ........................................ 88

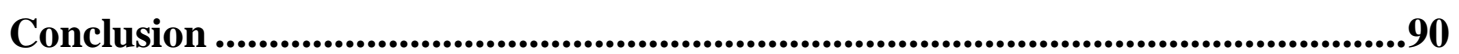

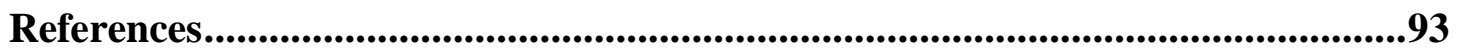

Appendix A. Survey .................................................................................................110

Appendix B. Participant Information Sheet ......................................................115

Appendix C. Reports of Preliminary Analyses .........................................................116 


\section{List of Tables}

Table 1. Achievement Data Amount and Sources.

Table 2. Summary of Correlations Between Engagement Subscales and Achievement

Table 3. Predictors of First-Year University Achievement........................53

Table 4. Hierarchical Multiple Regression of First-Year Achievement and Correlated

Variables

Table 5. Correlations Between Expected Academic Perseverance and Achievement

Table 6. Correlations Between Engagement Behaviours and Achievement...........63

Table 7. Summary of Correlations Between CUP Items as a Function of Achievement

Level.......................................................................64

Table 8. Top Five Most Useful Skills............................................65

Table 9. Students' Importance Ratings of Items.................................68

Table 10. Engagement Survey Prompts...................................... 110

Table 11. Factor Loadings of Academic Challenge Subscale.......................120

Table 12. Factor Loadings of Expected Academic Perseverance Subscale............122

Table 13. Factor Loadings for Academic Readiness Engagement Subscale.......... 124

Table 14. Factor Loadings for Active Learning Engagement Subscale...............126

Table 15. Factor Loadings for General Development Outcomes Engagement Subscale

Table 16. Factor Loadings for General Learning Outcomes Engagement Subscale

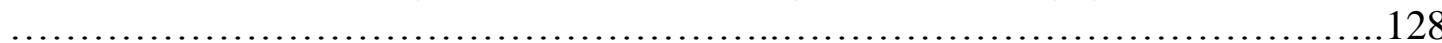

Table 17. Factor Loadings for Supportive Learning Environment Engagement

Subscale. 


\section{List of Figures}

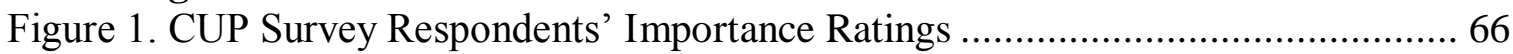

Figure 2. Importance Ratings by Percentage within Ethnicities................................... 71

Figure 3. Importance Ratings by Percentage within Age Groups ................................ 73

Figure 4. Histogram of CUP Students' Level 3 Achievement Standard Scale Locations

Figure 5. Q-Q Plot of CUP Students' Level 3 Achievement Standard Scale Location ...116

Figure 6. Histogram of CUP Awarded Achievement Scale Location ...........................117

Figure 7. Q-Q Plot of CUP Awarded Achievement Scale Location..............................117

Figure 8. Histogram of CUP-Awarded Students' VUW First-year Achievement Scale

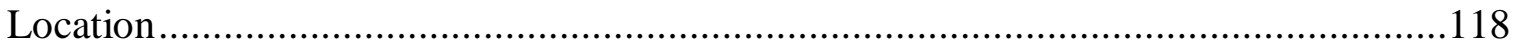

Figure 9. Q-Q Plot of CUP Awarded First-Year VUW Achievement Scale Location....118 Figure 10. Histogram of CUP-Failed Students' VUW First-year Achievement Scale Location.

Figure 11. Histogram of Academic Challenge Scale Locations for CUP Survey

Respondents

Figure 12. Histogram of Perseverance Scale Locations for CUP Survey Respondents ..123

Figure 13. Histogram of Academic Readiness Scale Locations for CUP Survey

Respondents

Figure 14. Histogram of General Development Outcomes Scale Locations for CUP

Survey Respondents ....

Figure 15. Histogram of General Learning Outcome Scale Locations for CUP Survey

Respondents

Figure 16. Histogram of Supportive Learning Environment Scale Locations for CUP

Survey Respondents 


\section{List of Abbreviations}

\section{Abbreviation Definition}

ACT

American College Test (U.S.A.)- administers and evaluates university preparedness measures, mainly for admissions purposes

AUSSE Australasian Survey of Student Engagement (Australia \& N.Z.)

BCSSE Beginning College (university) Survey of Student Engagement (Canada \& U.S.A.)

CUP Certificate of University Preparation - level 4 pre-degree programme (N.Z.)

GPA Grade point average

IRT Item Response Theory, statistical procedure used for calibrating data

ITP Institutes of Technology and Polytechnics (N.Z.)

MSD Ministry of Social Development (N.Z.)

NCEA National Certificate of Educational Attainment - secondary school qualification (N.Z.)

NSSE National Survey of Student Engagement (U.S.A.)

NZ New Zealand/Aotearoa

NZQA New Zealand Qualifications Authority (N.Z.)

OECD Organisation for Economic Cooperation and Development (global)

OLS Ordinary least-squares, linear regression statistical procedure

PFA Primary Factor Analysis, psychometric statistical procedure

SAT Scholarly Achievement Test (U.S.A.) - standardised test used for secondary to university admissions

TEC Tertiary Education Commission (N.Z.)

UE University Entrance (N.Z.)

VUW Victoria University of Wellington (N.Z.)

\section{List of Statistical Symbols}

$\begin{array}{ll}\text { Symbol } & \text { Definition } \\ \Delta & \text { Change } \\ \alpha & \text { Alpha, factor loading } \\ \beta & \text { Beta } \\ C I & \text { Confidence interval } \\ p & \text { Probability of significance } \\ \rho & \text { Spearman's Rho correlation coefficient } \\ M & \text { Mean } \\ n & \text { Sample size } \\ \eta^{2} & \text { Eta squared, effect size } \\ r & \text { Correlation } \\ S E & \text { Standard error } \\ R^{2} & \text { Change in regression co-efficient } \\ \chi^{2} & \text { Chi-Square }\end{array}$




\section{Acknowledgements}

Behind all data are stories. I was privileged to work alongside dedicated staff and students on the Certificate of University Preparation (CUP) programme at Victoria University of Wellington from 2008 to 2012. When the CUP closed at Vic, I was determined to explore the empirical basis for the personal transformations I witnessed. Thankfully, I earned a Master's scholarship, and financially supported this research pursuit with a part-time role with the Vic Careers team. I dedicate this thesis to these CUP students and staff members whose hard work reaped success and continue to inspire me.

Without the promotion of autonomy and intellectual growth by my self-designated mentor, Karen Davis, I may not have undertaken this particular project - originally inspired by Karen, along with collaborations with Meegan Mall and Peter Adds, who provided insights into supporting learner diversity. I also appreciate the support from Nyk Huntington of Ako Aotearoa, who liaised with relevant stakeholders to discuss extending my research prospects, and provided intellectual respite and witty interludes from my studies.

Being involved and volunteering were fulfilling supplements to my postgraduate education. Victoria University offered the Vic Plus Award, Victoria International Leadership Programme, Postgraduate Students' Association, International Buddy Programme, and Student Learning Support Service. And I am also eternally grateful for my undergraduate experience at Mills.

All of the committed Educators who taught me in the Faculty of Education (Lottie Thompson, Liz Jones, Cedric Hall, Kabini Sanga, Cherie Chu, Matt McCrudden, and the late Don Brown) truly extended my knowledge and inspired my research pursuits. However, I would not have been competent in employing more advanced quantitative methods without Michael Johnston's individualised attention. I was lucky to benefit from two superior supervisors: the ingenious, perceptive Michael Johnston; and the supportive, knowledgeable Stephanie Doyle, who thoughtfully organised the Higher Education cohort discussions with Lana, Ha, Kalyan and Tien, and diligently brought snacks too.

Gaining access to large achievement data sets would not have been possible without assistance from the Ministry of Education: Ralf Engler and Roger Smyth; and the VUW Banner Team: Des Kelly, Vidya, Dhaval, and Shanmuganathan. Also, I appreciate the humble availability of Hamish Coates and Ali Radloff regarding evaluating engagement variables. Also exciting was utilising Victoria's High Performance Computing facility, supported by Kevin Buckley, and undertaking analyses using the R code written by the quantitative mastermind, Michael Johnston, whose critical analysis and feedback were paramount to my growth as a researcher.

Personally, my faraway family and friends, my nearby whānau and love remind me to stay courageous and passionate about what I do. My nieces, Lana and Silvia, and nephews, Gregorio, Jake and Phaedrus, keep me connected to educational realities. Arohanui to Dad, Mom, big sisters (Cecile, Rachael, Serena and Jessica), Kylie (and the little ones), Beau, Zipporah, Lizzy, and Ian (even if you can't stand any more data talk). You all keep me balanced! 


\begin{abstract}
This study comprised an investigation of the longitudinal achievement of New Zealand first-year undergraduate students $(n=967)$ who transitioned to their degrees through the Certificate of University Preparation (CUP) programme at Victoria University of Wellington between 2008 and 2012 and the role of preparation and engagement on their achievement. Certain student behaviours, development of study skills, importance of academic challenge, and emphasis on academic support were all correlated with later university achievement. Although engagement is a highly acclaimed concept, its links to achievement were unsubstantiated. Using linear regressions, students' academic perseverance and their achievement in CUP each uniquely predicted first-year university degree programme achievement. CUP students' university achievement was higher than mainstream students with similar secondary school achievement, based on a statistical model of achievement that accounted for the relative difficulty of achieving each result. These findings indicate that the CUP programme was effective in preparing learners to access and achieve in university.
\end{abstract}





\section{Effects of University Preparation and Engagement on Achievement}

A student's eligibility to undertake degree-level study at university is typically determined on the basis of secondary school achievement. While secondary school achievement is correlated with postsecondary achievement (Engler, 2010a; Scott, 2005, 2008a, 2009; Shulruf, Hattie, \& Tumen, 2008a), secondary school achievement provides only a limited view of academic capability, and students who do not achieve at secondary school may nonetheless be capable of university achievement with adequate preparation. It is therefore important to investigate whether participation in university preparation programmes lead to the development or identification of students' academic capability. It is also important to understand whether non-academic elements of preparation, institutional practices, and students' academic behaviours can contribute to improving their achievement.

Victoria University of Wellington, New Zealand, offered a Certificate of University Preparation (CUP) programme from 2004 and 2012, on which I taught from 2008, and which I managed from 2010 to 2012. I became aware of the lack of empirical evaluations of the effectiveness of such preparatory programmes, and felt compelled to investigate whether these types of programmes actually improve academic achievement, beyond the personal transformations that I observed. Initially, my colleagues and I began systematically evaluating CUP students' experiences using an engagement survey, with the goal of improving the programme, as well as building an evidence base that has contributed to the research reported in this thesis. Analysing this evidence became even more imperative when a policy directive from the Tertiary Education Commission (TEC, 2011) resulted in the closure of CUP programmes at Wellington universities, and I led a project to develop a more flexible degree preparation programme option (Chinlund et al., 2011). 
Anecdotal evidence suggests that university preparation programmes, which have proliferated internationally in the last two decades, provide a viable pathway for students to access, engage with, prepare for, and achieve at university. However, few empirical studies have examined the links between participating in these programmes and achieving at university; in particular, whether the programmes improve academic performance, conditioned on prior achievement. Surprisingly, longitudinal studies that explore academic improvements in this domain are virtually non-existent, yet New Zealand policy prioritises parity of opportunity with the goal of lifting achievement rates for priority groups. Specifically, the Tertiary Education Commission (TEC) aims to improve educational outcomes for young people (those aged under 25 years old), Māori ${ }^{1}$, and Pasifika $^{2}$ students (2012).

Preparation, engagement and academic perseverance are all multifaceted constructs thought to contribute to university success, yet their relationship to achievement has not been empirically established. Effective university preparation can be influenced by personal, contextual, and behavioural factors in students' developing the skills, knowledge, and competencies to be successful in higher education pursuits (Conley, 2008; ConnectEd, 2012). Although not thoroughly researched, success at university often requires the ability to persevere despite challenges, which can be instrumental in university achievement outcomes (Duckworth, Peterson, Matthews, \& Kelly, 2007). Formal academic achievement, although not the only valuable outcome of education, is nonetheless a fundamentally critical outcome, a fairly objective measure, and highly valued by institutions, funders, policymakers, and students. To ensure that resources allocated to preparation programmes are being used effectively, it is important

\footnotetext{
${ }^{1}$ the New Zealand indigenous ethnicity

${ }^{2}$ the diverse populations of Pacific Island nations
} 
that institutions and practitioners are aware of the extent to which students' preparation and engagement, which were specifically promoted by the CUP programme, positively impact on achievement.

A concept of student engagement often utilised in higher education encompasses a substantive mix of institutional practices and student behaviours purported to enhance learning (Kuh, 2001a), but their links to achievement are weakly substantiated (Carini, Kuh, \& Klein, 2006; Kuh, Cruce, Shoup, Kinzie, \& Gonyea, 2008a; Kuh, Kinzie, Cruce, Shoup, \& Gonyea, 2006). The main engagement survey used in NZ encompasses students' perception of academic challenge, supportive learning environment, active learning, enriching educational experiences, student/staff interactions, and general learning and development outcomes (AUSSE, 2008). Although ideologically grounded, this engagement concept lacks evidence strongly linking it to desired student outcomes, such as achievement. Many publications and organisational reports profess the merits of engagement (for example, Coates, 2011; Kuh, 2001b; Radloff, 2011); however a deeper examination of the engagement literature reveals inconsistencies regarding its relationship to achievement, and small effect sizes with little practical value (as per above, Carini et al., 2006; Kuh, Cruce, et al., 2008a; Kuh, Kinzie, Cruce, et al., 2006). Therefore, it is imperative to empirically evaluate the merit of engagement, as it is predominately measured, particularly if funding decisions, resource allocation, and institutional ratings are influenced by results from national and institutional engagement surveys (Coates, 2005; Kuh, 2009).

In response to the paucity of research in this area, the aim of the present study was to investigate links between participation in a university preparation programme, longitudinal achievement, and an engagement concept that relates student behaviour and institutional practice to academic achievement (Kuh, 2001a). Respondents' perspectives 
about which engagement practices were important or useful to them, and which behaviours related to academic achievement, were analysed. The results from this study could contribute data and evidence towards future developments, both practical and theoretical, in the field of university preparation.

\section{Access and Opportunity}

It is a NZ policy imperative for all students to reach their 'academic potential' (e.g., Loader \& Dalgety, 2008; Tertiary Education Commission, 2011), yet 'academic potential' can be an elusive concept. Formally, having the potential to benefit from university is recognised through achieving university entrance (UE) at secondary school (NZQA, 2012a; Universities New Zealand, 2012). Tertiary institutions (and universities in particular), policymakers and funding bodies index academic potential with prior academic achievement because past achievement is correlated with future achievement (Engler, 2010a; Scott, 2005, 2008a, 2009; Shulruf, Hattie, et al., 2008a). However, such correlations are usually relatively modest in magnitude and some students' secondary school results may not adequately predict their academic potential.

Barriers to effective transition from secondary school to higher education include a lack of alignment of expected knowledge, skills, and behaviour between the two environments, and a lack of adequate academic preparation (Conley, 2005; Lombardi, Seburn, \& Conley, 2011; McCarthy \& Kuh, 2006). As a result, many students are not prepared for successful university study, even those who meet formal entry requirements (American College Test, 2004; Cohen, 2008; U.S. Department of Education, 2010). Such students may benefit from further preparation for university study (Bettinger \& Long, 2009; Cantwell, Archer, \& Bourke, 2001; Swail, 2000). With this in mind, it is important to ascertain which preparation areas were useful for students and whether preparation 
programmes assisted learners who did not attain strong academic results at school to be successful in university study.

\section{University Preparation}

The goal of preparation programmes is to provide students with an opportunity to develop and demonstrate their academic capability, and to gain other non-academic skills that enable their success. Yet concessionary access for students to higher education does not necessarily facilitate achievement. Rather, the risk of failure is high when under-prepared and underrepresented groups access intuitions that would otherwise have rigorous entry requirements (Spitzer, 2000). Thus, preparation programmes should only be endorsed by evidence that empirically shows how they influence higher educational achievement, but this is largely missing from the literature.

Nevertheless, many educational stakeholders agree that university preparedness is an important component to success (for example, Bettinger \& Long, 2009; Cabrera \& La Nasa, 2000; Choy, Horn, Nunez, \& Xianglei, 2000; Conley, 2007a; OECD, 2012a;

Polidano, Tabasso, \& Tseng, 2012; Swail, 2000; U.S. Department of Education, 2010). The area of education concerned with preparing learners for higher study has many names internationally: bridging (Benseman \& Russ, 2003; Ssempebwa, Eduan, \& Mulumba, 2012), enabling (Cantwell, 2004), developmental (Ley \& Young, 1998), foundation (Reddy \& Moores, 2008; Trewartha, 2008), transition (Beasley \& Pearson, 1999; Evans, 2000), access, gateway or remedial. (American College Test, 2004; Bettinger \& Long, 2009; Cohen, 2008; Complete College America, 2012; Swail, 2000). Regardless of the terminology, the intention of a university preparation programme is to prepare learners to access, engage with, and achieve in higher education (Bettinger \& Long, 2009; Swail, 2000). 
Many claims regarding the effectiveness of preparation programmes seem speculative, anecdotal, or solely based on qualitative interviews (e.g., Anderson, Stephenson, Millward, \& Rio, 2006; Trewartha, 2008). They tend to lack an evaluation of empirical data that affirms improved achievement on the basis of preparation. Studies typically discuss appropriate practices and the positive academic and affective influence of preparation programmes (Davidson-Toumu'a \& Dunbar, 2009; Evans, 2000), rather than demonstrating the effectiveness of the programmes in raising achievement. For instance, Cantwell (2004) asserted, using qualitative evidence, that a preparation course enabled participants to successfully complete study at undergraduate level and had influenced personal development and instigated underlying motivational and epistemological shifts. Although these studies provide insights into the unique preparatory student experience, particularly in relation to their adjustment, they do not explore links to achievement. Academic achievement is a salient indicator of educational success that may impact on learners' confidence, progression in higher education, and funding (MSD, n.d.). Therefore, it is also important to empirically evaluate ideological assumptions regarding the benefits of preparation programmes by investigating the extent to which the programmes impact on achievement.

A few studies have compared achievement between mainstream students and students who enter university through a preparation programme, with mixed results. In Australia, Levy and Murray (2005) suggested that under-qualified and underprepared learners achieved similar grades to mainstream students, but they only analysed results from the preparation courses themselves. Also, the research lacked rigor; they only described the means; they did not statistically compare between-group achievement means using $t$-tests. Another study from the U.S.A. demonstrated that 473 underprepared, underrepresented students, who completed an intensive preparatory programme, 
had university GPAs comparable to only the lowest quartile of mainstream university students (Clark \& Halpern, 1993). Also, although the students in the intensive preparation programme were also in the lowest quartile when they began their university studies, such poor achievement is hardly an aspirational objective. Moreover, 8,503 students who qualified to attend one Australian university through preparation programmes did slightly worse than mainstream entry students, although in this study the comparison did not condition on prior achievement making the results difficult to interpret (Cantwell et al., 2001). In the United States, Bettinger and Long (2009) demonstrated, using ordinary least square regressions on approximately 28,000 students, that, controlling for prior achievement and other demographic variables, students who participated in a preparation programme were $14 \%$ more likely to persist than mainstream students, but they did not examine their academic achievement.

Accordingly, evidence illustrating the relationship between preparation and achievement has produced mixed results. The lack of research rigor and empirical evidence from this domain provides ample opportunity for a longitudinal investigation into these links, particularly in New Zealand.

New Zealand Context of Preparation.

In New Zealand, the mainstream pathway into university study is through performance in a national qualifications framework. Since 2001, the New Zealand Qualifications Authority (NZQA), a national body responsible for assessing and moderating assessment standards, has administered national standards for secondary school achievement. These standards are listed in a directory, and are described by NZQA below:

Each standard listed describes what a candidate who has achieved the standard knows and can do. Each standard has a defined credit value, which represents the notional learning time, and a level, which reflects the level of complexity of the skills and knowledge that are recognised by the standard. The common currencies of credit values and levels enables the credits gained from standards to be portable among national qualifications (2012b, p. 1). 
Students are assessed against these national criteria, and are allocated one of four criterion-based levels (grades) on each Achievement Standard: excellence, merit, achieved or not achieved. Universities New Zealand, a conglomerate of all eight NZ universities Vice-Chancellors, have determined which subject areas and levels they accept towards university entrance - the minimum academic requirement to access university (Universities New Zealand, 2012). Students gain university entrance by achieving a specified number of credits in university-approved subject areas and levels (NZQA, 2012a); currently 42 (although this requirement will increase in 2014). Students who achieve the required number of credits from approved subject areas (and levels) are qualified for university admission.

Measuring achievement is not as simple as merely describing credit accumulation, or grade point averages (GPA), but should ideally take into consideration variability in the difficulty of achieving particular grades in different courses and papers. Certain statistical methods enable this type of achievement calibration (such as item response theory explained in the Method chapter). This statistical method accounts for variation in the probability of achieving higher marks in certain disciplines and lower marks in other disciplines. Accordingly, a student who achieves a higher mark in a more challenging discipline would then be ranked higher on the achievement scale than a student who received a higher mark in a less challenging subject. Engler (2010b) found that achievement in certain school subjects was less important than a students' overall achievement for indicating university success. Accordingly, ranking students’ achievement using item response theory to rank may help to indicate nuances in achievement levels and balance out students' achievement ranks when they did poorly in one subject, but better in another. 
In New Zealand, there is a moderate correlation (approximately 0.50) between secondary school achievement and first-year university achievement for students with university entrance (Scott, 2005; Shulruf, Hattie, et al., 2008a). Shulruf et al. (2008a) created a 'quality related' GPA accounting for relative difficulty of the NCEA (National Certificate of Educational Achievement) standards. The correlation between that model and first-year university achievement was substantially higher than it was for a model that did not account for the standards' difficulty. These results call into question the current way in which university entrance is obtained, because it relies solely on the accumulation of credits, irrespective of the relative difficulty of obtaining them.

Students who want to pursue tertiary study, but did not gain university entrance can either enrol in open entry polytechnic or, prior to 2012, they could take a university preparation course, such as the level 4 Certificate of University Preparation (CUP) at Victoria University of Wellington (VUW). Universities New Zealand accepted completion of an approved preparation programme as ad eundem statum, university entrance equivalent (NZQA, 2012a; Universities New Zealand, 2012). Programmes like CUP simultaneously sought to prepare students for successful university study and acclimatise them to the university study environment.

With shifting government funding priorities, the Tertiary Education Commission (TEC) advised VUW in 2011 to no longer fund domestic sub-degree programmes (NZQF level 4 or below) at universities. The government, through the TEC, indicated that each provider should have clearly differentiated roles and that funding would be allocated accordingly. This policy requires universities to focus on degree and postgraduate study, and polytechnics and wānanga ${ }^{3}$ to specialise in other qualifications, including preparatory and pre-degree studies, as well as some degrees. Hence, VUW would only receive

\footnotetext{
${ }^{3}$ the New Zealand indigenous higher education institution
} 
government funding for degree-level and postgraduate study. Victoria University responded to these institutional role differentiations and government funding limitations with the closure of CUP in 2012.

However, CUP's cessation at VUW has not eliminated the need to prepare learners for higher education. In fact, the revised 2012 Tertiary Education Strategy Pathways and Transitions advised polytechnics and wānanga to create and extend transition or preparation initiatives. In New Zealand, polytechnic study primarily offers practical or vocational study approaches, whereas universities generally focus on research and theoretical understandings of knowledge as outlined in the government differentiation:

Tertiary education in New Zealand is delivered by a variety of providers: universities, Institutes of Technology and Polytechnics (ITPs), Private Training Establishments (PTEs), Industry Training Organisations (ITOs) and Wānanga. These all deliver a variety of educational options, often in flexible ways to meet the needs of adult learners... Higher, degree-level education is mainly offered at universities. Programmes are research-led and generally academic, as distinct from vocational. Vocational degree level education is offered at ITPs, wānanga and a few larger PTEs. Such degrees tend to be specific and applied. PTEs' programmes are mostly in specific vocational niches at certificate and diploma level (Ministry of Education, 2011, p. 18).

Notably, this differentiation is less dichotomised in practice, and most tertiary study providers promote both theoretical and practical understandings of concepts.

Some universities persisted with offering their CUP programmes, mainly for equity purposes (for example, Auckland University, University of Otago, and University of Canterbury). Other universities, such as Lincoln and Waikato, developed programmes in partnership with polytechnics. Neither provider in the Wellington region (Victoria nor Massey universities) obtained funding to provide a level 4 university preparation programme. Accordingly, students in Wellington were left with limited preparatory options, which prompted the development of a regional collaborative Certificate of Degree Preparation programme, designed for flexible delivery in an appropriate context (Chinlund et al., 2011). Therefore, despite the cessation of the VUW CUP programme, 
similar programmes operate elsewhere and it remains important to examine the effectiveness of such programmes to determine whether their investment has value for educational stakeholders.

CUP at VUW was an intensive three-month preparation programme in which students undertook two compulsory courses: (i.) Academic Study Skills and (ii.) Academic Writing and Research, and two elective courses: (i.) Commerce, (ii.) Humanities, (iii.) Mathematics and Statistics, (iv.) Science, or (v.) Social Science, or (vi.) Directed Independent Study (typically a first-year Mathematics course). Each course entailed a total of five contact hours per week, totalling 20 contact hours, and students were expected to complete an additional 20 to 30 hours of work outside of class. The coursework was internally assessed and mainly consisted of essays, exams, presentations, laboratory work and projects. Students usually needed to achieve at least a passing grade in all four of their courses to earn the Certificate of University Preparation, and gain the university-entrance equivalent. 


\section{Diversity and Preparation Programmes.}

Under preparation and under-qualification are not the exclusive provinces of any student demographic group (Scott, 2008b). Yet some demographic groups do have lower achievement than average (Ministry of Education, 2010a). Educational institutions often seek to mitigate this situation in the interests of fairness and diversity and OECD (2012b) has emphasised that, "alternative routes or flexible pathways to higher education are necessary to strengthen equity in access to education" (p. 76). University preparation programmes constitute such alternative routes, and may therefore foster greater diversity in degree-programme cohorts. In university settings, diversity may encompass socioeconomic status, gender, age, time studying, and ethnicity - all of which may influence success prospects.

Greater diversity has the potential not only to shift learners' views of the world (Bolstad et al., 2012), but may also assist in addressing the below average achievement of some demographic groups at university. The concept of student diversity in higher education could benefit from being recognised as a fundamental opportunity to exchange ideas through critical discourse, rather than simply a policy-driven mechanism to increase participation and achievement statistics for minority groups. Diversity is about respecting, enabling and embracing the diverse mix of people in universities who, in turn, enhance learning experiences through ensuring consideration of both minority and statusquo points of view (Cabrera \& La Nasa, 2000; Zyngier \& McMahon, 2009). The retention and exploration of personal identities across the university environment enables this exchange of viewpoints (Astin, 1993). Through exposure to epistemologies involving a diverse range of ideas and influences, university students may experience ontological shifts (Cantwell, 2004; Zepke \& Leach, 2010a) in addition to economic advantage associated with degrees (OECD, 2012b). Embracing diversity may transform the 
university to a place where everyone can belong, feel validated and accepted because of who they are, not despite of their differences (Harper \& Quaye, 2008). It is, therefore, hoped that diversity becomes integral to higher institutions' philosophy, pedagogy, and practices - something universities value, promote, integrate and respond to.

In Ministry of Education statistics from 2009, only seven percent of Māori and six percent of Pasifika held a bachelor's degree or higher, relative to 17 percent of the Pākehā/European portion of all New Zealanders aged 15 and older (Ministry of Education, 2010a). These statistics prompted the NZ government in their Tertiary Education Strategy (2010-2015) to focus tertiary organisations on enabling Māori and Pasifika students' success at level 4 and above of the NZ qualifications framework (Tertiary Education Commission, 2011). Accordingly, current government policy highlights that Pasifika could benefit from tailored support and Māori should experience effective transitions into university (Ministry of Education, 2005; Tertiary Education Commission, 2011, p. 6).

Many students approach university study from indirect pathways, rather than directly from secondary school (Cantwell et al., 2001; Madjar, McKinley, Deynzer, \& Van Der Merwe, 2010), including a large percentage of students who are also typically underrepresented in New Zealand universities, such as Māori ${ }^{4}$ and Pasifika ${ }^{5}$ learners (Coxon, Anae, Mara, Wendt-Samu, \& Finau, 2002; Loader \& Dalgety, 2008). Indeed, these demographics tend to be overrepresented in preparation programmes (Scott, 2008b). Evidence of Māori and Pasifika students, or students from low socio-economic groups, achieving below the national average indicates that not all New Zealanders achieve to their fullest potential, and this might be true for other students as well (Ministry of Education, 2010a), particularly when factoring in the role of socio-economic status

\footnotetext{
${ }^{4}$ the New Zealand indigenous ethnicity.

${ }^{5}$ the diverse populations of Pacific Island nations.
} 
(Zwick \& Himelfarb, 2011). Additionally, nine to ten percent fewer males than females achieved university entrance in New Zealand in 2008 and 2009 (NZQA, 2010).

One explanation for underrepresentation and lower achievement is that institutions may not effectively serve all students, rather than the students themselves lacking the ability to achieve (McMahon \& Portelli, 2004). Some discourse in New Zealand challenges the inclination toward stereotypic or deficit model thinking, under which reasons for lower achievement in some demographics are ascribed solely to students rather than considering other factors (Trewartha, 2008). For instance, many students struggle with adjusting to an institutional culture not necessarily reflective of their own (Davidson-Toumu'a \& Dunbar, 2009; Tofi, Flett, \& TimutimuThorpe, 1996), or are unsure whether university is actually the right place for them (Astin, 1993; McKinley \& Madjar, 2010). Another perspective considers that some students have not acquired the cultural or intellectual capital associated with an educated background (Bourdieu \& Passeron, 1990) or are impacted by socio-economic barriers. For students not previously introduced to university culture, they may experience dissonance between their own and the university's expectations (Terenzini et al., 1994), perhaps because they were the first in their families to attend university (Pike \& Kuh, 2005). In view of the above, it is important that students are prepared for the intellectual and behavioural demands of university study (American College Test, 2004; Cohen, 2008; Conley, 2005; Gibney, Moore, Murphy, \& O’Sullivan, 2011; Lombardi et al., 2011; U.S. Department of Education, 2010). One purpose of preparation programmes is to acclimatise students to institutional expectations.

Suggested practical foci for embracing diversity include maintaining high expectations, academic challenge paired with support, and quality relationships (Kuh, Kinzie, Buckley, Bridges, \& Hayek, 2006). Culturally-responsive pedagogy, 
which entails understanding and respecting diverse ways of being, echoes the importance of quality relationships with staff (Bishop \& Berryman, 2007; Davidson-Toumu'a \& Dunbar, 2009). Understanding what students' value and recognising differences between groups may be beneficial for promoting learning whilst embracing diversity.

Because universities are the product of a Western-intellectual tradition and value individual autonomy (Gibney et al., 2011), they aim to empower learners with the capacity for critical analysis, and teach robust epistemologies (Pascarella \& Terenzini, 2005). However, this instructional basis may require an environment that does not feel overly inclusive to students not steeped in the traditions from which universities arose, perhaps leaving such students to adapt or sink (Terenzini et al., 1994). Tinto (1993) suggests the student should not be the only one to adapt. While adapting, it is important for institutions to retain high standards and encourage the development of critical analysis skills and the confident articulation of ideas; it is equally important that they do so from a variety of perspectives, in order to improve the accessibility of powerful epistemology to students from diverse cultures and backgrounds (Zyngier \& McMahon, 2009).

With the benefits of diversity in mind, it would be helpful to establish how students value institutional practices related to achievement. Garnering which institutional practices and skills students from various cultural backgrounds deem to be important could also assist with accommodating the needs of students belonging to underrepresented demographics. 


\section{Outline of Thesis}

University preparation programmes are thought to fulfil multiple purposes in relation to remedying under-prepared, under-qualified, and underrepresented student aspects. However, there are next to none empirical investigations into the effectiveness of such programmes in raising achievement. Participation in these programmes could indicate academic capability and improve longitudinal achievement, but evidence for these claims is still required. Understanding academic preparation should also include exploring which academic behaviours and institutional practices may relate to achievement.

An exploration of the literature regarding the contextual, personal, and behavioural facets to university preparation follows. Student engagement literature, particular institutional practices and student behaviours purported to impact on achievement, will also be critically reviewed. Instead of focussing on practices thought to impact on achievement, evidence establishing the links between preparation, and engagement on achievement will be discussed. The data sources and analytical treatment will be presented before a discussion of the implications of the results ensues. This thesis includes findings from an empirical investigation of university achievement, as impacted by participating in one university preparation programme, other preparation aspects, and engagement. 


\section{Chapter 2. Literature Review}

Relevant literature was reviewed to explore relationships between university preparation facets, student engagement and academic achievement in relation to students transitioning into or studying in higher education settings. As noted, there have been few empirical investigations into the effectiveness of preparation on higher educational achievement; therefore this review also incorporated studies into strategies, student behaviours and institutional practices that were associated with higher educational achievement.

\section{University Preparedness}

Conley (2008) defines university preparedness as having the skills, knowledge and competence to achieve at university. Another, more recent, Readiness Framework identifies four aspects of preparedness: (1) knowledge; (2) skills; (3) productive dispositions and behaviours; and (4) educational, career, and civic engagement (ConnectEd, 2012). Understandably, university preparation is multifaceted and affected by a variety of influences. Yet most literature on university preparedness can be classified as relating to one of three foci: personal, behavioural or contextual. Ideally, these types of programmes act to orientate students towards support networks; unify them with their class mates; address social and psychological barriers; and assist with their transition to becoming a successful undergraduate student (Terenzini et al., 1994).

\section{Personal facet.}

The personal facet, represented in the literature, includes influences such as background, motivation, attitude, prior achievement, and aptitude (Credé \& Kuncel, 2008; Hattie, Biggs, \& Purdie, 1996; Reason, Terenzini, \& Domingo, 2006; Shulruf, Hattie, \& Tumen, 2008b; Terenzini et al., 1994). Many studies acknowledge that preparation and transition are exceedingly complex phenomena that encompass the influences of multiple interrelated variables, from students' backgrounds, intellects, networks, ambitions, 
expectations and institutional situations (Cabrera \& La Nasa, 2000; Cantwell, 2004; Choy et al., 2000; Clark \& Halpern, 1993; Conley, 2005; Evans, 2000; Reason et al., 2006; Terenzini et al., 1994). Regardless of the factors associated with under preparation, unqualified learners have an opportunity to prove their academic potential and access higher education through preparation programmes, but they may also face significant barriers to effective transition, such as their personal disposition towards study or their goal commitment (Evans, 2000; Terenzini et al., 1994).

Terenzini et al. (1994) interviewed 132 traditional and non-traditional American students' to consider their processes of adapting and integrating into the university community. Academic transition was found to be the most difficult for non-traditional students. Although a potentially contentious term, the classification of non-traditional learners as expressed in the literature includes those who are underrepresented in postsecondary education, usually based on backgrounds or characteristics that might result in their marginalisation or lack of preparation (Harper \& Quaye, 2008). Moreover, for nontraditional students, the transition not only encompassed interpersonal adjustment, but also included academic, social, and cultural transitions, including a form of disjunction from their life expectations (Terenzini et al., 1994). This disjunction arose from the unexpected access to formal higher education, and a lack of family knowledge regarding higher educational contexts.

Acclimatising students into institutional culture or adjusting institutional practices may facilitate students' transition, provided such adjustment does not undermine the intellectual or cultural benefits that can accrue from university education. Conley (2005) views the development of intellectual maturity and "habits of mind" that promote higherorder thinking, as more indicative of university readiness than any specific knowledge. However, students also need to develop a clear understanding of university processes and 
procedures. Although some personal aspects may be beyond the control of any individual or institution, they nevertheless may impact on learning and achievement.

\section{Behavioural facet.}

The behavioural facet of preparation involves what students can do to be successful in their higher education pursuits, including study-strategies, self-regulation, and perseverance. Study strategies may be more predictive of university success than prior achievement (Credé \& Kuncel, 2008), and include behaviours such as time-management, self-regulation, organisation, and resource allocation - components of active learning that are linked to academic improvements or success. Preparing students to learn on their own is especially fundamental for university success (Zimmerman, 2002); therefore preparation programmes that equip students with these self-regulatory skills should observe higher achievement. Accordingly, preparation programmes aim to develop behaviours associated with academic success by explicitly teaching students how to learn in a tertiary environment, stressing metacognition, self-regulation, and adopting effective study strategies.

Many researchers agree that, above all, metacognitive ability is imperative for higher educational success (Conley, 2007b; ConnectEd, 2012; Credé \& Kuncel, 2008; Gettinger \& Seibert, 2002; Hattie et al., 1996; Vrugt \& Oort, 2008). Metacognition, as defined by Flavell (1979) is an awareness, evaluation, and adaptation of ones thinking process, that can be developed in a preparatory curriculum. Metacognition certainly affects behavioural aspects of university preparation, particularly in the self-regulatory use of study strategies and skills, a facet strongly endorsed as being paramount to university success in the literature (Adams, Proctor, Petscher, Prevatt, \& Reaser, 2006; Conley, 2007b, 2008; ConnectEd, 2012; Credé \& Kuncel, 2008; Gettinger \& Seibert, 
2002; Gibney et al., 2011; Hattie et al., 1996; Swail, 2000; Vrugt \& Oort, 2008; Zimmerman, 1990).

Research has linked study skills to university academic performance. For example, Adams et al. (2006) compared 263 academically struggling American students with achieving students, and found that the non-achieving students scored lower on the Learning and Study Strategies Inventory. However, the higher achieving sample could have been more aware of their strategies because this study used self-reports of anxiety, attention, and concentration, motivation, selecting main ideas, test strategies and timemanagement. Similarly, a New Zealand study on tertiary pathways (Vaughan, 2008) found that higher achieving students were more realistic in how they rated their study strategies, although such interviews cannot establish causality, and the relationship may be bi-directional.

One meta-analysis (Credé \& Kuncel, 2008), which claims to have performed "944 correlations from 344 independent samples representing 72,431 college (university) students" (p. 432) found that, not only were study skills and metacognition positively associated with academic performance, but the strength of the correlations were similar to those observed in relation to secondary school achievement. However, results from metaanalyses have been criticised because they do not account for variation in methodological procedures, aggregation techniques, or in measures, amongst the studies included in each meta-analysis (Ahn, Ames, \& Myers, 2012). Even so, although meta-analyses collate distinctive and perhaps divergent research methods, this particular meta-analysis employed rigorous procedures to assess the reliability of the distinctive measures. Their results indicate that the prevalence of study skills may explain why some capable students do not achieve as predicted from their achievement at school. 
Hattie et al. (1996) performed another meta-analysis of 51 studies that linked study strategies to achievement (with 270 effect sizes). This study challenges the programmes that teach study skills as topics (e.g., time management, note taking, reading, and exam strategies) because this strategy did not significantly affect academic performance. Instead, they argue that study strategies should be contextual, content relational, and metacognitive. However, the external validity and credibility of metaanalyses' effect sizes warrants caution, particularly when dealing with conceptual variation in operational definitions. The particular meta-analysis of Hattie et al. relied on the researchers' interpretation of the intervention, and did not seem to incorporate standard deviations or standard errors in their meta-analyses of effect sizes. Nevertheless, they recommended that learners be equipped with a variety of strategies to utilise in different contexts, rather than one strategy for all. Ideally, "strategy training should be seen as a balanced system in which the individual's abilities, insights, and sense of responsibility are brought into use, so that the strategies that are appropriate to the task at hand can be used" (Hattie et al., 1996, p. 131). This recommendation relates to the importance of understanding the personal facet of preparation and improving metacognitive function.

Metacognitive strategies theoretically enable learners to adapt to a variety of situations. In relation to the importance of using adaptive study strategies, many initiatives argue for learners' development of adaptability, flexibility, and preparation to cope with change for an uncertain future (See for example Bolstad et al., 2012; ConnectEd, 2012). Furthermore, these academic skills, knowledge and behaviours prepare students for life beyond their degrees in employment and citizenship (ConnectEd, 2012). 
Gettinger and Seibert (2002) stress the importance of students learning academic behaviours that contribute to academic success and competence; these behaviours include active learning, perseverance, effort, adaptive study strategies, and metacognition (conferred by Conley, 2005; Hattie et al., 1996; Ley \& Young, 1998; Lombardi, Seburn, \& Conley, 2011; Vrugt \& Oort, 2008). They also contend that study skills and student engagement are interrelated (Gettinger \& Seibert, 2002; Gibney et al., 2011). Accordingly, institutions and policymakers could adopt practices to help equip students with useful study resources that may support their success.

Research into student engagement evinces the importance of learners' effort (Kuh, Kinzie, Schuh, Whitt, \& Associates, 2005) as well as perseverance; the ability to continue in pursuit of a goal despite obstacles (BCSSE, 2009; Gettinger \& Seibert, 2002). Perseverance, although not clearly defined, recently gained some prominence in educational practice, and could be influenced by learners' academic mind-sets and study strategies (Farrington et al., 2012).

Research on high-achieving individuals by Duckworth et al. (2007) explored the influence of non-cognitive factors, including conscientiousness and "grit" on predicting success beyond IQ measures. They define grit as "passion and perseverance for long term goals" (Duckworth et al., 2007, p. 1087), which differs from self-control or prioritising study goals. In one of their studies of 1,218 U.S. military cadets, self-control predicted GPA better than grit, but grit predicted retention. The external validity of their studies was limited to high achievers, and may not necessarily apply to underprepared learners, whose perseverance has not been widely studied. Perseverance, although not yet documented in achievement studies, may be a particularly vital skill for underprepared students, and certainly remains an area ripe for research. 


\section{Contextual facet.}

Another facet of university preparation is the context in which learning takes place.

Contextual factors may include institutional practices, social interactions, support, and the role of a learning community. Students who require preparation to access higher education experience unique contextual influences due to their past experiences and their perceived low status within the tertiary system (Van der Meer, 2011). Particular contextual practices have been shown to impact learners' success - overwhelmingly the most remarkable is creating a supportive learning environment (Beasley \& Pearson, 1999; Kuh et al., 2005; Tinto, 2000).

Tinto's (1993) research into persistence and attrition asserts the importance of an institutional culture that embraces diversity and endorses the institutional student support role, rather than allocating sole responsibility to students themselves. Like Tinto, Gibney et al. (2011) and Reason et al. (2006) found that social and peer support was imperative for an effective transition. Interestingly, all 132 students interviewed by Terenzini et al. (1994) alluded to the challenges of interpersonal adjustment and the desire to be validated through their studies. Students particularly valued having someone on campus who encouraged them and cared about their wellbeing. Institutional practice to encourage university preparation includes creating a supportive environment (Gibney et al., 2011; Hattie et al., 1996; Kuh et al., 2005; Scott, 2005; Terenzini et al., 1994) as evinced by the value and prevalence of pastoral care and student/faculty interactions. Yet a New Zealand examination of Māori and Pasifika university students' engagement found modest positive correlations between perceptions of a supportive learning environment and general learning and development outcomes, but no correlation with overall grade point average (Van der Meer, 2011). 
Insight into the complexity, multidimensional and multi-influential aspects of university success arose from a multi-campus $(n=30)$ study by Reason et al. (2006) of 6,700 American students and 5,000 staff members who participated in the National Survey of Student Engagement (NSSE, 2008; Reason et al., 2006). Using ordinary leastsquares regression, they revealed that gains in academic competence were associated with students' perception of a supportive institutional environment, as well as cognitive and academic engagement, and institutional challenge. This study suggests that institutions actually have more influence over whether a student develops academic competence than the students' own personal background; however the related control variables only included parental education, entrance status, and student demographics. While this study had a very large sample size, it was cross-sectional, rather than longitudinal and used student-reported general development outcomes rather than actual achievement as the dependent variable they called "academic competence". Yet they conclude that the, "vast majority of the explained variance in academic competence is attributable to what happened to students during their first-year and not to the characteristics they brought with them to college" (Reason et al., 2006, p. 164).

Increasing achievement and other educational outcomes seems to be a result of a complex, multidimensional, and multi-influential mix of factors (Reason et al., 2006). Accordingly, institutions were advised by Reason et al. to "adopt a holistic approach to supporting students academically, as well as personally and socially" (2006, p. 170). These factors - including the prevalence of a supportive learning environment (Beasley \& Pearson, 1999; Carini et al., 2006; Kuh et al., 2005; Radloff, 2011) - are also endorsed in the engagement literature.

The importance of integrating into a learning community is another contextual practice thought to support university preparation. Zhao and Kuh (2004) produced 
substantial evidence of the impact of participating in a learning community; one that is characterised by learners being supported by cooperative learning pedagogy (elaborated by Johnson, Johnson, \& Smith, 1998), feeling part of an academic cohort, and being in multiple classes together. Notably, the salutary effects of participating in a learning community include links to favourable educational performance and overall satisfaction (Zhao \& Kuh, 2004), a perception echoed by Tinto's foundational theories of university student retention (Tinto, 1993). Tinto (2000) specifically endorses linked and coordinated courses that also enable learners 'learning to learn' or developing study skills (p. 4).

Zhao and Kuh's (2004) study surveyed whether 80,479 randomly selected participants participated, or planned to, participate in a learning community. The research focussed only on students' self-reported grades from the survey, rather than the impact of engagement on actual achievement. This study relied on data from 365 American fouryear universities who participated in the National Student Engagement Survey. While reinforcing external validity, data from multiple institutions cannot account for possible institutional variation in the practice, perception, and definition of learning communities.

When Zhao and Kuh, using logistic regressions, measured the engagement variance (from the NSSE survey) associated with students' claims of participating in a learning community, the effect sizes were substantial, ranging from .23 to .60. However, the relationship to (self-reported) achievement was negligible. Controlling for prior achievement, senior students who reported participation in learning communities also self-reported slightly better grades than students who did not. These self-reported grades of senior students, who claimed to have participated in a learning community, were only slightly higher, with a tiny effect size of 0.01 , than senior students who did not make that claim. However, the question itself may be problematic because participating in a 
learning community was not explicitly defined, nor were any relationships established as being causal.

Notwithstanding apparent limitations of the study by Zhao and Kuh, further evidence garnered from student interviews endorses the importance of underrepresented students feeling part of a learning community (Terenzini et al., 1994). It could be that perception of participating in a learning community enables students to access other engagement practices that may be more influential on their success.

The value of external support has also been endorsed in the literature, although with uncorroborated links to achievement. Researchers stress the importance of students developing relationships with peers who also value learning (Leach \& Zepke, 2011; Zepke \& Leach, 2010b), and having opportunities to interact with staff outside of formal classes (Cantwell, 2004; Gibney et al., 2011; Reason et al., 2006; Terenzini et al., 1994). Other NZ researchers proclaim the importance of educational experiences encompassing a holistic view that includes family involvement (Benseman, Coxon, Anderson, \& Anae, 2006; Davidson-Toumu'a \& Dunbar, 2009) and cultural responsiveness (Benseman et al., 2006; Bishop \& Berryman, 2007; Harper \& Quaye, 2008) particularly for underrepresented learners. In accordance with the lack of empirical evidence to strengthen these claims, it would be useful to gather more information about what is important to learners themselves and attest how these elements link with achievement. 


\section{Student Engagement}

Engagement as a concept is a complex abstraction that attempts to encapsulate all of what can be done to improve student learning. The divergent definitions that have been adopted throughout the sector may therefore create confusion amongst practitioners, politicians and educators (Axelson \& Flick, 2010; Trowler, 2010). Therefore, the present research will utilise the operational definition of engagement as developed for the National Student Engagement Survey in America (Kuh, 2001a) and later for the Australasian context (Coates, 2005). This definition recognises the complexity of student learning and includes both students' effort and what institutions can do to promote learning (Kuh, 2001a). Kuh conceptualised engagement as an interaction between institutional practices, and students' effort, development and general satisfaction. The Australasian engagement measure was developed to provide information on institutional support and students' involvement in educational activities that may enhance their experience (Radloff, 2011).

The Australasian Survey of Student Engagement (AUSSE, 2008) included the following subscales:

- Academic challenge - extent to which expectations and assessments challenge students to learn

- Active learning - students' efforts to actively construct their knowledge

- Enriching educational experiences - participation in broadening educational activities

- General learning outcomes - development of general competencies

- General development outcomes - development of general forms of individual and social development; closely aligned with the concept of preparation.

- Student and staff interactions - level and nature of students' contact with teaching staff

- Supportive learning environment - feelings of legitimation within the university community

The individual components of the AUSSE survey and its subscales are presented in Appendix A. 
The concept of measuring student engagement began with an intention to offer formative feedback to students about ways to improve their learning, although the original theorists admit to the necessity of also ensuring that the institutions themselves created conditions to foster student development (Coates, 2005; Kuh, 2009; Trowler, 2010). The focus is now on the reciprocal actions of the institution and the student; Engagement is generally accepted as a complementary process that entails simultaneous accountability and responsibility on the part of students and institutions. This evolving definition of engagement encompasses the extent to which students are participating in "empirically derived good educational practices" (Kuh, 2001a, 2001b) and the institution's incorporation and support for these engagement practices (Kuh et al., 2005). For universities, engagement not only involves students' own effort, but also how well their institution supports them in this regard (Coates, 2005; Harper \& Quaye, 2008; Kuh et al., 2005). The actual practices are measured by evidence gathered over years of educational research, but that have only recently been applied to an Australasian context.

Engagement principles are based on theoretical understandings of 'effective higher education practices' - practices that support learning (Kuh, 2001a). Chickering and Gamson's (1987) influential seven principles of good practice in undergraduate education (revisited in 1999) served as initial proxies for engagement indicators: "student-teacher contact; co-operation among students; active learning; prompt feedback; time on task; high expectations; respect for diverse talents and ways of learning” (pg. 2). The concept of engagement became popularised in the United States in the early 1990s (Astin, 1993), but did not fully emerge in Australasia until the mid-2000s (Coates, 2005).

Other major contributors to describing effective engagement practices in higher education include Pascarella \& Terenzini (2005), and Kuh (2001b, 2008), whose studies considering effective university practice were instrumental in the development of the US 
National Survey of Student Engagement (NSSE, 2008). Coates (2005) contributed to amending the NSSE for an Australasian context and ensuring that the Australasian Survey on Student Engagement (AUSSE, 2008) measures had content, face and construct validity (Coates, 2010). Subsequent studies explored the extent to which engagementpromoting educational practices were represented in higher education (Hockings, Cooke, \& Bowl, 2007; Krause \& Coates, 2008) in order to activate institutional improvements. Some of the literature related to the development and psychometric properties of the engagement survey measure were published in-house by the developers themselves (Coates, 2011), and additional peer-reviewed analyses also endorsed the reliability and validity of the survey (Coates, 2010; Pike, 2006). However, when Gordon, Ludlum, and Hoey (2008) tested the Student Engagement survey used in America, they discovered that the individual items were more predictive of GPA than the subscales, and challenged the internal consistency -reliability indexed by the strength of Cronbach's $\alpha$ - of the subscales themselves; this will also be explored in the present study.

There may be a temptation to reverently view student engagement as a fundamental proxy for learning (Coates, 2005; Kuh, 2009; Pascarella, Seifert, \& Blaich, 2010), or in other words, a "reliable proxy for understanding students' learning outcomes" (Radloff, 2011, p. viii). Student engagement may be inaccurately presented as increasing the prevalence of desired educational outcomes, such as persistence and achievement, without strong practical evidence verifying those links (Carini et al., 2006; Kuh et al., 2008a; Kuh, Kinzie, Cruce, et al., 2006). Realistically, educators should accept components of the student engagement concept that have been empirically tied to desired results, yet acknowledge the potential influence of other factors (such as non-academic influences) not measured by the engagement survey. 
Although well-established, student engagement remains an evolving concept and not without critiques (see for example, Campbell \& Cabrera, 2011; Hagel, Carr, \& Devlin, 2012; Trowler, 2010). It is important to heed the caveat that engagement is not a panacea or a substitute for achievement. Although engagement principles may be perceived as idealised and indoctrinated in educational discourse, the initial purpose of measuring engagement was to provide a baseline for making improvements to students' learning, and not to be overly prescriptive (Astin, 1993). Interestingly, these principles predominantly rely on North American educational researchers' evaluations of what is effective in engaging students, although students may not actually agree that these institutional efforts to engage them are of great importance. The engagement measure "is specifically designed to assess the extent to which students are engaged in empiricallyderived good educational practices and what they gain from their college experience" (Coates, 2005). Still, an opportunity remains to establish how important learners themselves rate these practices to be, and to what extent engagement relates to achievement itself. Accordingly, researchers and evaluators are only able to assess the importance of the existing engagement survey questions, but there is still further opportunity for researchers to reform and test other conceptions of engagement, and they are beginning to do (Coates, 2010; Krause \& Coates, 2008).

Central to the notion of student engagement is the importance of consistently maintaining high expectations of students and prioritising academic challenge (Kuh et al., 2005). Even so, "people rarely exceed their own expectations without being challenged" (Kuh et al., 2005, p. 111), to reap the benefits of academic achievement, high expectations and academic challenge need to be paired with appropriate support. Zyngier and McMahon (2009), in consideration of students in transition, adds that engagement should encompass a critical analysis component that encourages challenging the status 
quo. Contextually, engagement principles may vary culturally, but fundamentally, engagement measures are designed to explore and promote learning regardless of the location.

However, research into student engagement illustrates the practices deemed to be effective and desirable by educators and institutions. If the rationale for measuring engagement is to tailor institutional and learners' behaviour to these historical assumptions, then we should carry on responding to existing results. But, it is equally important to garner perspectives from a variety of students about what they deem to be important to their learning and measure whether engagement is linked to improved academic achievement, particularly for the cohort of underprepared students.

\section{Academic Achievement and Engagement.}

Underachievement remains an issue in higher education, creating an opportunity to evaluate the role engagement plays in students' achievement gains. Unfortunately, even with a plethora of engagement survey data analysed in the United States, statistical links to students' achievement reveal negligible correlations (Carini et al., 2006; Kuh et al., 2008a; Kuh, Kinzie, Cruce, et al., 2006). However, measures of student engagement are associated with some educational gains for underprepared students. Studies indicate that less-prepared students reap slightly better results when engaged (Carini et al., 2006; Kuh, Kinzie, Cruce, et al., 2006), although this study relied on self-reported GPAs for students with lower scores on admissions tests and the self-reported GPAs could be inaccurate. Still Kuh (2009) argues, “... engagement has compensatory effects on grades and persistence for students who most need a boost in performance because they are not adequately prepared academically when they start college..." (p. 685). Yet some researchers alternatively attribute effective preparation to raised engagement or claim 
engagement may have indirect effects on achievement (Gettinger \& Seibert, 2002; Gibney et al., 2011) because causality cannot be determined.

Kuh, Cruce, Shoup, Kinzie, and Gonyea (2008) explored the role that engagement plays in persistence and university grade point averages (GPA) conditioning for prior achievement, precollege experiences, ethnicity and other demographic variables for 6,193 students from 18 US universities. Using linear regression, they found that measures from the National Survey for Student Engagement account for 13 percent of the variance in first-year GPAs, and 12 percent of the variance in persistence. Notably, 85 percent of their sample persisted, which suggests that the results may be influenced by a selection bias. The engagement variable included measures of time spent studying, time spent in co-curricular activities, and the summative engagement survey score. This study demonstrated a relationship, albeit not causal, between engagement and grade point averages. They found that students with higher engagement scores who achieved lower scores on US standardised tests achieved slightly better in their degree studies than others with matching test scores.

Another large scale study conducted in the USA showed that engagement is related to achievement and persistence for students regardless of their ethnic background (Kuh, Kinzie, Cruce, et al., 2006). Controlling for prior achievement and background characteristics, students who scored higher on the engagement scale (at least one standard deviation above average) were more likely to persist (91\%) than those one standard deviation below the average ( $85 \%)$. Additionally, engagement scores were correlated with achievement - GPA went up by 0.04 points (or half of a grade) per standard deviation increase in the engagement measure. These results were accentuated for students who had lower prior achievement. Ergo, they posit that engagement seems to level out achievement rates for students differing in prior achievement. 
However, engagement seems to be correlated only with negligible achievement gains, albeit statistically significant ones, and improvements to engagement have not been empirically linked to achievement improvements. Carini, Kuh, and Klein (2006), explored "whether students with identical Scholastic Achievement Test (SAT) scores (and control variables), but different engagement levels exhibit different learning outcomes" (p. 10). Their study examined a large sample of 1,058 students from 14 four year universities in the US who completed the NSSE, and found scores on engagement subscales were positively correlated with GPA achievement, hitherto only producing very modest correlations, ranging from 0.06 to 0.16 . Although all of the engagement survey subscales showed such modest positive correlations with the samples' GPA and other measures of higher order thinking, the correlations were higher $(0.16$ to 0.26$)$ for students with low ability (measured by SAT scores). Accordingly, they claim that students who arrive at university with lower ability seem to benefit more from a supportive learning environment and enjoy a higher quality of relationship with faculty. Although achievement differences with lower ability students may be influenced by regression to the mean or ceiling effects, underprepared university students may benefit slightly more from the aforementioned engagement practices; however the practical significance of such small correlations is questionable. 


\section{Chapter 3. Method}

\section{The present study}

The purpose of the current study was to empirically evaluate the effectiveness of one Certificate of University Preparation programme offered at VUW, in terms of establishing links to first-year university academic achievement. Additionally, this study gathered empirical evidence analysing the relationship between preparation, student engagement and achievement, and ascertained which of these practices students also valued. Non-academic factors, such as students' academic perseverance were also analysed in relation to achievement.

The current study involved an examination of the role of preparation and engagement in the subsequent degree-programme achievement of CUP students at VUW. Due to the complexity of the engagement and preparation components, only selected engagement components were measured: academic challenge, enriching educational experience, general development and general learning outcomes, and supportive learning environment (AUSSE, 2008). These components were selected on the basis of their alignment with preparatory programme objectives. Students also were asked to rate their expected academic perseverance; student certainty that they would persist in the face of academic adversity (BCSSE, 2009); and the prevalence of active learning; students' efforts to actively construct their knowledge in their studies (AUSSE, 2008). See Appendix A for more details.

Student perspectives were gathered in reference to how important students rate academic challenge, a supportive-learning environment, academic feedback, nonacademic assistance, and family inclusion in their studies. They also rated the utility of certain preparatory functions and how well CUP prepared them in the following areas (BCSSE, 2009): 
- Acquiring a broad general education

- Comprehending instructions/information

- Learning effectively on your own

- Managing your time

- Reading and understanding academic material

- Speaking clearly and effectively

- Staying committed and motivated

- Staying organised

- Taking notes

- Thinking critically and analytically

- Using computers in academic work

- Using computing and information technology

- Using the library for research

- Working effectively with others

- Writing clearly and effectively

It is important to establish which of these practices, if any, are linked with achievement, and to ascertain whether any achievement gains could be attributable to the CUP programme. To meet this evaluative claim, university achievement was measured relative to that predicted by a regression model, conditioned on secondary school results. All achievement data were calibrated for difficulty using item response theory (e.g., Samejima, 1969). In an attempt to address a number of questions not yet addressed in published literature, the researcher sought to answer:

1. What is the impact of engagement and participation in the Certificate of University Preparation (CUP) programme on first-year degree programme university academic achievement?

a. Did passing CUP at VUW improve first-year university academic achievement relative to those predicted from secondary school results?

b. To what extent is academic achievement related to students' engagement, preparation, and academic perseverance?

2. How do university preparation students rate the importance of selected engagement practices, and do these ratings correlate with achievement? 
The study relied on analysing retrospective survey data collected between 2008 and 2012 by the researcher, and necessitated obtaining and analysing current achievement data. The basis of these analyses was a statistical model of achievement that accounted for the difficulty of achieving results (using achievement data from the New Zealand secondary school population and a year of VUW first year students), and placed each student on an interval scale location based on what students' achieved relative to the probability associated with that achievement level. Engagement, preparation, and perseverance were analysed using correlations, ANOVA, $t$-tests and Chi-Square methods, as relative to each data set. The effectiveness of the university preparation programme was analysed using OLS linear regression. The researcher sought to establish an empirical basis for the effectiveness of university preparation programmes, and consider the role of nonacademic factors, on impacting achievement.

\section{Participants}

Participants were from Victoria University of Wellington's Certificate of University Preparation (CUP) programme between Trimester One (beginning March) 2008 and Trimester Three (ending February) $2012(n=967)$. The survey data comprised a sample of thirty three percent $(n=220)$ of these CUP students; those who completed the survey directly after finishing the CUP programme. Achievement data also included 24,434 New Zealand secondary school students' level 3 achievement standards results, and 3,746 VUW university students' first-year grades.

Of the students who were awarded the CUP $(n=665), 73$ percent $(n=484)$ achieved two or more level 3 Achievement Standard results from NZ university-entrance approved subjects at secondary school, and $82 \%(n=544)$ of them obtained first-year degree results from their studies at VUW. It is not known which of these students progressed to other institutions. Interestingly, 61 students who did not pass CUP 
matriculated to VUW through other admission methods (such as special admission - over age 20 - or discretionary entrance), and the means of these students' achievement in their first-year of university were also separately analysed and compared with students who passed CUP. All students who completed the CUP programme during 2008 to 2011 were included in the achievement analyses.

\section{Demographic Variables.}

While socio-economic status may have implications on general achievement, the socioeconomic indicator most readily used in New Zealand (the decile of each secondary school) was not available from VUW Banner Student Records. Other demographic variables (ethnicity, age, and gender) were explored accordingly.

\section{Gender.}

Slightly fewer females $(n=446,46.1 \%)$ than males $(n=521 ; 53.9 \%)$ participated in the CUP programme. This corresponds with the gender achievement gap in secondary schools because fewer males earn university entrance (NZQA, 2010). Accordingly, the cohort passing CUP was 56 percent male $(n=347)$, although the survey respondents were 53 percent female $(\mathrm{n}=108)$.

Age.

The age of students who took CUP during 2008 to 2011 ranged between 16 and 52 $(\mathrm{N}=967)$, with a large majority $(n=754,78 \%)$ being aged younger than 20 years of age; the average age was 19 years, six months. Over half of the students were aged 18 ( $n$ $=459)$. Six percent were 25 and older, and five percent were between the ages of 22-24.

For analyses, the ages of these CUP students were compressed into three categories of 1619, 20-24, and 25 and older.

\section{Ethnicity.}

The majority of students were of a New Zealand European/Pākehā ethnicity ( $n=550$, 
$56.9 \%)$, although a larger percentage of Māori $(n=168,17.4 \%)$ and Pasifika $(n=131$, $13.5 \%$ ) students enrolled in the CUP programme compared with general university rates of $8.9 \%$ and $5.8 \%$ respectively (Ministry of Education, 2010b). Over representation of Māori and Pasifika students in preparation programmes is related to their lower rates of obtaining university entrance. In 2009, only 35 percent of Pasifika and 42 percent of Māori final year secondary school students achieved university entrance, compared with 69 percent of European and 70 percent of Asian students also in their final year of secondary school studies (NZQA, 2010).

Of the Pasifika students, most were Samoan $(n=82,8.5 \%)$, although some identified as Tongan $(n=14,1.4 \%)$ and Cook Islander $(n=10,1 \%)$. Seven each identified as Fijian and Niuean, and five were of Tokelauan ethnicity. The remaining six claimed the 'Other Pacific Peoples' ethnic category.

Eight percent of students were Asian $(n=77)$, comprising Filipino $(n=20,2.1 \%)$, Chinese $(n=17,1.8 \%)$, Indian $(n=15,1.6 \%)$ and Southeast Asian $(n=11,1.1 \%)$ ethnicities. Five each were Sri Lankan and Other Asian, whereas two each were Japanese and Korean. Almost three percent of CUP students $(n=27,2.8 \%)$ identified as African ( $n=15)$, Middle Eastern $(n=6)$, or Latin American $(n=6)$, while 14 students $(1.4 \%)$ identified as an 'Other' ethnicity.

Because of the international component in the cohort, CUP students were required to demonstrate English-language competency and completed a diagnostic assessment prior to acceptance on the programme. For students from a non-English speaking background, VUW offered other programmes tailored to international students who could benefit from improving their English.

A higher percentage of NZ European/Pākehā (72.4\%) and Asian (68.8\%) students achieved the CUP, whereas Māori students achieved in slightly lower proportions 
(64.9\%). Only 58 percent of the Pasifika students passed CUP compared with the 68.8 percent CUP average.

The ethnic profile of the subset of CUP students who completed the survey closely resembles that of the overall cohort: Māori $(n=30,14.8 \%)$; Pasifika $(n=22,10.7 \%) ; \mathrm{NZ} /$ European/Pākehā $(n=130,64 \%) ;$ Asian $(n=13,6.4 \%) ;$ Middle Eastern/Latin American/African $(n=6,3 \%)$; and Other $(n=4,2 \%)$.

\section{Data}

In order to establish academic improvement, longitudinal achievement data included (a) national and local secondary school results achieved on the New Zealand Qualifications Framework from 2001 to 2011, (b) local achievement results from the Victoria University of Wellington (VUW) Certificate of University Preparation programme from 2008 to 2012, and (c) full first-year university results from VUW during 2008-2012. Each data set contained detailed achievement results from each individual standard or course available to study.

To generate quantitative interval variables, data were calibrated using a oneparameter logistic graded response model (Samejima, 1969). This model establishes interval scales on which both items and individuals can be located. The graded response model is more effective at accurately measuring shifts in achievement than grade point averages (GPA) because it takes into consideration variation in difficulty between each standards and courses. All parameters were estimated using a Newton-Raphson procedure for maximum log-likelihood estimation. In this study, the latent variables constructed with the item-response model included ability estimates based on manifest achievement results, and individual engagement scale locations based on manifest item responses to the online survey. Item response theory was used to establish quantitative scales for the achievement results and the engagement subscales to locate each participant on these 
scales. Four variables with different scales were calibrated using this technique:

secondary school achievement, engagement survey results, and achievement at VUW (including CUP and first-year results). A summary of the data sources and numbers is presented in Table 1.

Table 1.

Achievement Data Amount and Sources

\begin{tabular}{|c|c|c|c|}
\hline & $\begin{array}{r}\text { Secondary School } \\
\text { Results }\end{array}$ & CUP Results & First-year Results \\
\hline Items & 152 & 7 & 163 \\
\hline $\begin{array}{l}\text { Number of } \\
\text { candidates with } \\
\text { calibrated values }\end{array}$ & 24,434 & 967 & 3,746 \\
\hline $\begin{array}{l}\text { Number of CUP } \\
\text { Participants }\end{array}$ & 484 & 967 & 544 \\
\hline$\%$ of Participants & 50 & 100 & $82^{\mathrm{a}}$ \\
\hline
\end{tabular}

Results from an entire student cohort were used to calibrate item parameters for each achievement level before applying them to the CUP participant cohort. One item parameter was calibrated for each grade of each achievement standard (or course) before these parameters were applied to the achievement data from the CUP cohort. For secondary school results, the calibration sample included all students who completed at least two NZQA level 3 Achievement Standards in university-entrance approved subject areas in 2009. For first-year results, the calibration sample was based on all first-year students who took a first-year paper at VUW in 2010. 


\section{Achievement.}

\section{Secondary School Achievement.}

National achievement data were gathered in anonymous form from the Ministry of Education. The secondary school achievement data, specifically level 3 universityentrance approved NZQA achievement standards, were calibrated using item response theory. This approach locates participants on an interval variable measuring achievement, taking into account the relative difficulty of the standards. This analysis also enabled control of prior achievement, by establishing a control group based on these calibrated achievement results, in relation to the difficulty of the standards.

First, item parameters were calculated for all level 3 university-entrance approved Achievement Standards using national data. During 2009, 25,137 domestic students gained credit in two or more such standards (152). Students who completed too few achievement standards (fewer than two, $n=451$ ) or students who received all excellence or all not-achieved grades $(n=252)$ were not included in the IRT analysis $(n=703)$ because perfect-score and zero-score results cannot be calibrated. This meant that item parameters were estimated on a sample of 24,434 secondary students' achievement data, $97 \%$ of the student cohort who completed appropriate standards in 2009.

Scale locations were calculated for 484 CUP students based on results from the aforementioned 142 national NZQA level 3 university-entrance approved Achievement Standard results from 2009. Many CUP students had no secondary school results $(n=370)$, or invalid results, e.g. all excellence $(n=2)$ or all not achieved $(n=111)$. As a result, only half of the full 967 students who studied CUP from 2008 to 2011 could be included in the analyses involving secondary school results. The reason for these missing data is that many CUP students were early school leavers who did not actually achieve results in level 3 university-entrance approved achievement standards from their 
secondary school. Hence, they undertook the CUP programme to prepare for and gain access to university level study.

\section{CUP and First-year Degree Level University Achievement.}

Certificate of University Preparation students' achievement data were obtained from Banner student records databases at Victoria University of Wellington. CUP data included students' demographic (but not personal) information, and results from secondary school, CUP and first-year degree study. Age and other demographic variables (such as gender and ethnicity) were collected to facilitate analysis of any differences in the surveyed items or the effectiveness of CUP, based on these variables. CUP and other first-year university achievement data were treated for anonymity before being analysed.

The IRT process was repeated for CUP results and first-year degree level achievement data. Scale locations (person parameters, $n=967$ ) were also calibrated based on achievement on seven possible CUP courses. First-year achievement data were calibrated based on the full population from $2010(n=3,749)$ using 163 first-year courses. Then CUP students who studied these first-year courses at VUW ( $n=544$, $81.8 \%$ of the 665 students who passed CUP) were also calibrated based on item parameters on the population data. This technique placed students on an interval scale based on their achievement on each level of study. Perfect and zero scale location estimations were interpolated based on the person parameters that were associated with the most extreme achievement (or lack thereof) that could be calibrated. For example, students who achieved all fail grades were allocated the same score as students who achieved three $\mathrm{E}$ grades and one $\mathrm{D}$ grade.

All the achievement results from VUW were coded into four categories, corresponding to achievement data at secondary school. Tertiary and secondary school results are reported on slightly different scales; universities give grades $(\mathrm{A}+, \mathrm{A}, \mathrm{A}-, \mathrm{B}+$, 
B, B-, C, D, E), whereas secondary school achievement standards are ranked results as either Excellence, Merit, Achieved, or Not Achieved. These categories connote similar levels of merit, but the secondary and tertiary achievement results would vary accordingly. This difference should not affect the inferential statistics particularly because each achievement level was calibrated into a quantitative interval scale continua before performing further analyses.

All university achievement data were spot checked for accuracy. The researcher manually compared a random sample $(n=20)$ from the provided university achievement data with each student's official online records. No discrepancies were discovered.

\section{Engagement.}

The engagement survey data used in this study were sourced from a previous research project (Chinlund \& Hall, 2010). Most of the survey questions were drawn from Australasian Survey of Student Engagement (AUSSE, 2008) and Beginning College Survey of Student Engagement (BCSSE, 2009), selected because of its established content and construct validity (Coates, 2011; Kuh, 2001a). Engagement was measured by survey items derived from existing validated engagement measures (see Appendix A; AUSSE, 2008; BCSSE, 2009; Coates, 2010) and VUW focal areas. The survey measured respondents' perceptions pertaining to academic challenge, active learning, expected academic perseverance, supportive learning environments, and general learning and development outcomes (these variables are elaborated in Appendices A and C). The 'importance of' questions were ranked with a 4-point Likert scale (1=not important and $4=$ very important , and the 'extent included' questions Likert Scale ranged from 1=not at all to $4=$ very much. See Appendix A for the survey in its entirety.

The content validity and reliability of the AUSSE measures were evaluated in existing publications (Coates, 2010, 2011), as well as by acquiring factor analyses from 
the survey developers (A. Radloff, \& H. Coates, personal communication, March 26, 2012). The AUSSE data seemed to have undergone sufficient psychometric analyses to warrant using it to measure its claimed constructs. Examination of the factor analyses revealed that most items associated with each of the engagement subscale loaded fairly strongly on a distinct factor. These factor scores provided by Radloff and Coates were compared with factor analyses of the current survey data (presented in Appendix C) to establish concurrent and convergent validity.

Each variable that was correlated with achievement was assessed to confirm that the subscales were unidimensional - i.e. that they measured one component. Initially, principle component analyses were performed to check the dimensionality of each subscale, using Varimax with Kaiser Normalization rotation. Selecting factors with eigenvalues greater than one, quantitative variables were calculated, using item response theory, for the set of items that loaded strongly on each factor.

\section{Preparation and Perseverance.}

This research used existing data from a survey that gathered CUP students' perspectives regarding their preparation and perseverance. Using four-point Likert scales, the survey measured CUP students' expected academic perseverance, and their ratings of the efficacy of the CUP programme in preparing them for subsequent study. Preparedness was indexed by students' ratings of the contribution of CUP to their knowledge, skills and personal development in the areas of academic, and general learning outcomes (BCSSE, 2009):

- Acquiring a broad general education

- Comprehending instructions/information

- Learning effectively on your own

- Managing your time

- Reading and understanding academic material

- Speaking clearly and effectively

- Staying committed and motivated

- Staying organised 
- Taking notes

- Thinking critically and analytically

- Using computers in academic work

- Using computing and information technology

- Using the library for research

- Working effectively with others

- Writing clearly and effectively

Students rated the extent to which their experience on the CUP programme contributed to their knowledge, skills, and personal development in the above areas and which ones they nominated as important to their academic pursuits.

The expected academic perseverance measure from the Beginning College Survey on Student Engagement (2009) measures "student certainty that they will persist in the face of academic adversity". Students rate how certain they are that they will do the following in their degree study:

- Study when there are other interesting things to do

- Find additional information for course assignments when you don't understand the material

- Participate regularly in course discussions, even when you don't feel like it

- Ask instructors for help when you struggle with course assignments

- Finish something you have started when you encounter challenges

- Stay positive, even when you do poorly on a test or assignment

These items were individually evaluated in terms of their relationship to achievement.

The expected academic perseverance subscale was also calibrated using item response theory before being analysed.

\section{Importance to students.}

The researcher was not only interested in the prevalence of engagement items, but also how important the participants rated each of those items to be. Therefore, participants were also asked to rate how important (based on a four point Likert Scale, ranging from $1=$ not important to $4=$ very important) it was to them that their study place provided:

- Academic challenge

- A challenging academic experience

- Supportive learning environment 
- Support to help you succeed academically

- Support to help you thrive socially

- Assistance coping with your non-academic responsibilities (work, family, etc.)

○ Opportunities to attend campus events and activities

- Academic feedback

○ Received prompt written or verbal feedback from teachers/tutors on your academic performance

- Enriching educational experience

- Opportunities to interact with students from different economic, social, and racial or ethnic backgrounds

- Family inclusion

○ Opportunities to include my family/whānau in my studies

The family inclusion prompt was added to the survey based on New Zealand literature regarding the importance of developing a culturally responsive learning environment (Benseman \& Russ, 2003; Bishop \& Berryman, 2007; Davidson-Toumu'a \& Dunbar, 2009; McMurchy-Pilkington, 2009), particularly for Māori and Pasifika students. This item was developed in collaboration with Māori and Pākehā (NZ/European) faculty from across the University (P. Adds, K. Davis, \& M. Hall, personal communication, November 20, 2008), who were interested in assessing its prevalence and importance. 


\section{Missing Data.}

Missing data were accounted for in the quantitative analyses by excluding cases pairwise, which ensures that all participants included in an analysis had data for each variable included in that analysis. Notably, almost 50 percent of CUP students did not have any level 3 Achievement Standards from university-approved subjects $(n=483)$. These missing data are consistent with CUP students not being high achievers in secondary schools; many having left secondary school before completing any level 3 Achievement Standards. A separate variance $t$-test did not reveal any significant differences in CUP achievement means between those with secondary school achievement scores, and those missing them; $t(940)=1.0, p=.321,2$-tailed, $M=-.616$ and -0.826 respectively.

\section{Design and Analyses}

The quantitative analyses were performed with Predictive Analysis Software (PASW) statistics data editor and R software. A codebook was prepared using Microsoft Excel and variables were labelled in PASW. All statistical tests utilised 95\% criteria for significance. Spearman's $\rho$ correlation matrixes were generated to analyse associations between the dependent and independent variables. Spearman's $\rho$ rather than Pearson's $r$ was utilised because the engagement items were derived from ordinal Likert scales. Frequencies of the importance of the engagement measures were analysed by age and ethnicity for all participants using a $\chi^{2}$ (Chi-Square) test. Quantitative analyses were used for achievement and student demographics at three points: (1) NCEA results, (2) CUP achievement, and (3) achievement in the first-year of degree programmes.

Preliminary analyses assessed normality, outliers, and missing data. These analyses were conducted for each variable before calibrating data or running inferential statistics. This ensured that data sets were not violating any assumptions that would invalidate the use of certain statistical techniques. For each continuous variable, 
descriptive statistics were gathered regarding the means, standard deviations, range of scores, skewness and kurtosis. Histograms and Normal Q-Q Plots were inspected to ascertain the normality of the distribution (see Appendix C). Negative and positive skewness indicate clusters of scores on the top or bottom range, whereas kurtosis refers to the shape of the curve - flat or peaked. Distribution, dimensionality, and factor analyses were also evaluated on each relevant variable before gathering additional results (see Appendix C).

All variables were relatively normally distributed except university first-year results for students who failed CUP, which were, not surprisingly, positively skewed (i.e., towards lower achievement). The academic challenge variable presented with a negative kurtosis that would only limit conducting $t$-tests, which were not used for that variable. The factor loadings for all engagement variables suggested unidimensionality, except that active learning loaded with two components and was therefore not calibrated to a quantitative scale (see Appendix $\mathrm{C}$ for factor loadings).

The basis of the analysis of effectiveness of CUP was a model predicting firstyear degree programme achievement from secondary school achievement, using ordinary least-squares linear regression. The model was established using data from all first-year degree students at VUW in $2010(n=2,464)$. Academic improvement attributable to participating in CUP was measured by the difference between the predicted university results and CUP students' actual achievement (i.e. the residuals from the model). Achievement in level 3 University-Entrance approved Achievement Standards was compared with first-year degree paper results, as mediated by achievement in the CUP programme.

University achievement was regressed on all other variables with which it was significantly correlated. Ordinary least-squares multiple regressions were thus used to 
examine the role that the engagement subscales play in predicting CUP achievement and first-year achievement. Achievement shifts were examined between secondary school results and first-year university results as mediated by CUP achievement. A hierarchal regression was also used to predict achievement from the correlated independent variables, controlling for prior achievement, demographic variables, academic workload, and years between study levels.

Using the residuals from the regression model, this approach enabled the researcher to compare each CUP student's actual first-year university results with their predicted achievement outcomes to determine whether CUP amended first-year achievement. A predictive model of achievement was based on regressing first-year degree level achievement from NCEA results on a sample of VUW students from 2011. This model was then applied to CUP students, and $t$-tests were conducted to compare predicted versus actual first-year degree level university achievement. Measuring individual students against their own predicted achievement minimised the potentially confounding influences of prior achievement. It is nonetheless important to note that achievement is complexly influenced by an abundance of personal factors, which could not be taken into account by the statistical models.

\section{Ethical Considerations}

Pre-existing administrative data form the basis of this study. Ethical approval was obtained for use of existing data through Victoria University Human Ethics Committee (Ethics Approval Numbers: 17153 \& 17574), and approval was modified to gather the same data for subsequent trimesters, and postgraduate use. VUW Ethical Approval was obtained for using achievement data from student records and existing databases, and later granted to use the retrospective survey data for the current Master's thesis. 
The researcher followed a protocol to ensure that participants did not feel coerced into participating in the study, and ensured their confidentiality. Informed consent was gained from each participant for permission to collect survey and achievement data (see Appendix B). Invitations to participate in the research were sent to students directly after completing the CUP programme and before completing the Master's thesis. Participants were required to read and acknowledge the research information sheet and agree to participate before they were able to proceed with the survey.

In order to establish predictive inferences, a personal identifying number must be available to track achievement (such as the National Student Number or VUW Student ID Number) and this information was filed securely. To further minimise risk, the researcher ensured that the data were treated for anonymity, personally collated all data reported here, and ensured that students were not personally identifiable. All data were stored electronically with password-protected files. 


\section{Chapter 4. Results}

\section{Academic achievement as mediated by CUP and engagement}

Linear regression analyses were used to investigate the impact engagement and achievement on the CUP programme had on later academic (first-year university degree programme) achievement. This approach indicated which of these variables were the most predictive of first-year degree programme achievement, and determined the CUP programme proportion of variance in the latter that was attributable to the demographic, engagement, and CUP performance variables.

Table 2 shows intercorrelations between all of the engagement subscales and the three achievement levels. The engagement subscales were all intercorrelated with one another to varying degrees, although general development outcomes and academic preparation were strongly correlated. Academic achievement on both CUP and degree programme were not significantly correlated with any of the students' reported engagement subscales, except expected academic perseverance; $r(145)=.345, p<.001$. Only variables that correlated with first-year achievement were included in the regression analysis (secondary school scale location, CUP achievement scale location, and expected academic perseverance). 
Table 2.

Summary of Correlations Between Engagement Subscales and Achievement

\begin{tabular}{|c|c|c|c|c|c|c|c|c|}
\hline Measure & NCEA & CUP & $\mathrm{AC}$ & DEV & LRN & PER & PREP & SLE \\
\hline 1. VUW & $.15^{*}$ & $.57^{* * *}$ & 0.15 & -0.11 & 0.11 & $.35^{* * *}$ & 0.15 & 0.10 \\
\hline 2. NCEA & & $.14^{* *}$ & -0.15 & -0.10 & -0.09 & -0.17 & -0.14 & 0.15 \\
\hline 3. CUP & & & 0.13 & -0.04 & 0.02 & 0.09 & 0.03 & 0.04 \\
\hline 4. AC & & & & $.41^{* *}$ & $.47^{* * *}$ & $.42^{* *}$ & $.47^{* *}$ & $.32^{* * *}$ \\
\hline 5. DEV & & & & & $.60^{* *}$ & $.28^{* * *}$ & $.67^{* *}$ & $.35^{* *}$ \\
\hline 6. LRN & & & & & & $.51^{* * *}$ & $.81^{* *}$ & $.42^{* *}$ \\
\hline 7. PER & & & & & & & $.59^{* * *}$ & $.32^{* *}$ \\
\hline 8. PREP & & & & & & & & $.49^{* * *}$ \\
\hline 9. SLE & & & & & & & & \\
\hline
\end{tabular}

Note. $\rho=$ Spearman's Rho correlation coefficient.

$\mathrm{AC}=$ academic challenge scale location, $\mathrm{DEV}=$ general development outcome scale location, $\mathrm{PER}=$ expected academic perseverance scale location, PREP $=$ academic preparation scale location; and SLE $=$ supportive learning environment scale location. NCEA = Secondary school level 3 Achievement Standard scale locations. CUP $=$ Certificate of University Preparation achievement scale locations. VUW = first-year university achievement scale locations.

$* p<.01 ; * * p<.000$.

Table 3 shows the ordinary least-squares (OLS) regression results, which determined that $40 \%$ of the variance in degree-programme achievement could be explained by a combination of CUP achievement and academic perseverance. Secondary school achievement was not a significant predictor of first-year university achievement for CUP students; however CUP was. CUP achievement contributed to accounting for $29 \%$ of the variance in first-year degree level achievement, whereas expected academic perseverance accounted for $8.6 \%$ of the variance.

To determine the extent that these two variables (CUP achievement and expected academic perseverance) overlapped in explaining the variance in first-year achievement, 
the order in which they were entered into the regression model was reversed, and the difference between the sums of both steps was calculated. Five percent of the variance in degree programme performance was shared between the two predictors. Notably, expected academic perseverance was also not significantly correlated with CUP achievement. This indicates that students may have developed perseverance behaviours while on the CUP programme itself, particularly because perseverance was only correlated with university achievement, not CUP achievement.

\section{Table 3.}

Predictors of First-Year University Achievement

First-Year University Achievement

\begin{tabular}{lllll}
\cline { 2 - 3 } Variable & Total $R^{2}$ & $\Delta R^{2}$ & $\beta$ & $95 \% C I$
\end{tabular}

\section{Step 1}

NCEA Achievement

.03

.13

$[-0.08,0.79]$

Step 2

CUP Achievement

$$
.32 *
$$

$.29 *$

$.50 *$

$[0.45,0.87]$

Step 3

Perseverance

$.403 * \quad .086^{*}$

$.299 *$

$[0.23,0.73]$

Note. $d f=105 . \beta=$ Beta. $\Delta R^{2}=$ Change in regression co-efficient. $C I=$ confidence interval. $*_{p}<.000$.

CUP achievement accounted for more variance in first-year university achievement than secondary school achievement, and expected academic perseverance scores contributed to explaining this variance. Evidence from this model suggests that for the students in the CUP cohort, CUP was a better predictor of university degree-level achievement than academic perseverance, and secondary school achievement was not a significant predictor at all. The other engagement components also were not significantly associated with degree programme achievement. 


\section{Controlling for Variables Related to Achievement.}

It is important to determine the proportion of variance in degree programme achievement that is associated with variables other than CUP achievement and expected academic perseverance. A benefit of statistically controlling for other variables is that researchers can more accurately isolate the individual impact of each independent variable.

Therefore, any variables that were correlated with first-year university achievement were entered into a hierarchal regression model, which began with the control variables, then added expected academic perseverance, followed by CUP achievement.

Correlations were significant between degree-programme achievement and the following variables: students' prior (NCEA) achievement, age commencing CUP, secondary school results, years between leaving secondary school and studying in the CUP programme, and university course load. Secondary school achievement was included because prior achievement was significantly correlated with subsequent achievement, although this correlation was rather small. Also, years between leaving school and attending CUP were entered to statistically control for any maturation effects. The number of university courses students took in their first-year, course load, was also included to account for the potential effects of academic workload on degree-level achievement (the dependent variable).

As shown in Table 4, the effects of secondary school achievement, years between school and CUP, age at commencement of degree, and number of first-year degree courses were statistically controlled for using hierarchal multiple regression; expected academic perseverance and CUP achievement were entered into the regression stepwise. The model presented in Table 4 still explained a total statistically significant $44.8 \%$ of the variance in degree-programme achievement; $F(6,101)=13.676, p<.001$. All of the 
variables in the full model made a statistically significant contribution to predicting firstyear university achievement, except the number of degree courses students enrolled in.

\section{Table 4.}

Hierarchical Multiple Regression of First-Year Achievement and Correlated Variables ( $n$ =107)

\begin{tabular}{lcccc}
\cline { 2 - 4 } Predictor & \multicolumn{3}{c}{ VUW First-year Achievement } \\
\cline { 2 - 4 } & Total $R^{2}$ & $\Delta R^{2}$ & $\beta$ & $95 \% C I$ \\
\hline Step 1. Controls & & $.17^{*}$ & {$[.04, .92]$} \\
$\quad$ School achievement ${ }^{\mathrm{a}}$ & $.65^{*}$ & {$[.01,1.01]$} \\
Years btw. study & & & \\
Age began degree & & $-.64^{*}$ & {$[-1.03,-.00]$} \\
First-year course amount & $.09 *$ & .14 & {$[-.02, .46]$}
\end{tabular}

Step 2.

$\begin{array}{lllll}\text { Perseverance } & .218^{* *} & .125^{* *} & .319^{* *} & {[.26, .78]}\end{array}$

Step 3.

$\begin{array}{lllll}\text { CUP Achievement } \quad .448 * * & .230 * * & .498 * * & {[.32, .60]}\end{array}$

Note. ${ }^{a}$ based on secondary school achievement scale locations. ${ }^{b}$ leaving secondary school and commencing CUP.

$* \mathrm{p}<.05 . * * \mathrm{p}<.0001$.

After controlling for variables that correlated with university achievement, expected academic perseverance accounted for $12.5 \%$ of first-year achievement variance, and made an $8.7 \%$ unique contribution to explain the variance; $F(5,102)=5.687, p<.001$. CUP achievement was uniquely associated with an additional $23 \% ; F(6,101)=13.676$, $p<.001$. When conditioned by the control variables, the effects of CUP achievement and expected academic perseverance increased. This suggests that both achievement on CUP, and students' academic perseverance are individually and distinctly associated with achievement in first-year university degree studies. 


\section{Predicting university achievement from past achievement}

As indicated by the previous regression analyses, CUP performance and expected academic perseverance statistically accounted for a significant portion of first-year university achievement variance at VUW.

Achievement data were then used to determine whether passing CUP at VUW improved first-year university academic achievement, relative to that predicted from secondary school results. A linear regression was used to establish a model predicting VUW grade point averages based on students' secondary school achievement scale locations. This regression model was created using the cohort of all VUW students from 2011 who had both NCEA (level 3 university-entrance approved Achievement Standards) and VUW GPAs; $r(1,1907)=.57$. Then, CUP students' predicted GPAs were calculated using the slope $(b=1.01)$ and y-intercept $(a=4.43)$ obtained from the regression model.

Next, paired sample $t$-tests were conducted to compare the actual first-year GPAs with predicted GPAs for students who gained university entrance traditionally (mainstream students), and for CUP-entry students. There were no significant differences between CUP students actual and predicted first-year university GPAs; $t(282)=-1.03$, $p=.30$. Also, the correlation between CUP students' NCEA scale locations (secondary school achievement) and first-year GPAs was not significant; $r(283)=0.11, p=.07$; which suggests their secondary school achievement would not appropriately indicate their academic capability. This model did not take into account the number of results students obtained in secondary school or university studies, or which specific courses they attempted. However, the predictions were based on secondary school scale locations that considered the quality of achievement based on the difficulty of obtaining the results, not the quantity of results or the subjects they studied. Because the researcher was not able to acquire individual grades for this particular sample, the predicted values were solely 
university grade point averages, which does not account for the level of difficulty. However, these findings suggest that CUP students achieved to a level similar to the achievement of those who gained university entrance, despite CUP students not achieving well in secondary school.

These results are not surprising for two reasons. First, they are very different groups based on their prior achievement, and other contextual factors. Second, for the CUP cohort, university achievement was only weakly correlated with secondary school achievement; $r(299)=.15, p=.01$; but was more strongly correlated with CUP achievement; $r(532)=.57, p<.01$. For the VUW university-entrance student sample, scale locations for secondary school results were strongly correlated with scale locations for achievement in university degree level studies; $r(1,909)=.57, p<.01$. The magnitude of the correlations between CUP achievement and first-year degree level university achievement were similar to the correlation level between mainstream university-entrance students' secondary school achievement and degree level achievement. Furthermore, CUP students in this study enrolled at the same institution to do their degree, and half of them had no secondary-school results to begin with. Also, correlations between educational achievement variables are usually stronger when the variables are measured closer in time. Accordingly, floor effects may have influenced the results, because so many of the CUP students achieved poor secondary school results. Reassuringly, examinations of the achievement scatter plots did not reveal any floor effects between achievement levels.

Of course, the two groups are vastly different when it comes to their past educational experiences, and other variables not accounted for. Mainstream students also achieved higher GPAs on average; $M=4.18, S E=0.04$; than CUP students; $M=2.97$, $S D=0.89 ; t$-test $t(793)=12.49, p<.001$. The $\eta^{2}$ (eta squared), or effect size, of this 
difference was a small to moderate 0.06. This suggests that CUP students, as a whole, were not comparable to mainstream-entry students in their overall achievement, which illustrates the importance of matching them by prior achievement.

To exemplify these differences, independent sample $t$-tests were conducted to compare CUP-entry and mainstream-entry secondary school achievement scale locations. CUP students' secondary school scale locations were significantly lower than mainstream students; $t(2,258)=25.67, p<.001$. The $\eta^{2}$, or effect size, of this difference was a strong 0.23. This shows a marked reduction in the magnitude of the difference between the secondary school achievement and university achievement GPAs for CUP and mainstream students. The gap between the two study levels was reduced for CUP students, possibly influenced by their participation in the CUP programme.

To enter degree programmes, CUP students completed a three-month intensive preparation course; whereas mainstream university-entrance students completed at least 42 credits from secondary school in university-entrance approved subjects. An independent sample $t$-test revealed significant differences between the numbers of credits each group earned from secondary school. CUP-entry students also earned significantly fewer NCEA credits (of the sample who had NCEA results); $n=337, M=27.55, S D$ $=13.88$; than mainstream students; $n=2,345, M=46.22, S D=17.66 ; t(2,680)=18.67$, $p<.001$. The $\eta^{2}$, or effect size, of this difference was also a strong 0.12 . Considering the prior achievement of CUP students, their achievement in first-year university degree study seems commendable. 


\section{Comparative group by prior achievement.}

To further explore the links from CUP to university achievement, two comparison groups were used to compare first-year university achievement with students who passed CUP: (1) students who failed CUP, and (2) a sample of first-year university students who were matched to the CUP group on their secondary school achievement scale locations.

An independent samples $t$-test revealed significant differences between the firstyear university achievement scale locations for those who passed CUP; $n=483$, $M=-2.17, S D=2.98 ;$ and those who failed CUP; $n=53, M=-4.68, S D=2.73$; $t(534)=-5.86, p<.001$. The difference between the pass and fail CUP means suggests a moderate effect size $\left(\eta^{2}=.06\right)$. Not surprisingly, students who passed CUP did significantly better than students who failed CUP, although the sample sizes between students who passed and failed CUP are markedly different.

The same process was repeated to compare degree-programme achievement between CUP students and first-year university students who were matched on secondary school achievement scale locations. No significant differences were found in NCEA achievement between the CUP; $n=262, M=-1.74, S D=0.59$; and students who earned university entrance through secondary school; $n=262, M=-1.72, S D=0.57$; students' secondary school achievement means with an independent samples $t$-test; $t(522)=-0.20$, $p=.842$. In fact, the high $p$ value indicates that they were a well-matched comparative sample based on prior achievement.

An independent samples $t$-test was then conducted to compare the first-year grade point average means between students who did CUP and those who did not. GPA was used because mainstream students' first-year university achievement results were not calibrated using IRT. There was a significant difference in first-year VUW achievement grade point averages for CUP students; $n=262, M=2.77, S D=1.68$; and mainstream 
students; $n=262, M=2.21, S D=1.33 ; t(522)=3.84, p<.001$. The magnitude of the difference was small $\left(\eta^{2}=0.03\right)$. This suggests that when students are matched on prior achievement at secondary school, students who access university through the Certificate of University Preparation programme actually do slightly better than their equivalent counterparts who earned university entrance. 


\section{Achievement as related to academic perseverance, engagement, and preparation}

To investigate the extent to which academic achievement related to students' engagement, preparation, and academic perseverance, correlations between the engagement items and CUP/first-year university achievement were conducted. Academic achievement was related to academic perseverance, as well as specific student behaviours, particular itemised engagement practices, and focal preparation areas. While almost none of the engagement subscales were significantly correlated with achievement, some of the individual engagement items were slightly correlated, and are elaborated accordingly. Of course, correlations cannot determine whether one variable is causally related to another, rather, they provide evidence as to the strength of the association.

\section{Academic perseverance.}

Table 5 shows the extent to which students' responses to items from the expected academic perseverance subscale correlated with students' achievement on CUP and in the first-year of their degree programme.

\section{Table 5.}

Correlations Between Expected Academic Perseverance and Achievement

\begin{tabular}{lrr}
\hline Students' Expectation to: & CUP Achievement & $\begin{array}{r}\text { VUW First-Year } \\
\text { Achievement }\end{array}$ \\
\hline $\begin{array}{l}\text { Study when there are other interesting } \\
\text { things to do }\end{array}$ & $.28^{* *}(203)$ & $.34^{* *}(150)$ \\
Locate additional information & $.17 *(204)$ & $.31^{* *}(150)$ \\
$\begin{array}{l}\text { Finish something they have started } \\
\text { when they encounter challenges }\end{array}$ & $.10(206)$ \\
$\begin{array}{l}\text { Participate regularly in course } \\
\text { discussions even when they don't feel } \\
\text { like it }\end{array}$ & $.07(206)$ \\
\hline $\begin{array}{l}\text { Note. CUP }=\text { Certificate of University Preparation scale locations. VUW = Victoria University of } \\
\text { Wellington scale locations. Degrees of freedom }(\mathrm{N}-2) \text { are in parenthesis adjacent to the correlation. } \\
\text { Actual } p \text { values are reported in text. } \\
* * p>.01 ; * p>.05 .\end{array}$
\end{tabular}


Students' willingness to finish something they have started when they encounter challenges was positively correlated with first-year achievement; $r(150)=.322, p<.001$. First-year achievement was also correlated with students reporting that they will participate regularly in course discussions even when they don't feel like it; $r(150)=.252, p<.012$. Additionally, willingness to study when there are other interesting things to do was significantly correlated with achievement in CUP; $r(203)=.217, p<.012$; and achievement in degree-level study; $r(150)=.335, p<.001$. Students' indication that they will find additional information for course assignments when they don't understand the material was correlated with CUP achievement; $r(204)=.169, p=.015$; and first-year university achievement; $r(150)=.308, p<.001$.

Notably, while these perseverance items were all moderately correlated with degree-level university achievement, two correlations with CUP achievement were not significant, and the other two were significant, but weak. This suggests that this measure of expected academic perseverance may be more related to university degree-level achievement, or that students may have developed these perseverance behaviours while on the CUP programme itself.

\section{Students' engagement behaviours.}

Table 6 shows students' reports of some of their engagement behaviours were correlated with achievement scale locations on CUP and VUW first-year. In particular, students' reports of their self-management were somewhat related to achievement. Respondents' reports of being prepared for class - having completed readings and assignments - was positively correlated with achievement in both CUP; $r(209)=.211, p<.012$; and degree; $r(151)=.221, p<.016$. Keeping up to date with their studies was correlated with CUP achievement; $r(209)=.222, p<.011$; and first-year university achievement; $r(151)=.233, p<.014$. 
Table 6.

Correlations Between Engagement Behaviours and Achievement

\begin{tabular}{lll}
\hline How often students: & CUP Achievement & $\begin{array}{l}\text { VUW First-Year } \\
\text { Achievement }\end{array}$ \\
\hline Kept up to date with studies & $.22^{* *}(209)$ & $.23^{* *}(151)$ \\
$\begin{array}{l}\text { Attended class having completed } \\
\text { readings or assignments }\end{array}$ & $.21^{* *}(209)$ & $.22^{* *}(151)$ \\
$\begin{array}{l}\text { Contacted tutor or lecturer outside } \\
\text { of class time about your studies }\end{array}$ & $.15^{*}(206)$ & $-.00(153)$ \\
& & $.10(153)$ \\
$\begin{array}{l}\text { Worked hard to master difficult } \\
\text { content }\end{array}$ & $.14^{*}(211)$ & \\
\hline $\begin{array}{l}\text { Note. CUP }=\text { Certificate of University Preparation scale locations. VUW = Victoria University of } \\
\text { Wellington scale locations. Degrees of freedom }(\mathrm{N}-2) \text { are in parenthesis adjacent to the correlation. } \\
\text { Actual } p \text { values are reported in text. } \\
* * p>.01 ; * p>.05 .\end{array}$
\end{tabular}

Contacting a tutor or lecturer outside of class time about studies was positively correlated with CUP achievement; $r(209)=.152, p=.027$. Students' reports of working hard to master difficult content (a component of academic challenge) was also positively correlated with CUP achievement; $r(209)=.140, p=.042$; which suggests perceived effort into studies is related to academic success - albeit with only a small effect size.

\section{Achievement and Preparation.}

Table 7 shows perceptions that the CUP programme developed students' study strategies and learner autonomy were significantly related to academic achievement. Specifically, the development of particular study skills, such as time management and writing clearly and effectively, were linked with achievement. Achievement was also related to students' perception that the CUP programme prepared them to stay committed and motivated, stay organised and to learn effectively on their own. Students' reports that the CUP programme prepared students to learn effectively on their own, manage their time, and write clearly and effectively were positively correlated with both CUP and degree-level study achievement. 
Table 7.

Summary of Correlations Between CUP Items as a Function of Achievement Level

\begin{tabular}{|c|c|c|}
\hline Item & CUP Achievement & $\begin{array}{l}\text { VUW First-Year } \\
\text { Achievement }\end{array}$ \\
\hline $\begin{array}{l}\text { Evaluation of entire CUP } \\
\text { educational experience }\end{array}$ & $.21 * *(200)$ & $.17 *(145)$ \\
\hline Inclusion of Academic support & $.22 * *(191)$ & $.22 * *(141)$ \\
\hline Inclusion of Academic feedback & $.15^{*}(194)$ & $.14(143)$ \\
\hline $\begin{array}{l}\text { Extent Students' Reported CUP } \\
\text { Prepared them to: }\end{array}$ & & \\
\hline Stay committed and motivated & $.11(203)$ & $.30 * *(151)$ \\
\hline Manage time & $.15^{*} \quad(204)$ & $.25^{* *}(151)$ \\
\hline Stay organised & $.06(207)$ & $.24 * *(153)$ \\
\hline Write clearly and effectively & $.21 * *(204)$ & $.23 * *(150)$ \\
\hline Learn effectively on their own & $.16^{*}(206)$ & $.21 * *(152)$ \\
\hline
\end{tabular}

Note. CUP = Certificate of University Preparation scale locations. VUW = Victoria University of Wellington scale locations. Degrees of freedom $(\mathrm{N}-2)$ are in parenthesis adjacent to the correlation. Actual $p$ values are reported in text.

$* * p>.01 ; * p>.05$.

Respondents who felt CUP prepared them to stay organised achieved in the first-year of their degrees; $r(151)=.236, p<.013$. Also, preparation to stay committed and motivated was not surprisingly linked to higher first-year university achievement; $r(149)=.302$, $p<.001$. The extent that the preparation programme prepared students in other areas was linked with achievement. Preparation to write clearly and effectively was correlated with CUP; $r(204)=.207, p<.013$; and degree-level study; $r(150)=.232, p<.014$; achievement. Additionally, developing time management skills were correlated with CUP; $r(204)=.146, p=.036 ;$ and degree-level study; $r(151)=.248, p<.012$; achievement. CUP achievement was positively correlated with preparation to learn effectively on their own; $r(204)=.158, p=.023$; as was university degree-level 
achievement; $r(150)=.209, p=.010$. These findings indicate that certain study skills and behaviours are associated with higher achievement.

Table 8 shows which five skills survey participants ranked as most useful for their degree level study.

Table 8.

Top Five Most Useful Skills

\begin{tabular}{lcc}
\hline Skill & $\begin{array}{c}\text { Percentage of } \\
\text { respondents ranking } \\
\text { skill in top three }\end{array}$ & $n$ \\
\hline 1. Thinking critically and analytically & $53 \%$ & 107 \\
2. Reading and understanding academic material & $45 \%$ & 91 \\
3. Writing clearly and effectively* & $45 \%$ & 90 \\
4. Managing your time* & $40 \%$ & 60 \\
5. Staying committed and motivated* & $33 \%$ & 66
\end{tabular}

Note. The percentage refers to the \% of respondents who ranked that item within the top three most useful skills based on the survey question. Survey respondents were asked to select their top three skills from the following list: Comprehending instructions/information; Learning effectively on your own; Managing your time; Reading and understanding academic material; Speaking clearly \& effectively; Staying committed and motivated; Staying organized; Taking notes; Thinking critically and analytically; Using computing and information technology; Using the library for research; Working effectively with others; or Writing clearly and effectively.

* Item is correlated with degree level achievement; $p>.01$.

Programme satisfaction was also linked to achievement outcomes. Students who were more satisfied with CUP also did better in the programme; $r(200)=.207, p<.013$; as well as in their first-year of degree study; $r(145)=.168, p=.041$. Satisfied CUP students who reported that they would do the same preparation programme if they could start over again also achieved in CUP; $r(201)=.227, p<.011$. Students who perceive institutional support to succeed academically also tend to achieve well in both CUP; $r(191)=.220, p<.012 ;$ and in their VUW first-year achievement; $r(141)=.219, p<.019$. 


\section{The Value of Engagement Practices and Their Links to Achievement.}

University preparation students' ratings of the importance of selected engagement practices were described and analysed to determine whether they also correlated with achievement. The survey required students to rate how important each of the following engagement items was to them: academic challenge, family inclusion, feedback, diverse interactions, academic support, non-academic support, social support, and campus events. Respondents rated these items on a four point Likert scale from not important, somewhat important, important or very important (ordinal categories). Understanding students' ascribed importance of certain engagement practices may enable institutions to make informed decisions about what practices are worth resource allocation. Figure 1 displays the survey items in order of importance to CUP survey respondents.

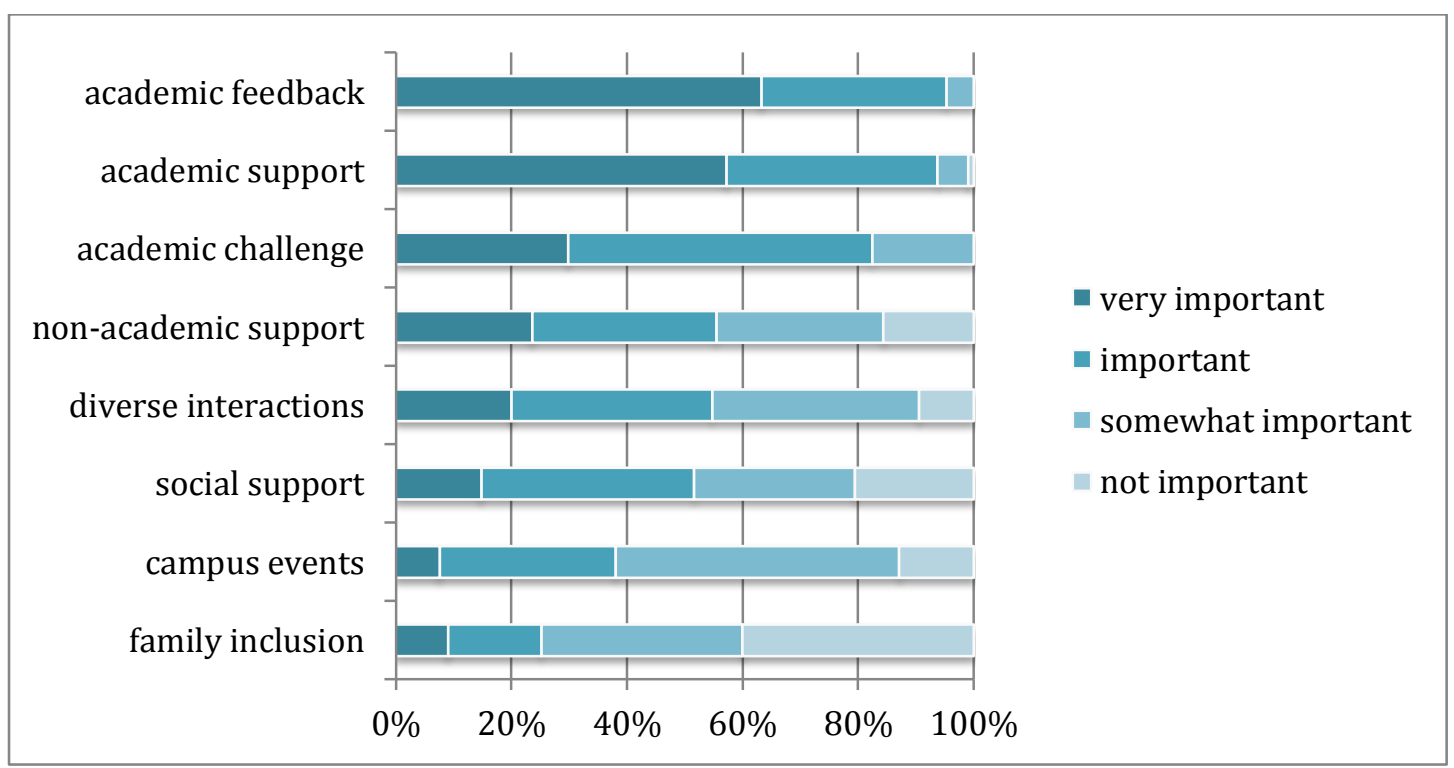

Figure 1. CUP Survey Respondents' Importance Ratings

The majority of CUP students nominated academic feedback, support, and challenge highly important - practices that are reassuringly within institutional control, as well as supported by past research (e.g., Hattie \& Timperley, 2007; Kuh et al., 2005). The importance of academic challenge was positively correlated with both levels of 
achievement, whereas the inclusion of academic feedback and academic support demonstrated a positive relationship to CUP achievement.

The item ranked most important to survey respondents was academic feedbackreceived prompt written or verbal feedback from teachers/tutors on your academic performance - with $63.3 \%(n=210)$ nominating it as very important, $31.9 \%$ important, and $4.8 \%$ somewhat important. Student perception that the CUP programme provided prompt feedback was also positively correlated with CUP achievement; $r(192)=.153$, $p=.034$.

Students who placed value on academic challenge also did well in their measured tertiary academic achievement in both levels. The importance of a challenging academic experience was correlated with CUP achievement scale locations; $r(206)=.143, p=.039$; and more strongly correlated with first-year university achievement scale locations; $r(151)=.282, p<.001$.

The engagement items are listed in Table 9 by the percentage of CUP respondents who rated the item important or very important. None of the survey respondents rated academic feedback or academic challenge $(n=211)$ as not important, with $29.9 \%$ of respondents ranking it very important, $52.6 \%$ important and $17.5 \%$ somewhat important. This suggests that the majority of CUP respondents valued academically related engagement practices.

In consideration of the Supportive learning environment questions, CUP students also highly valued academic support $(n=208)$ with $57.2 \%$ rating it very important, $36.5 \%$ important, 5.3\% somewhat important, and only $1 \%$ not important. The inclusion of academic support was correlated with achievement in CUP; $r(191)=.220, p<.012$; and in first-year university; $r(141)=.219, p<.019$; but not the importance of academic support. 
Table 9.

Students' Importance Ratings of Items

Item Rated Important or Very Important Percentage

$n$

1. Academic feedback

$95.2 \%$

200

2. Academic support*

$93.7 \%$

195

3. Academic challenge*

$82.5 \%$

174

4. Non-academic support

$55.5 \%$

5. Diverse interactions

$54.8 \%$

6. Social support

$51.6 \%$

108

7. Campus events

$38.1 \%$

80

8. Family inclusion

$25.2 \%$

Note.

* Item is correlated with degree level achievement; $p>.01$.

The importance ratings for assistance coping with your non-academic responsibilities (work, family, etc.) were more dispersed (23.7\% very important; $31.8 \%$ important; $28.9 \%$ somewhat important; \& $15.6 \%$ not important). Interestingly valuing non-academic assistance and social support were negatively linked with students' achievement, whereas the perception of including family in studies was negatively associated with achievement. Those who did not place high value on social support or non-academic assistance tended to do well in CUP. Students' perception of the importance of assistance coping with your non-academic responsibilities (work, family, etc.) was linked with lower CUP achievement; $r(206)=-.158, p=.023$; as is the importance of support to help you thrive socially; $r(204)=-.146, p=.037$. Additionally, CUP achievement scale locations were negatively correlated with students perceptions of 
the importance; $r(205)=-.157, p=.024 ;$ as well as the incorporation; $r(192)=-.283$, $p<.001$; of including family/whānau in studies.

\section{Comparing Ethnicities and Age Groups}

One-way between-groups analyses of variance were conducted to explore the impact of ethnicity and age on each achievement scale location (secondary, CUP and first-year) as well as the engagement subscales. There were no significant differences amongst age or ethnic groups on CUP achievement, although significant differences were present between ethnic groups on VUW first-year and secondary school results. There were also significant differences between age groups with scale locations on VUW first-year achievement results and the academic challenge subscale. There were no significant differences apparent on any of the other engagement subscales.

To examine whether there were any between group differences among the importance of items, Chi-Square $\left(\chi^{2}\right)$ tests were applied to the ratings based on ethnicity and age. In order to examine between group differences with a smaller sample size, important and very important ratings were collapsed along with not important and somewhat important before performing the analyses. The findings revealed that Pasifika students' importance ratings statistically varied from other ethnic groups.

As noted, there was some variation between age and ethnicity in achievement and how university preparation students rated the importance of the surveyed engagement items, as well as the extent that each of those items related to achievement. Recognising these differences may encourage institutions to offer tailored support to students, although exploration of the reasons for any group differences was beyond the scope of this present work. 


\section{Ethnicity.}

Notable, but small, differences were apparent between Pasifika and European students in both secondary school and first-year university achievement, although no significant differences between ethnicities were apparent in CUP achievement. There was a statistically significant difference by ethnicity for both secondary school achievement; $F(3,475)=4.33, p<.015$; and first-year achievement; $F(3,532)=7.79, p<.001$. Posthoc comparisons using the Tukey HSD test indicated that the mean achievement scores varied between Pasifika $(n=82, M=-2.27, S D=1.26)$ and NZ/European $(n=257$, $M=1.79, S D=1.26)$ students on both secondary school achievement scale locations (Mean difference $=-0.48, S E=0.14, p<.013$ ) as well as with VUW first-year achievement scale locations, reported below.

Pasifika students also varied from Māori students in their scale locations on firstyear achievement. Mean VUW first-year achievement scores also differed between Māori $(n=93, M=-2.48, S D=2.81)$ and Pasifika $(n=74, M=-3.85, S D=2.33)$ students (Mean difference $=1.37, S E=.47, p=.018$ ) as well as with Pasifika and NZ/European $(n=302, M=-2.00, S D=3.23)$ students (Mean difference $=1.85, S E=.39, p<.001)$. There were no significant differences between any of the other ethnic categories. The effect size of ethnicity on first-year achievement, calculated using $\eta^{2}$ was a small 0.04 , corresponding with a small effect size $\left(\eta^{2}=0.03\right)$ for secondary school achievement scale locations.

Pasifika students placed different value on engagement practices than respondents from other ethnicities (including Māori, Pākehā, Asian and other), as evident from $\chi^{2}$ tests, and displayed in Figure 2. Between Pasifika students and students of other ethnicities, there were statistically significant differences amongst importance of family inclusion; $\chi^{2}(1, n=210)=9.113, p<.013 ;$ academic support $; \chi^{2}(1, n=208)=6.085, p=.014 ;$ 
non-academic support; $\chi^{2}(1, n=211)=15.385, p<.001 ;$ social support; $\chi^{2}(1, n=209)$ $=4.980, p=.026$; and feedback; $\chi^{2}(1, n=210)=4.132, p=.042$.

Notably, $82.6 \%(n=19)$ of all Pasifika respondents rated prompt feedback as highly important, along with $81.8 \%(n=18)$ rating academic support and 56.5\% $(n=13)$ non-academic assistance as important or very important. These figures show that Pasifika students do value these feedback and support loops possibly more than other ethnicities, although there were only 22 Pasifika respondents in this survey data.

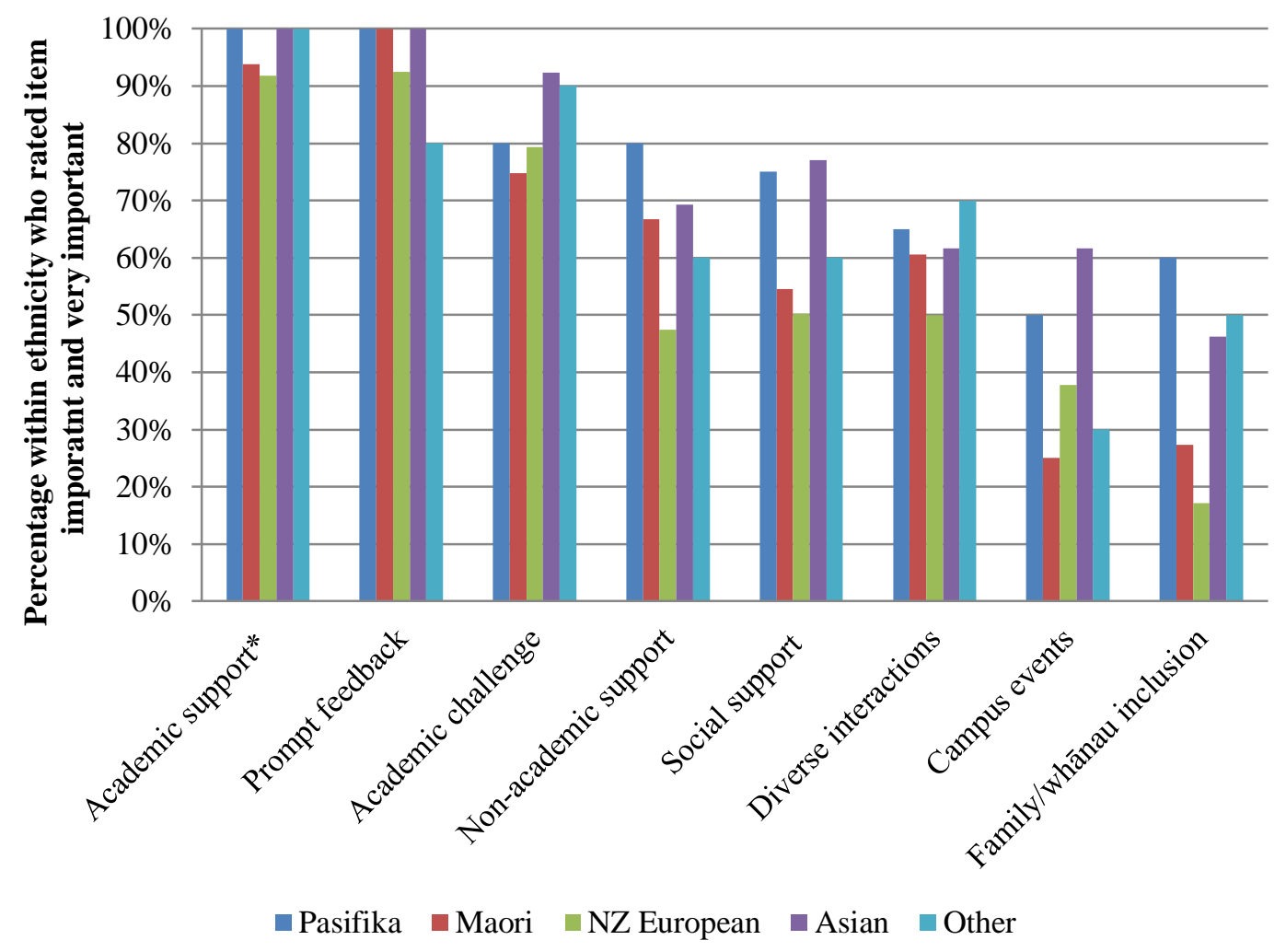

Figure 2. Importance Ratings by Percentage within Ethnicities

As presented in Figure 2, most CUP respondents' valued academic feedback, academic support, and academic challenge, but Pasifika students were most likely to value the first two. The ethnic groups did not differ in how important they rated academic challenge, diverse interactions, and attending campus events. All students regardless of their ethnic heritage valued academic challenge, whereas the other items were rated as being less important. 
Understanding the similarities and differences across ethnicities enables institutions to decide which support services may be worth investing in. Unfortunately, these results only represent a total of 22 Pasifika students' perspectives, which although a relative composition of the CUP survey respondents, are quite a small sample. These results obviously warrant further exploration before instituting changes to practice or externally generalising the findings.

Age.

Older students demonstrated the greatest variance from younger students in both firstyear university achievement and their perception of academic challenge. The age groups included those who were the following ages when they started CUP: 16-19, 20-24, and over 25 years of age.

The effect size for age on first-year university achievement was also a small 0.04 $\eta^{2} ; F(2,533)=9.85, p<.001$; with significant differences (using Tukey HSD) between students aged $16-19(n=428, M=-2.67, S D=2.93)$ and those 25 and older $(n=30$, $M=-0.42, S D=3.68 ;$ Mean difference $=-2.25, S E=.57, p<.001)$ as well as with those aged 20-24 $(n=78, M=-1.81, S D=3.08)$ although the mean difference between the two younger groups is not actually that large; Mean difference $=-0.87, S E=.37, p=.050$.

This suggests students aged 25 and older achieve slightly better in university degree-level studies than younger students.

However, the effect size of age on academic challenge was a large $0.14 \eta^{2}$ suggesting the perception of academic challenge may vary quite a bit between the age groups of 16-19, 20-24 and 25 and above; $F(2,211)=16.50, p<.001$. Post-hoc comparisons using Tukey HSD revealed that the largest mean difference was between those aged 25 and above $(n=23, M=2.57, S D=1.52)$ and those aged $16-19 ; n=151$, $M=-0.52, S D=2.80 ;$ Mean difference $=3.09, S E=0.59, p<.001$. The youngest group 
also statistically differed from the group aged 20-24; $n=40, M=1.02, S D=2.55 ;$ Mean difference $=-1.54, S E=0.47, p<.014$. Older students also found studying to be more academically challenging than younger students.

Figure 3 displays the percentage of students who rated the item important and very important by age group. A greater number of older students rated academic challenge as important or very important than expected; $\chi^{2}(1, n=211)=13.791, p$ $=.001$. Students in the $16-19$ year old age range $(84.4 \%, n=124)$ did not value diverse interactions as much as the two older age groups; $\chi^{2}(1, n=210)=5.807, p=.055$; although $80 \%$ of all respondents rated this item as not or somewhat important. The importance of academic support was rated by $57.2 \%$ of respondents as important or very important, with older students valuing it more than younger students; $\chi^{2}(1, n=208)=$ 9.311, $p=.010$.

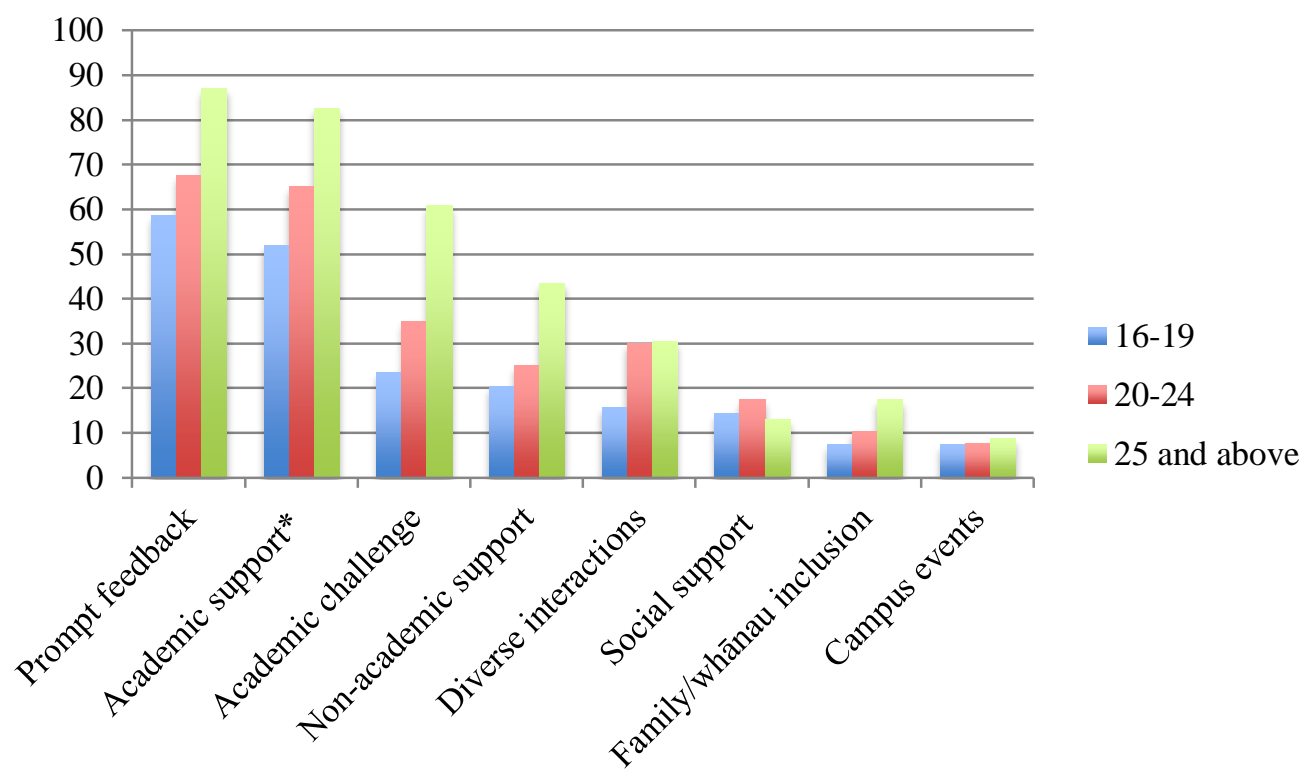

Figure 3. Importance Ratings by Percentage within Age Groups

More respondents aged 25 and above rated non-academic support as important and very important than expected; $\chi^{2}(1, n=211)=5.976, p=.050$, along with $85 \%$ of those above 25 who equally valued the importance of feedback; $\chi^{2}(1, n=210)=7.303, p=.026$. 
Overall, older students seemed to value academic challenge, support and feedback, as well as non-academic support and diverse interactions more than younger students. 


\section{Chapter 5. Discussion and Conclusion}

This study provided empirical evidence of the impact of preparation and engagement on the longitudinal achievement of students who participated in VUW's Certificate of University Preparation programme. The primary research goal was to evaluate the effectiveness of CUP in preparing learners to access, engage with, and achieve in their first-year of their university degree programmes. Both CUP achievement and students' expected academic perseverance each made a unique and statistically significant contribution to predicting first-year degree level university achievement, although CUP was the stronger predictor. Students' academic perseverance was the only engagement subscale that significantly correlated with, and predicted, university degree level achievement. CUP students also achieved slightly higher grades than mainstream students who achieved similar levels at secondary school, matched to the CUP students' prior achievement. This finding was surprising when considering the apparent differences between the past educational experiences of the two groups. This study has also contributed to understanding which preparation and engagement facets have a relationship to achievement and which are also important to students themselves. Taken together, these findings may indicate for providers particular facets that are worth developing or investing in.

The findings have filled a significant gap in educational research, and may be relevant for students, educators, policymakers, or institutions. Mainly, this study has established an empirical relationship between participation in a CUP programme, academic perseverance, and achievement in university studies. While the concept of engagement may be highly acclaimed, the results from this study not reveal strong links to achievement, challenging the proposition that engagement significantly impacts on achievement. Additionally, the main engagement surveys (AUSSE \& NSSE) previously 
did not enquire which practices were important to students, whereas this study gathered students' perceptions of both the prevalence of engagement practices and their level of importance. This enabled the exploration of any variation between groups in valued practices, and an illustration of to what extent the practices related to achievement.

This study contributed to developing an empirical basis establishing the impact of a preparation programme on achievement, and gathered data that evaluated the link between measured engagement and achievement. Some individual engagement and preparation items were minimally correlated with university degree-level achievement, but most were not correlated at all. Some of the individual engagement items produced small correlations with achievement, and expected academic perseverance was the only engagement subscale that significantly correlated with achievement. Certain student behaviours, institutional behaviours, ratings of importance, and preparation areas were also related to achievement, which indicates which practices may be beneficial for learners. Significant differences were apparent between the achievement and ratings of importance amongst students who identify as Pasifika and other ethnicities, as well as for students aged over 25 and their younger counterparts.

The objectives of the CUP programme were to assist underprepared and under qualified students to prepare for, access, and achieve in university. Although this study provided evidence consistent with the CUP programme successfully achieving its objectives, variation in first-year university achievement was associated with a combination of university preparation provision, and student behaviours - and they may have developed the latter on the programme itself. Gathering data solely from one programme at one university may challenge the external validity of the study. However, it is hoped that the findings may inform other similar preparatory programmes. 


\section{Academic Achievement}

Students who passed CUP had greater achievement than students who did not successfully complete CUP, furthermore CUP students achieved slightly higher than mainstream-entry students who had similar prior achievement (scale location scores). CUP performance also statistically predicted 23 percent unique variance in first-year achievement at VUW even when controlling for prior achievement. These results indicate that CUP impacted first-year degree performance.

Students were matched on prior achievement based on the item response theory analysis of secondary school results, which considered the difficulty of standards, and developed an interval scale that located students on a continuum based on the quality of their achievement, not the quantity of credits they earned. Matching scale locations indicated that the mainstream comparative students were likely to have similar priorachievement capability levels, and should, therefore, theoretically achieve similar results in university. To gain university entrance at secondary school, students must earn credits in specified university-entrance approved subjects. However, despite not achieving secondary school results sufficient to gaining university entrance, CUP students actually performed slightly better in first-year university than their achievement-matched peers who earned university entrance, although the effect size was small. In other words, CUP students' who didn't have UE achieved slightly better than students who earned UE, conditioning on prior achievement. This suggests that participation in CUP revealed and perhaps developed students' competency to achieve in university.

Although prior achievement may be a fairly reliable indicator of future achievement, it is not possible to match individual students on every possible confounding variable. The achievement-matching process was such that CUP students and matched comparison students demonstrated similar levels of prior ability, but these 
students may differ in other ways. For example, students who enter university from mainstream and non-mainstream means may be coping with different academic, personal, or contextual factors during their transition (Choy et al., 2000; Evans, 2000; Terenzini et al., 1994). There is potential for bias in the data because it is not possible to determine whether these CUP students had the same characteristics of the students who did achieve NCEA results. The lack of NCEA data for half the CUP students could indicate that these students had lower academic ability than students who achieved level 3 Achievement Standards in university-entrance approved subjects. Yet all of the students who participated in CUP were defined to be underprepared for university based on their prior results. Considering these circumstances, the relative achievement of CUP students seems commendable.

However, CUP students had a very strong proximal goal: to earn university entrance, which they could not achieve without passing CUP. The influence of this personal study objective may have contributed to their success. CUP students also may have placed more value on the opportunity to have a 'second chance' at university education, which also may have influenced their behaviours and achievement.

This study cannot necessarily be applied to other university preparation programmes because different programmes are likely to vary considerably in form. It has not gathered evidence as to whether the programme location impacts on achievement, an important distinction given the NZ policy strategic direction to move preparation provision outside of universities (Tertiary Education Commission, 2011). CUP students may have been particularly acclimatised to VUW, and evidence pertaining to how they would academically fare elsewhere, or how students who were prepared elsewhere would fare at VUW could not be obtained. For students in preparation programmes, the university environment may be more conducive to supporting their achievement than an 
authoritarian style secondary school experience. Also, international contextual variations to university preparation could not be established by this study. It would therefore be important to ascertain whether these results are applicable to other students before making claims about the generalizability of these findings.

Also, prior research has attributed achievement gains to participation in a learning community (Tinto, 2000; Zhao \& Kuh, 2004). As suggested by Tinto (2000) and Zhao and Kuh (2004), a learning community is classified by sharing two or more classes, perhaps through programmes tailored for particular groups of people, such as an underprepared cohort. It may be difficult to ascertain whether achievement was impacted by particular elements of the CUP programme itself or simply from being part of a learning community. Most likely achievement gains are a result of many factors, of which CUP may have facilitated preparation, support provided as well as benefits contained with participating in a learning community.

\section{Predicting University Achievement from Secondary School Achievement}

Performance on national level-3 Achievement Standards in NZ university-approved subjects did not statistically predict the achievement of CUP students in first-year VUW courses. For these under-qualified students, secondary school results were not an adequate indicator of their academic capability to achieve at university. This study provided empirical evidence that CUP, along with academic perseverance, could be better indicators of academic capability to achieve in university, specifically for under-qualified students.

CUP students' secondary school results were also only minimally correlated with their CUP and university achievement. CUP achievement, however, was much more strongly correlated with university achievement $(r=.57)$. The correlation between CUP achievement and university achievement of CUP students was on par with correlations 
between mainstream-entry students' secondary school and university achievement. This suggests that CUP may also be a robust indicator of university capability.

Due to the predominance of early school leavers and half of CUP students missing level 3 achievement (secondary school) data, it is not surprising that NCEA achievement was not predictive of first-year achievement. Correlations weaken with time. Elapsed time between studies could enact maturation or history effects. To test whether maturation posed a threat to reliability, the number of years between leaving school and studying CUP was considered, yet potential achievement effects could be derived from how students were spending this time. This study used achievement data from three points in time: results from level 3 university-entrance Achievement standards, CUP results, and first-year university results. Further research could include links between achievement at both lower levels of secondary school through to higher university levels, perhaps even to employment outcomes. Notably, measuring academic achievement through study progression could enact selection bias because the analyses only included students who progressed through each level. This study has not examined factors that led to student attrition or academic failure.

Prior secondary-school achievement scale locations were based on results from NZQA level 3 Achievement Standards from university-entrance approved subjects, rather than cumulative university-entrance scores. Further research could compare other secondary-school achievement models, such as those used by Shulruf, Hattie, and Tumen (2008a), especially as university entrance requirements shift. Although prior achievement at secondary schools is correlated with postsecondary achievement (Engler, 2012; Scott 2009; Shulruf et al., 2008a), the results from this study suggest that other measures add to the indicators of university academic success - such as participation in a university preparation programme or scores on expected academic perseverance. 


\section{Academic Perseverance}

Studying can be arduous; therefore it is not surprising that perseverance goals and behaviours were linked to achieving well in both study levels. Students' reports of their expected academic perseverance behaviours correlated with achievement. Students who achieved well also persisted despite obstacles, prioritised study and demonstrated autonomy in learning. Other behaviours that related to achievement included selfmanagement and being prepared for class. These results associate achievement with an on-going commitment to prioritising academic goals. In fact, Expected academic perseverance was the only calibrated engagement subscale that correlated, and was associated, with first-year university achievement. Four of the six individual items from the expected academic perseverance subscale were also correlated with achievement.

Although the complexity of university preparation and achievement has not been unpacked in this study, the evidence suggests that achievement on the CUP programme at VUW was significantly associated with variance in degree-level achievement at VUW. Additionally, students' expectations of their academic perseverance made an additional and separate contribution to predicting the variance degree-level achievement, but not to predicting CUP achievement. However, the perseverance survey questions asked students what they expected to do in their degree studies, not what they did in CUP. Nevertheless, little variance was shared between these two predictors. This separate contribution, unrelated to CUP achievement, suggests that academic perseverance could be something students developed while on the CUP programme itself.

Interestingly, this study has contributed to providing evidence of the significant effect of perseverance, a non-academic factor, on underprepared students' achievement. The operational definition of academic perseverance requires further development because it is an emerging concept. The existing literature focussed on the role of 
perseverance with high achievers' success (Duckworth et al., 2007), although it did not qualify expected academic perseverance in the same way as the BCSSE did (BCSSE, 2009). The achievement findings are attributable only to the particular way perseverance was measured by the survey utilised and to this particular sample, but these results may prompt further investigations. Relying on self-reported behaviours may not adequately represent actual behaviours, although replication would support the generalizability of these results. In any case, the findings associating academic perseverance with university achievement suggest it could be beneficial to develop perseverance behaviours in students. Also, those responsible for university admissions may be interested in considering other non-academic university readiness indicators, along with achievement, as suggested by Maruyama (2012).

\section{Engagement}

Although engagement may be a concept with its own merit and be worth investigating in its own right (Krause \& Coates, 2008), the findings from this study contradict the NSSE and AUSSE claims regarding the significance of engagement links to educational gains; namely, achievement. None of the engagement subscales significantly accounted for any of the variance in first-year achievement, although some individual survey items did weakly correlate with achievement, which was a similar finding to that of Gordon et al. (2008). If engagement practices do enhance learning, their impact on achievement was not evident in this study.

These findings suggest that the utility of the engagement survey data for policy or practical decision-making is questionable. Engagement, as it is conceptualised in the AUSSE, may have indirect or influential effects on learning, but their direct links to achievement were not strongly evident from this study. The argument that engagement may level out achievement for the underprepared (Kuh, Kinzie, Buckley, et al., 2006; 
Kuh, Kinzie, Cruce, et al., 2006; Kuh, 2009) was not apparent from this study, nor was engagement found to predict any variance in degree-programme achievement as reported by Kuh, Cruce, Shoup, Kinzie, and Gonyea, (2008). Establishing a correlation between engagement and achievement cannot establish causality. In any event, tiny correlations produced from the engagement items suggest engagement relationships may have limited practical application or significance. If we continue to endorse the merits of engagement, it is imperative to ensure the measured practices and behaviours have a more robust empirical relationship to achievement.

Some prior studies reported modest links between engagement and achievement, as well as persistence (Carini et al., 2006; Kuh et al., 2008a; Kuh, Kinzie, Cruce, et al., 2006). Reliance on self-reporting (e.g., Reason et al., 2006; Zhao \& Kuh, 2004), rather than observations of actual behaviours, may be problematic, particularly when results from engagement surveys are based on self-reported achievement rather than actual grades. Alternatively, the present study used actual institutional achievement data. Selfreported achievement, as utilised by the AUSSE survey, may somewhat inflate the responses (Hagel et al., 2012; Porter, 2011).

One possible explanation for not establishing a direct link between engagement and achievement is that the present study used survey results for only 220 students, rather than the thousands of students who are surveyed in the United States (e.g., Gordon, Ludlum, \& Hoey, 2008; Kuh et al., 2008; Kuh, Kinzie, Cruce, et al., 2006; Pascarella, Seifert, \& Blaich, 2010) or Australia (e.g., Hagel, Carr, \& Devlin, 2012; Hagel et al., 2012; Radloff, 2011). Due to the smaller sample of respondents to the engagement survey in the present study, not all the items exhibited much variation between Likert categories. Larger data sets can identify more statistical nuances, although there is greater potential to enact a Type 2 error with an abundance of data, and significant relationships between 
variables are often discovered when the links are weak at best (See Cohen, 1988 for a seminal discussion of this issue).

The surveyed sample of CUP students may differ from the mainstream university population. The students surveyed in most of the engagement literature were from the university population at large, and usually did not include pre-degree students, such as the CUP cohort. Accordingly, CUP students may benefit from particular practices that may not necessarily be important or useful to the general student population. It would be interesting for further research into engagement to also survey the importance of items for other groups of students and relate their importance ratings to actual achievement scale locations, rather than rely on students' self-reported achievement as they do in much of the published engagement research.

These results contain only pieces of the achievement puzzle. This study only evaluated certain aspects of engagement, whereas other student behaviours and institutional practices may impact on achievement. In particular, it would be interesting to measure how students' metacognitive function relates to achievement because metacognition has been strongly endorsed by educational researchers (e.g., Flavell, 1979; Hattie et al., 1996; Vrugt \& Oort, 2008). Existing literature stressed the influence of other factors (Conley, 2005; ConnectEd, 2012; Lombardi et al., 2011), however this study did not gather data on personal background, socio-economic status, intellectual maturity, adaptability, attitude, or motivation. Nor do the results take into consideration external factors and influences, such as family or community obligations and support (DavidsonToumu'a \& Dunbar, 2009; Prebble et al., 2005; West, 1985) or being the first one in their family to begin university (Pike \& Kuh, 2005). The claims made in the literature would be strengthened by empirical validation. 
The results from this study indicate that it may be useful to reconceptualise which student behaviours, institutional practices, and policies impact on student achievement. The current engagement survey that purports to measure effective learner behaviours and institutional practice (endorsed in the AUSSE and NSSE) could be revised based on establishing empirical relationships with achievement, and on gathering students' feedback. Solely basing policy, practice or process decisions from the engagement survey data warrants caution if educational stakeholders are interested in influencing achievement. However, this would require gathering achievement and engagement data from different student populations.

\section{Diversity}

If it is agreed that gaining knowledge about what is important to students may enhance their experience, and that understanding differences could assist institutions to be more responsive to student diversity within their institution, then the results of this study provide some basis for these discussions. Yet present findings are based on a sample of pre-degree students who may not necessarily be representative of the university population as a whole. Additionally, the reported group differences are based on an even smaller number of student respondents. Therefore, gathering more student feedback could assist institutions to determine what is important to learners in the university environment, and what impacts their achievement.

In this study, a challenging academic experience and receiving prompt written or verbal feedback from teachers/tutors on your academic performance was scored as important by all students, regardless of their ethnic group, and has been endorsed in the literature (Hattie \& Timperley, 2007). There were no significant differences in the importance of academic challenge amongst all ethnicities, which implies that all students 
tend to value challenging study. As Kuh et al. (2005) commented, "people rarely exceed their own expectations without being challenged" (p. 111).

Older students, those aged 25 and over, differed from their younger counterparts in what they valued, as well as how they achieved. The findings suggest that not only do the older student perform well in university, but they may be engaged by slightly different practices than the younger students - such as incorporating both academic and nonacademic support.

Pasifika students varied from students from other ethnic backgrounds in valued practices. In particular, Pasifika students were over represented in their rating of the following practices as important and very important: non-academic support, family/whānau inclusion, academic support, social support, and prompt feedback. However, importance ratings for non-academic support, family/whānau inclusion, and social support were negatively correlated with achievement. Illustrating these differences is only one step; is important to investigate the reasons that they exist, before institutions can tailor their services to address them. Other in-depth case studies or interviews may help to deepen our understanding of these differences, and, as mentioned previously, these results were only from a small sample of Pasifika students, hardly enough to warrant generalising the findings. Yet, establishing differences is especially interesting when considering the significant achievement gaps.

Reports of valuing social support, non-academic assistance and family inclusion were negatively correlated with achievement. Students who valued these components may prioritise socialising over academic study. They may have more external responsibilities or be from a group who is not necessarily culturally supported at VUW. Cultural variation could be a factor; the strongest ratings were from Pasifika and Asian respondents. Also, some students cope with additional family responsibilities that may 
reduce their ability to focus fully on their studies, circumstances particularly evident in Pasifika cultures (Davidson-Toumu'a \& Dunbar, 2009). These lower achievement results may be associated with the unfortunate and pervasive lower achievement amongst Pasifika students across the New Zealand educational sector (Coxon et al., 2002). This is an area worth further exploration. Although the presented results are limited, it may be useful for institutions to be aware of what is important to students particularly when they are focusing on efficient resource allocation.

Considering the New Zealand tertiary priorities of enabling and increasing Pasifika and Māori students’ success (Tertiary Education Strategy, 2010-2015), an awareness of what is important to these respective groups may assist with acclimatising in to the university environment, and promoting a sense of belonging. However, it is probably inaccurate to assume that Māori and Pasifika students value the same institutional behaviours. The only commonality found in this study was that both Pasifika and Māori students rated academic support as very important. Pasifika students also rated non-academic assistance as very important, whereas Māori students did not statistically differ from other ethnicities in this regard. Social support and family inclusion were rated as important by Pasifika students, although both Māori and New Zealand/European students rated them as only somewhat important on average. It is important to gather more evidence, perhaps in qualitative case studies, to help understand the reasons for these findings. Nonetheless, this study may provide a constructive basis for discussing the implications of homogenous thinking: Pasifika and Māori students significantly differed in what they valued; therefore it may be beneficial for institutions to challenge perceptions of cultural homogeneity and evaluate how well the provision of shared services meets the various needs of distinctive ethnicities. 


\section{Practices and behaviours related to achievement}

Of what was measured from the survey, certain practices, preparation aspects, and learner behaviours were correlated with university achievement. These included the development of study skills, such as time-management, staying organised, and writing clearly and effectively. University achievement was also correlated with students' reports that the CUP programme prepared them to learn effectively on their own and stay committed and motivated. Additionally, self-management and prioritising study were linked to university achievement.

Learner behaviours that correlated with achievement included academic perseverance and two active learning aspects: keeping up to date with studies, and coming to class having completed readings or assignments. The importance of academic challenge and inclusion of academic support were also correlated with achievement, which confirms existing literature (Bryson \& Hand, 2007; Kuh, Kinzie, Cruce, et al., 2006; Kuh et al., 2005). Reassuringly, CUP students placed high value on academic feedback, challenge, and support.

The findings from this study predominately endorsed behavioural aspects of preparation, as well as study strategies and skills, as posited by the literature (see, for example, Conley, 2005; Gettinger \& Seibert, 2002; Hattie et al., 1996; Ley \& Young, 1998; Lombardi et al., 2011; Vrugt \& Oort, 2008). Certain preparation elements that related to achievement have been acknowledged in prior research, particularly the development of skills and study strategies, including autonomous study, persistence, research and clear communication (Conley, 2005). Also, evidence from this study supports one aspect of the productive dispositions and behaviours thought to indicate university readiness (ConnectEd, 2012, p. 15): Self-management, time-management, 
persistence, initiative, self-direction, and task completion all related to achievement in this study.

Students who valued academic challenge and experienced academic support from the programme also achieved. Given the overwhelming value placed on academic challenge, and its links with achievement, institutions (universities) could tailor their programmes to be sufficiently academically challenging, and advise students as to what level of academic challenge they should expect from their study context (Bryson \& Hand, 2007; Kuh, Kinzie, Cruce, et al., 2006, p. 06; Kuh et al., 2005). Moreover, academic support (Beasley \& Pearson, 1999; Carini et al., 2006; Kuh et al., 2005; Radloff, 2011; Reason et al., 2006) and prompt feedback (Hattie \& Timperley, 2007) are important for academic success. Interestingly, these behaviours and study skills may be reinforcing behavioural expectations that require learners to adapt to their institution, rather than a reciprocal exchange (Zyngier \& McMahon, 2009). Nevertheless, to ensure on-going academic success, it may be useful to gather formative feedback about students' satisfaction with their study, level of academic challenge, and how supportive they perceive the environment to be.

Understanding these preparation facets may be relevant to building secondary school curriculum for preparation and university readiness, or could contribute to provision of student services within the universities themselves. Illustrating the preparation aspects that related to achievement may also assist educators to clarify expectations for students. There is certainly opportunity for educators to develop smooth transitions and more effective university preparation by working across sectors, perhaps between secondary schools and between the varieties of tertiary institutions, including universities. 
In accordance with reciprocal engagement strategies (Anderson et al., 2006;

Coates, 2005, p. 05; Harper \& Quaye, 2008; Kuh et al., 2005, p. 05; van der Meer, 2011), these practices that were correlated with achievement included both variables relating to the role of the institution as well as those relating to the student. Institutions and programmes may provide a mechanism for students to develop behaviours linked with achievement, and they can also assist learners to become aware of the way in which their specific behaviours may impact on their educational success.

\section{Conclusion}

This study investigated the effects of university preparation, and engagement on achievement. It provided empirical evidence endorsing the links between first-year degree level university achievement, participation in the Certificate of University Preparation programme at Victoria University of Wellington, and students' expected academic perseverance. Also, the results suggest that CUP students' academic perseverance behaviours may have been developed on the programme itself. Students who were underprepared and under-qualified according to their secondary school results achieved better, with university preparation, than mainstream students when matched by the quality of their secondary school results. This evidence suggests that CUP achievement could be an additional indicator for students' capability to be academically successful in university.

The findings from this study emphasise the importance of critically analysing links between acclaimed engagement surveys and achievement before making any decisions solely based on engagement data. In this study, engagement alone was not an empirically validated proxy for students' achieving, but academic perseverance and some aspects of preparation, including student behaviours and study skills, were significantly related to university achievement. The perception of academic support was the main 
institutional practice linked to achievement, along with students' valuing academic challenge. Although preparation is multifaceted, focusing on practices and behaviours that empirically link with achievement could extend students' academic development. Although some preparation elements were moderately linked to achievement in this study, further investigations surrounding the personal, behavioural and contextual facets to university preparation would be beneficial. Furthermore, insights into some of the notable differences between valued practices could be elaborated through research employing both quantitative and qualitative approaches.

Consequently, the findings from this research have both theoretical and practical implications. Empirical evidence regarding the effectiveness of university preparation programmes in impacting achievement has implications for policy and procedures. The results from this study suggest university admissions may consider achievement in preparation programmes as a useful indicator of university readiness. Educators could embed the development of student study strategies, empirically linked to achievement, into curricula. Students could benefit from understanding which behaviours may influence their achievement, and what is expected for degree level study. Also, educational developers and educators might consider incorporating academic perseverance awareness or instruction into the curriculum.

However, all of these inferences presently depend on the results of this singular study; thus it is important that more empirical studies investigate the effectiveness of other preparation programmes, particularly cross-sectional preparation provision. To take into account New Zealand's present policy settings in respect to institutions able to offer preparation programmes, it is important to analyse empirical data regarding the effectiveness of such programmes, taught outside of universities, in preparing learners to achieve in degrees taught at university. 
Even so, the evidence from this study suggests, beyond anecdotes, that achievement on the CUP programme was a robust indicator of students' academic capability, and that preparation impacted university achievement. This study provided evidence that the VUW CUP programme was successful in preparing learners to achieve at university, by developing students' academic perseverance and sufficient preparatory study skills, which were empirically associated with achievement. Providing students with a second chance to gain the skills, knowledge, and behaviours required for university can be a genuinely valuable opportunity to improve students' academic capability, not simply a concessionary policy. 


\section{References}

Adams, K. S., Proctor, B. E., Petscher, Y., Prevatt, F. F., \& Reaser, A. (2006). Study skills profiles of normal-achieving and academically-struggling college students. Journal of College Student Development, 47(1), 37-51. doi:10.1353/csd.2006.0011

Ahn, S., Ames, A. J., \& Myers, N. D. (2012). A review of meta-analyses in education: Methodological strengths and weaknesses. Review of Educational Research, 82(4), 436-476. doi:10.3102/0034654312458162

American College Test. (2004). Crisis at the core: Preparing all students for college and work (pp. 1-56). Iowa City, Iowa: ACT, Inc. Retrieved from http://www.act.org/research/policymakers/reports/crisis.html

Anderson, H., Stephenson, M., Millward, P., \& Rio, N. (2006). Access and engagement: A New Zealand study. In Proceedings of the 5th Conference of the New Zealand Association of Bridging Educators (Vol. 5, pp. 83-89). Presented at the Access to higher education: Bridging education in New Zealand, New Zealand Association of Bridging Educators. Retrieved from http://victoria.lconz.ac.nz/cgibin/Pwebrecon.cgi?BBID=1014673

Astin, A. W. (1993). What matters in college? Four critical years revisited. San Francisco, CA: Jossey-Bass.

AUSSE. (2008). Australasian Survey of Student Engagement. Camberwell, Australia: Australian Council for Educational Research. Retrieved from http://ausse.acer.edu.au/images/docs/AUSSE_2009_SEQ.pdf

Axelson, R. D., \& Flick, A. (2010). Defining student engagement. Change: The Magazine of Higher Learning, 43(1), 38-43. doi:10.1080/00091383.2011.533096 
BCSSE. (2009). Beginning College Survey of Student Engagement Survey instrument. Bloomington, Indiana: Center for Postsecondary Research (CPR). Retrieved from http://bcsse.iub.edu/

Beasley, C. J., \& Pearson, C. A. L. (1999). Facilitating the learning of transitional students: Strategies for success for all students. Higher Education Research \& Development, 18(3), 303-321. doi:10.1080/0729436990180303

Benseman, J., Coxon, E., Anderson, H., \& Anae, M. (2006). Retaining non-traditional students: Lessons learnt from Pasifika students in New Zealand. Higher Education Research \& Development, 25(2), 147-162. doi:10.1080/07294360600610388

Benseman, J., \& Russ, L. (2003). Mapping the territory: A survey of Bridging Education in New Zealand. New Zealand Journal of Adult Learning, 31(1), 43-62.

Bettinger, E. P., \& Long, B. T. (2009). Addressing the needs of under-prepared students in higher education: Does college remediation work? Journal of Human Resources, 44(3), 34.

Bishop, R., \& Berryman, M. (2007). Te Kōtahitanga phase 3 whānaungatanga: Establishing a culturally responsive pedagogy of relations in mainstream secondary school classrooms. Wellington, N.Z.: Ministry of Education. Retrieved from internal-pdf://Bishop2007 Te_Kotahitanga_Phase3-3246353961/Bishop2007 Te_Kotahitanga_Phase3.pdf

Bolstad, R., Gilbert, J., McDowall, S., Bull, A., Boyd, S., \& Hipkins, R. (2012). Supporting future-oriented learning and teaching - A New Zealand perspective. Wellington, N.Z.: Ministry of Education. Retrieved from http://hdl.voced.edu.au/10707/216897

Bourdieu, P., \& Passeron, J.-C. (1990). Reproduction in education, society and culture. SAGE. 
Bryson, C., \& Hand, L. (2007). The role of engagement in inspiring teaching and learning. Innovations in Education and Teaching International, 44(4), 349-362. doi:10.1080/14703290701602748

Cabrera, A. F., \& La Nasa, S. M. (2000). Understanding the college-choice process. In New Directions for Institutional Research (pp. 5-22). San Francisco, CA: JosseyBass. Retrieved from http://onlinelibrary.wiley.com/doi/10.1002/ir.10701/abstract

Campbell, C. M., \& Cabrera, A. F. (2011). How sound is NSSE? Investigating the psychometric properties of NSSE at a public, research-extensive institution. Review of Higher Education, 35(1), 77-103.

Cantwell, R. (2004). Positioning the bar: Outcomes associated with successful completion of an enabling course. Australian Journal of Adult Learning, 44(3), 354-388.

Cantwell, R., Archer, J., \& Bourke, S. (2001). A comparison of the academic experiences and achievement of university students entering by traditional and non-traditional means. Assessment \& Evaluation in Higher Education, 26(3), 221-234. doi:10.1080/02602930120052387

Carini, R. M., Kuh, G. D., \& Klein, S. P. (2006). Student engagement and student learning: Testing the linkages. Research in Higher Education, 47(1), 1-32.

Chickering, A. W., \& Gamson, Z. F. (1987). Seven principles for good practice in undergraduate education. AAHE Bulletin, 3-7.

Chinlund, E., \& Hall, M. (2010). Views from “last resort": Experiences of Māori undergraduate students who transitioned from tertiary bridging programmes. In Making the Links: Learning, Teaching and High Quality Student Outcomes. (Vol. 9, pp. 27-40). Presented at the New Zealand Association of Bridging Educators Conference, Auckland, NZ: Department of Foundation Studies, Unitec Institute of Technology. Retrieved from 
http://www.academia.edu/1185928/Views_from_Last_Resort_Experiences_of_M aori_undergraduate_students_who_transitioned_from_tertiary_bridging_program mes

Chinlund, E., Shaw, A., McKay, J., Appleby, P., Davis, K., Manderson, M., \& Kirkland, G. (2011). Regional collaborative development of a degree preparation programme. Wellington, N.Z.: Ako Aotearoa. Retrieved from http://akoaotearoa.ac.nz/regional-degree-prep

Choy, S. P., Horn, L. J., Nunez, A.-M., \& Xianglei, C. (2000). Transition to college: What helps at-risk students and students whose parents did not attend college? New Directions for Institutional Research, (107), 45-63.

Clark, J. M., \& Halpern, D. F. (1993). The million dollar question: Can an intensive learning experience help lowest-quartile students? Journal of Instructional Psychology, 20(1), 29-39.

Coates, H. (2005). The value of student engagement for higher education quality assurance. Quality in Higher Education, 11(1), 25-36.

Coates, H. (2010). Development of the Australasian Survey of Student Engagement (AUSSE). Higher Education, 60(1), 1-17. doi:10.1007/s10734-009-9281-2

Coates, H. (2011). An overview of psychometric properties of the AUSSE Student Engagement Questionnaire (SEQ) (No. 7) (pp. 1-14). Camberwell: Australian Council for Educational Research (ACER).

Cohen, J. (1988). Statistical power analysis for the behavioral sciences (2nd ed.). Hillside, NJ: Erlbaum.

Cohen, M. (2008). Improving college preparation: Lessons from the American Diploma Project. New England Journal of Higher Education, 22(5), 21-23. 
Complete College America. (2012). Remediation: Higher education's bridge to nowhere (pp. 1-37). Washington, D.C.: Author. Retrieved from http://www.completecollege.org/resources_and_reports/

Conley, D. (2005). College knowledge: What it really takes for students to succeed and what we can do to get them ready. San Francisco, CA: Jossey-Bass.

Conley, D. (2007a). The challenge of college readiness. Educational Leadership, 64, 2329.

Conley, D. (2007b). Toward a more comprehensive conception of college readiness. Eugene, OR: Educational Policy Improvement Center.

Conley, D. (2008). Rethinking college readiness. New Directions for Higher Education, (144), 3-13. doi:10.1002/he.321

ConnectEd (Ed.). (2012). College and career readiness: What do we mean? A proposed framework. Berkeley, CA: ConnectEd: California Center for College and Career. Retrieved from http://www.connectedcalifornia.org/direct/files/resources/CACRFramework_V11_2012_0126.pdf

Coxon, E., Anae, M., Mara, D., Wendt-Samu, T., \& Finau, C. (2002). Literature review on Pacific Education issues. Wellington, N.Z.: Ministry of Education.

Credé, M., \& Kuncel, N. R. (2008). Study habits, skills, and attitudes: The third pillar supporting collegiate academic performance. Perspectives on Psychological Science, 3(6), 425-453. doi:10.1111/j.1745-6924.2008.00089.x

Davidson-Toumu'a, R., \& Dunbar, K. (2009). Understanding the experiences of Pacific students and facilitating socio-cultural adjustment into higher education in Aotearoa, New Zealand. Journal of Australia and New Zealand Student Services Association, 33, 69-88. 
Duckworth, A. L., Peterson, C., Matthews, M., \& Kelly, D. R. (2007). Grit: Perseverance and passion for long-term goals. Journal of Personality and Social Psychology, 92(6), 1087-1101. doi:10.1037/0022-3514.92.6.1087

Engler, R. (2010a). School Leavers' Progression to Bachelors-Level Study. Ministry of Education - Education Counts. Retrieved from http://www.educationcounts.govt.nz/publications/tertiary_education/schoolleavers-progression-to-bachelors-level-study/summary

Engler, R. (2010b). Are particular school subjects associated with better performance at university? Wellington, N.Z.: Ministry of Education. Retrieved from http://www.educationcounts.govt.nz/publications/tertiary_education/79296/summ ary

Evans, M. (2000). Planning for the transition to tertiary study: A literature review. Journal of Institutional Research, 9(1), 1-13.

Farrington, C. A., Roderick, M., Allensworth, E., Nagaoka, J., Keyes, T. S., Johnson, D. W., \& Beechum, N. O. (2012). Teaching adolescents to become learners: The role of noncognitive factors in shaping school performance: A critical literature review. Chicago, IL: The University of Chicago Consortium on Chicago School Research. Retrieved from http://ccsr.uchicago.edu/publications/teachingadolescents-become-learners-role-noncognitive-factors-shaping-school

Flavell, J. H. (1979). Metacognition and cognitive monitoring: A new area of cognitivedevelopmental inquiry. American Psychologist, 34(10), 906-911. doi:10.1037/0003-066X.34.10.906

Gettinger, M., \& Seibert, J. K. (2002). Contributions of study skills to academic competence. School Psychology Review, 31, 350-366. 
Gibney, A., Moore, N., Murphy, F., \& O'Sullivan, S. (2011). The first semester of university life; "Will I be able to manage it at all?" Higher Education, 62(3), 351366. doi:10.1007/s10734-010-9392-9

Gordon, J., Ludlum, J., \& Hoey, J. (2008). Validating NSSE against student outcomes: Are they related? Research in Higher Education, 49(1), 19-39. doi:10.1007/s11162-007-9061-8

Hagel, P., Carr, R., \& Devlin, M. (2012). Conceptualising and measuring student engagement through the Australasian Survey of Student Engagement (AUSSE): a critique. Assessment \& Evaluation in Higher Education, 37(4), 475-486. doi:10.1080/02602938.2010.545870

Harper, S. R., \& Quaye, S. J. (2008). Student engagement in higher education: Theoretical perspectives and practical approaches for diverse populations. (1st ed.). Hoboken: Routledge.

Hattie, J., Biggs, J., \& Purdie, N. (1996). Effects of learning skills interventions on student learning: A meta-analysis. Review of Educational Research, 66(2), 99136. doi:10.3102/00346543066002099

Hattie, J., \& Timperley, H. (2007). The power of feedback. Review of Educational Research, 77(1), 81-112. doi:10.3102/003465430298487

Hockings, C., Cooke, S., \& Bowl, M. (2007). “Academic engagement” within a widening participation context - A 3D analysis. Teaching in Higher Education, Special Issue: Diversity and Commonality in Higher Education, 12(5-6), 721-734.

Johnson, D. W., Johnson, R. T., \& Smith, K. A. (1998). Cooperative learning returns to college: What evidence is there that it works? Change: The Magazine of Higher Learning, 30(4), 26-35. 
Krause, K.-L., \& Coates, H. (2008). Students' engagement in first-year university. Assessment \& Evaluation in Higher Education, 33(5), 493-505.

Kuh, G. D. (2001a). The National Survey of Student Engagement: Conceptual framework and overview of psychometric properties. (pp. 1-26). Bloomington, Indiana: Indiana University Center for Postsecondary Research.

Kuh, G. D. (2001b). Assessing what really matters to student learning: Inside the National Survey of Student Engagement. Change: The Magazine of Higher Learning, 33(3), $10-17$.

Kuh, G. D. (2009). What student affairs professionals need to know about student engagement. Journal of College Student Development, 50(6), 683-706.

Kuh, G. D., Cruce, T. M., Shoup, R., Kinzie, J., \& Gonyea, R. M. (2008a). Unmasking the effects of student engagement on first-year college grades and persistence. The Journal of Higher Education, 79(5), 540-563.

Kuh, G. D., Kinzie, J., Buckley, J. A., Bridges, B. K., \& Hayek, J. C. (2006). What matters to student success: A review of the literature (Commissioned Report). Washington, D.C.: National Postsecondary Education Cooperative.

Kuh, G. D., Kinzie, J., Cruce, T. M., Shoup, R., \& Gonyea, R. M. (2006). Connecting the dots: Multi-faceted analyses of the relationships between student engagement results from the NSSE, and the institutional practices and conditions that foster student success. Indiana University: Center for Postsecondary Research.

Kuh, G. D., Kinzie, J., Schuh, J. H., Whitt, E. J., \& Associates. (2005). Student success in college: Creating conditions that matter. San Francisco, CA: Jossey-Bass.

Leach, L., \& Zepke, N. (2011). Engaging students in learning: A review of a conceptual organiser. Higher Education Research \& Development, 30(2), 193-204. doi:10.1080/07294360.2010.509761 
Levy, S., \& Murray, J. (2005). Tertiary entrance scores need not determine academic success: An analysis of student performance in an equity and access program. Journal of Higher Education Policy and Management, 27(1), 129-141. doi:10.1080/13600800500046529

Ley, K., \& Young, D. B. (1998). Self-regulation behaviors in underprepared (developmental) and regular admission college students. Contemporary Educational Psychology, 23(1), 42-64. doi:10.1006/ceps.1997.0956

Loader, M., \& Dalgety, J. (2008). Students' transition between school and tertiary education (pp. 1-22). Wellington, N.Z.: Ministry of Education.

Lombardi, A., Seburn, M., \& Conley, D. (2011). Development and initial validation of a measure of academic behaviors associated with college and career readiness. Journal of Career Assessment, 19(4), 375-391. doi:10.1177/1069072711409345

Madjar, I., McKinley, E. A., Deynzer, M., \& Van Der Merwe, A. (2010). Stumbling blocks or stepping stones? Students' experience of transition from low-mid decile schools to university. Auckland, NZ: University of Auckland. Retrieved from https://researchspace.auckland.ac.nz/handle/2292/16706

Maruyama, G. (2012). Assessing college readiness should we be satisfied with ACT or other threshold scores? Educational Researcher, 41(7), 252-261. doi:10.3102/0013189X12455095

McCarthy, M., \& Kuh, G. D. (2006). Are students ready for college? What student engagement data say. Phi Delta Kappan, 87(9), 664-669.

McKinley, E., \& Madjar, I. (2010). Uni bound? Students' stories of transition from school to university. Wellington, N.Z.: New Zealand Council for Educational Research. Retrieved from http://www.eric.ed.gov/ERICWebPortal/detail?accno=ED512597 
McMahon, B., \& Portelli, J. P. (2004). Engagement for what? Beyond popular discourses of student engagement. Leadership and Policy in Schools, 3(1), 59-76. doi:10.1076/lpos.3.1.59.27841

McMurchy-Pilkington, C. (2009). Te pakeke hei ākonga/Māori adult learners. Wellington, N.Z.: Ministry of Education.

Ministry of Education. (2005). Māori participation in tertiary education- 2004. Wellington, N.Z.

Ministry of Education. (2010a). Percentage of New Zealanders aged 15 and over by highest educational qualification and ethnic group 1991-2009 (No. EAP-13). Wellington, N.Z.: Education Counts. Retrieved from http://www.educationcounts.govt.nz/statistics/tertiary_education/retention_and_ac hievement

Ministry of Education. (2010b). Distribution of New Zealanders aged 15 and over by highest qualification and ethnic group 2006 - Percentages (No. EAP.5). Wellington, N.Z.: Education Counts. Retrieved from http://www.educationcounts.govt.nz/statistics/tertiary_education/retention_and_ac hievement

Ministry of Education. (2011). The New Zealand education system: An overview.

Wellington, N.Z.: Ministry of Education. Retrieved from http://www.minedu.govt.nz/NZEducation/EducationPolicies/InternationalEducati on/ForInternationalStudentsAndParents/NZEdOverview.aspx

MSD. (n.d.). Five year rolling performance assessment - Student Loans - StudyLink. Ministry of Social Development: Study Link. Retrieved February 24, 2013, from http://www.studylink.govt.nz/about-studylink/glossary/five-year-rollingperformance-assessment.html 
NSSE. (2008). National Survey on Student Engagement. Bloomington, Indiana: Center for Postsecondary Research (CPR). Retrieved from http://nsse.iub.edu/html/about.cfm

NZQA. (2010). Annual Report on NCEA \& New Zealand Scholarship data \& statistics (2009). Wellington, N.Z.: New Zealand Qualifications Authority. Retrieved from http://www.nzqa.govt.nz/studying-in-new-zealand/secondary-school-andncea/secondary-school-statistics/

NZQA. (2012a). University entrance. New Zealand Qualifications Authority. Retrieved October 5, 2012, from http://www.nzqa.govt.nz/qualificationsstandards/awards/university-entrance/

NZQA. (2012b). Standards. New Zealand Qualifications Authority. Retrieved October 25, 2012, from http://www.nzqa.govt.nz/qualifications-standards/standards/

OECD. (2012a). Better skills, better jobs, better lives: A strategic approach to skills policies. Paris, France.: Organisation for Economic Cooperation and Development: OECD Publishing. Retrieved from http://www.oecdilibrary.org/education/better-skills-better-jobs-better-lives_9789264177338-en

OECD. (2012b). Education at a glance 2012: Highlights. Paris, France.: Organisation for Economic Cooperation and Development: OECD Publishing. Retrieved from http://dx.doi.org/10.1787/eag_highlights-2012-en

Pascarella, E. T., Seifert, T. A., \& Blaich, C. (2010). How effective are the NSSE benchmarks in predicting important educational outcomes? Change: The Magazine of Higher Learning, 42(1), 16-22.

Pascarella, E. T., \& Terenzini, P. T. (2005). How college affects students: Findings and insights from twenty years of research (2nd ed.). San Francisco, CA: Jossey-Bass. 
Pike, G. R. (2006). The convergent and discriminant validity of NSSE scalelet scores. Journal of College Student Development, 551-564.

Pike, G. R., \& Kuh, G. D. (2005). First- and second-generation college students: A comparison of their engagement and intellectual development. The Journal of Higher Education, 76(3), 276-300.

Polidano, C., Tabasso, D., \& Tseng, Y.-P. (2012). A second chance at education for early school leavers. IZA Discussion Paper No. 6769. Melbourne, Australia: Institute for the Study of Labor (IZA). Retrieved from http://ftp.iza.org/dp6769.pdf

Porter, S. R. (2011). Do college student surveys have any validity? Review of Higher Education, 35(1), 45-76.

Prebble, T., Hargraves, H., Leach, L., Naidoo, K., Suddaby, G., \& Zepke, N. (2005). Impact of student support services and academic development programmes on student outcomes in undergraduate tertiary study: A synthesis of the research. Retrieved from http://digital.library.adelaide.edu.au/dspace/handle/2440/48371

Radloff, A. (2011). Student engagement in New Zealand's universities. Wellington, N.Z.: Ako Aotearoa and the Australian Council for Educational Research. Retrieved from http://akoaotearoa.ac.nz/ako-aotearoa/student-engagement

Reason, R. D., Terenzini, P. T., \& Domingo, R. J. (2006). First things first: Developing academic competence in the first year of college. Research in Higher Education, 47(2), 149-175.

Reddy, P. A., \& Moores, E. J. (2008). Widening access to higher education: An evaluative case study of a foundation year alternative to Access. Psychology Teaching Review, 14(1), 51-64. 
Samejima, F. (1969). Estimation of Latent Ability Using a Response Pattern of Graded Scores. Richmond, VA.: Psychometric Society. Retrieved from http://www.psychometrika.org/journal/online/MN17.pdf

Scott, D. (2005). What factors make a difference to getting a degree in New Zealand? Wellington, N.Z.: Ministry of Education.

Scott, D. (2008a). How does achievement at school affect achievement in tertiary education? Post-school choices. Wellington, N.Z.: Ministry of Education: Education Counts. Retrieved from http://www.educationcounts.govt.nz/publications/tertiary_education/23110

Scott, D. (2008b). Different tracks: A Look at the different ways New Zealanders get tertiary qualifications (pp. 1-26). Wellington, N.Z.: Tertiary Sector Performance Analysis and Reporting, Strategy and System Performance, Ministry of Education.

Scott, D. (2009). A closer look at completion in higher education in New Zealand. Journal of Higher Education Policy and Management, 31(2), 101-108. doi:10.1080/13600800902825819

Shulruf, B., Hattie, J., \& Tumen, S. (2008a). The predictability of enrolment and firstyear university results from secondary school performance: The New Zealand National Certificate of Educational Achievement. Studies in Higher Education, 33(6), 685-698. doi:10.1080/03075070802457025

Shulruf, B., Hattie, J., \& Tumen, S. (2008b). Individual and school factors affecting students' participation and success in higher education. Higher Education, 56(5), 613-632. doi:10.1007/s10734-008-9114-8

Spitzer, T. M. (2000). Predictors of college success: A comparison of traditional and nontraditional age students. NASPA Journal, 38(1), 82-98. 
Ssempebwa, J., Eduan, W., \& Mulumba, F. N. (2012). Effectiveness of university bridging programs in preparing students for university education a case from East Africa. Journal of Studies in International Education, 16(2), 140-156. doi: $10.1177 / 1028315311405062$

Swail, W. S. (2000). Preparing America's disadvantaged for college: Programs That increase college opportunity. New Directions for Institutional Research, 2000(107), 85-101. doi:10.1002/ir.10706

Tabachnick, B. G., \& Fidell, L. S. (2001). Using multivariate statistics. Allyn and Bacon. Terenzini, P., Rendon, L., Lee Upcraft, M., Millar, S., Allison, K., Gregg, P., \& Jalomo, R. (1994). The transition to college: Diverse students, diverse stories. Research in Higher Education, 35(1), 57-73. doi:10.1007/BF02496662

Tertiary Education Commission. (2011). Tertiary Education Strategy 2010 - 2015. Wellington, N.Z.: Ministry of Education. Retrieved from http://www.minedu.govt.nz/NZEducation/EducationPolicies/TertiaryEducation/Po licyAndStrategy/TertiaryEducationStrategy.aspx

Tertiary Education Commission. (2012). Tertiary Education Commission statement of intent 2012/13 - 2014/15. Wellington, N.Z.: Tertiary Education Commission. Retrieved from http://www.tec.govt.nz/About-us/News/TEC-Now/TECStatement-of-Intent-for-201213--201415/

Tinto, V. (1993). Leaving college: Rethinking the causes and cures of student attrition (2nd ed.). Chicago, IL: The University of Chicago Press.

Tinto, V. (2000). Learning better together: The impact of learning communities on student success in higher education. Journal of Institutional Research, 9(1), 48-53.

Tofi, T., Flett, R., \& TimutimuThorpe, H. (1996). Problems faced by Pacific Island students at university in New Zealand: Some effects on academic performance 
and psychological wellbeing. New Zealand Journal of Educational Studies, 31, $51-59$.

Trewartha, R. (2008). Innovations in bridging and foundation education in a tertiary institution. Australian Journal of Adult Learning, 48(1), 30-49.

Trowler, V. (2010). Student engagement literature review. Lancaster, U.K.: The Higher Education Academy: Lancaster University. Retrieved from http://www.heacademy.ac.uk/assets/documents/studentengagement/StudentEngag ementLiteratureReview.pdf

U.S. Department of Education. (2010). Postsecondary education transition: A summary of the findings from two literature reviews. (pp. 1-22). Washington, D.C.: U.S. Department of Education, Office of Vocational and Adult Education. Retrieved from http://www.ed.gov/about/offices/list/ovae/pi/cclo/index.html

Universities New Zealand. (2012, October 9). The common entrance standard. Universities New Zealand - Te Pōkai Tara. Retrieved October 25, 2012, from http://www.universitiesnz.ac.nz/studying-in-nz/domestic/entrance

Van der Meer, J. (2011). Māori and Pasifika students' academic engagement: What can institutions learn from the AUSSE data? In A. Radloff (Ed.), Student engagement in New Zealand's universities (pp. 1-10). Wellington, N.Z.: Ako Aotearoa and the Australian Council for Educational Research. Retrieved from http://akoaotearoa.ac.nz/ako-aotearoa/student-engagement

Vaughan, K. (2008). Student perspectives on leaving school, pathways and careers. Ministry of Education, 4, 1-82. doi:978-0-478-13955-6

Vrugt, A., \& Oort, F. J. (2008). Metacognition, achievement goals, study strategies and academic achievement: Pathways to achievement. Metacognition and Learning, 3(2), 123-146. doi:10.1007/s11409-008-9022-4 
West, L. H. T. (1985). Differential prediction of first year university performance for students from different social backgrounds. Australian Journal of Education, 29(2), 175-187. doi:10.1177/000494418502900209

Zepke, N., \& Leach, L. (2010a). Beyond hard outcomes: "Soft” outcomes and engagement as student success. Teaching in Higher Education, 15(6), 661-673. doi:10.1080/13562517.2010.522084

Zepke, N., \& Leach, L. (2010b). Improving student engagement: Ten proposals for action. Active Learning in Higher Education, 11(3), 167-177. doi:10.1177/1469787410379680

Zhao, C.-M., \& Kuh, G. D. (2004). Adding value: Learning communities and student engagement. Research in Higher Education, 45(2), 115-138.

Zimmerman, B. J. (1990). Self-regulated learning and academic achievement: An overview. Educational Psychologist, 25(1), 3-17.

Zimmerman, B. J. (2002). Becoming a self-regulated learner: An overview. Theory Into Practice, 41(2), 64-70.

Zwick, R., \& Himelfarb, I. (2011). The effect of high school socioeconomic status on the predictive validity of SAT scores and high school grade-point average. Journal of Educational Measurement, 48(2), 101-121. doi:10.1111/j.17453984.2011.00136.x

Zyngier, D., \& McMahon, B. (2009). Student engagement: Contested concepts in two continents. Research in Comparative and International Education, 4(2), 164-181. doi:10.2304/rcie.2009.4.2.164 
APPENDICES 


\section{Appendix A. Survey}

Table 10.

Engagement Survey Prompts.

NOTE: This survey was presented and distributed electronically using Qualtrics software.

\begin{tabular}{|c|c|c|c|c|}
\hline $\begin{array}{l}\text { Scale } \\
\text { Academic } \\
\text { Challenge }\end{array}$ & \multirow[b]{2}{*}{\begin{tabular}{|l|} 
Description \\
extent to which \\
expectations and \\
assessments \\
challenge students \\
to learn
\end{tabular}} & \multirow{2}{*}{$\begin{array}{l}\text { Prompt } \\
\text { Overall, how academically challenging was the CUP } \\
\text { How academically challenging is your degree (if started)? }\end{array}$} & \multicolumn{2}{|c|}{ Reference Likert Scale (1-4) } \\
\hline $\begin{array}{l}\text { Academic } \\
\text { Challenge }\end{array}$ & & & $\begin{array}{l}\text { BUSSE } \\
(2009) \\
\text { BUSSE } \\
(2009)\end{array}$ & $\begin{array}{l}\text { Not at all Challenging/ Somewhat } \\
\text { challenging/ challenging/ Extremely } \\
\text { Challenging } \\
\text { Not at all Challenging/ Somewhat } \\
\text { challenging/ challenging/ Extremely } \\
\text { Challenging }\end{array}$ \\
\hline & & $\begin{array}{l}\text { During your preparation programme, about how often did you } \\
\text { spend on each of the following? Leave blank if the item does } \\
\text { not apply. }\end{array}$ & $\begin{array}{l}\text { AUSSE } \\
\text { (2008) }\end{array}$ & Never/Sometimes/Often/Very often \\
\hline & & Worked hard to master difficult content & $\begin{array}{l}\text { AUSSE } \\
(2008)\end{array}$ & \\
\hline & & $\begin{array}{l}\text { Worked harder than you thought you could to meet a } \\
\text { teacher's/tutor's standards or expectations }\end{array}$ & $\begin{array}{l}\text { AUSSE } \\
(2008)\end{array}$ & Never/Sometimes/Often/Very often \\
\hline & & $\begin{array}{l}\text { Spending significant amounts of time studying and on academic } \\
\text { work }\end{array}$ & $\begin{array}{l}\text { AUSSE } \\
(2008)\end{array}$ & Not at all/Some/Quite a bit/Very much \\
\hline $\begin{array}{l}\text { Enriching } \\
\text { Educational } \\
\text { Experiences }\end{array}$ & $\begin{array}{l}\text { Participation in } \\
\text { broadening } \\
\text { educational } \\
\text { activities }\end{array}$ & $\begin{array}{l}\text { Had serious conversations with students who are very different to } \\
\text { you in terms of their religious beliefs, political opinions or } \\
\text { personal values }\end{array}$ & $\begin{array}{l}\text { AUSSE } \\
(2008)\end{array}$ & Never/Sometimes/Often/Very often \\
\hline $\begin{array}{l}\text { Active } \\
\text { Learning }\end{array}$ & $\begin{array}{l}\text { Students' efforts } \\
\text { to actively } \\
\text { construct their }\end{array}$ & $\begin{array}{l}\text { Used student learning support Services } \\
\text { Came to class having completed readings or assignments }\end{array}$ & $\begin{array}{l}\text { AUSSE } \\
(2008) \\
\text { AUSSE }\end{array}$ & $\begin{array}{l}\text { Never/Sometimes/Often/Very often } \\
\text { Never/Sometimes/Often/Very often }\end{array}$ \\
\hline
\end{tabular}


\begin{tabular}{|l|l} 
knowledge & $\begin{array}{l}\text { Kept up to date with your studies } \\
\text { Worked with other students on projects during class } \\
\text { Worked with other students outside class to prepare assignments } \\
\text { Learned something that changed the way you understood an issue } \\
\text { or idea }\end{array}$
\end{tabular}

To what extent has your experience on the preparation programme contributed to your knowledge, skills and personal development in the following areas?

\begin{tabular}{l|l} 
Academic & Extent learners
\end{tabular}

Readiness feel prepared for

\begin{tabular}{|l|l|}
\hline & academic studies \\
& \\
\hline $\begin{array}{l}\text { General } \\
\text { Development } \\
\text { Outcomes }\end{array}$ & $\begin{array}{l}\text { Development of } \\
\text { general forms of } \\
\text { individual and }\end{array}$ \\
\hline
\end{tabular}

Using computers in academic work

Reading and understanding academic material

Comprehending instructions/information

Taking notes

Using the library for research

Staying committed and motivated

Managing your time

Staying organised

Understanding yourself

Understanding people of other cultural or ethnic backgrounds
(2008)

AUSSE Never/Sometimes/Often/Very often

(2008)

AUSSE Never/Sometimes/Often/Very often

(2008)

AUSSE Never/Sometimes/Often/Very often

AUSSE Never/Sometimes/Often/Very often

(2008)

AUSSE Not at all/Some/Quite a bit/Very much (2008)

BUSSE Not at all/Some/Quite a bit/Very much (2009)

BUSSE Not at all/Some/Quite a bit/Very much (2009)

BUSSE Not at all/Some/Quite a bit/Very much (2009)

BUSSE Not at all/Some/Quite a bit/Very much (2009)

BUSSE Not at all/Some/Quite a bit/Very much (2009)

BUSSE Not at all/Some/Quite a bit/Very much (2009)

BUSSE Not at all/Some/Quite a bit/Very much (2009)

BUSSE Not at all/Some/Quite a bit/Very much (2009)

AUSSE Not at all/Some/Quite a bit/Very much

AUSSE Not at all/Some/Quite a bit/Very much 


\begin{tabular}{|c|c|c|c|c|}
\hline & $\mid \begin{array}{l}\text { social } \\
\text { development }\end{array}$ & Contributing to the welfare of your community & $\begin{array}{l}(2008) \\
\text { AUSSE } \\
(2008)\end{array}$ & Not at all/Some/Quite a bit/Very much \\
\hline \multirow{7}{*}{$\begin{array}{l}\text { General } \\
\text { Learning } \\
\text { Outcomes }\end{array}$} & \multirow{7}{*}{$\begin{array}{l}\text { Development of } \\
\text { general } \\
\text { competencies }\end{array}$} & Acquiring a broad general education & AUSSE & Not at all/Some/Quite a bit/Very much \\
\hline & & Writing clearly and effectively & $\begin{array}{l}\text { AUSSE } \\
(2008)\end{array}$ & Not at all/Some/Quite a bit/Very much \\
\hline & & Speaking clearly and effectively & $\begin{array}{l}\text { AUSSE } \\
(2008)\end{array}$ & Not at all/Some/Quite a bit/Very much \\
\hline & & Thinking critically and analytically & $\begin{array}{l}\text { AUSSE } \\
(2008)\end{array}$ & Not at all/Some/Quite a bit/Very much \\
\hline & & Using computing and information technology & $\begin{array}{l}\text { AUSSE } \\
(2008)\end{array}$ & Not at all/Some/Quite a bit/Very much \\
\hline & & Working effectively with others & $\begin{array}{l}\text { AUSSE } \\
(2008)\end{array}$ & Not at all/Some/Quite a bit/Very much \\
\hline & & Learning effectively on your own & $\begin{array}{l}\text { AUSSE } \\
(2008)\end{array}$ & Not at all/Some/Quite a bit/Very much \\
\hline NZ & $\begin{array}{l}\text { Culturally } \\
\text { responsive } \\
\text { practice }\end{array}$ & Including my family/ whānau in my studies & $\begin{array}{l}\text { VUW } \\
(2009)\end{array}$ & Not at all/Some/Quite a bit/Very much \\
\hline \multicolumn{3}{|c|}{ How important is it to you that your study place provides each of the following? } & $\begin{array}{l}\text { VUW } \\
(2009)\end{array}$ & $\begin{array}{l}\text { Not important/ Somewhat important/ } \\
\text { Important/ Very important }\end{array}$ \\
\hline $\begin{array}{l}\text { Importance } \\
\text { to Learner }\end{array}$ & $\begin{array}{l}\text { Learners' rating of } \\
\text { important skills, } \\
\text { behaviours, or } \\
\text { provision. }\end{array}$ & $\begin{array}{l}\text { A challenging academic experience } \\
\text { Opportunities to include my family/ whānau in my studies } \\
\text { Support to help you succeed academically } \\
\text { Assistance coping with your non-academic responsibilities (work, } \\
\text { family, etc.) }\end{array}$ & $\begin{array}{l}\text { BUSSE } \\
(2009) \\
\text { VUW } \\
(2009) \\
\text { BUSSE } \\
(2009) \\
\text { BUSSE } \\
(2009)\end{array}$ & $\begin{array}{l}\text { Not important/ Somewhat important/ } \\
\text { Important/ Very important } \\
\text { Not important/ Somewhat important/ } \\
\text { Important/ Very important } \\
\text { Not important/ Somewhat important/ } \\
\text { Important/ Very important } \\
\text { Not important/ Somewhat important/ } \\
\text { Important/ Very important }\end{array}$ \\
\hline
\end{tabular}




\begin{tabular}{|c|c|c|c|c|}
\hline & & $\begin{array}{l}\text { Support to help you thrive socially } \\
\text { Opportunities to attend campus events and activities } \\
\text { Opportunities to interact with students from different economic, } \\
\text { social, and racial or ethnic backgrounds }\end{array}$ & $\begin{array}{l}\text { BUSSE } \\
(2009) \\
\text { BUSSE } \\
(2009) \\
\text { BUSSE } \\
(2009)\end{array}$ & $\begin{array}{l}\text { Not important/ Somewhat important/ } \\
\text { Important/ Very important } \\
\text { Not important/ Somewhat important/ } \\
\text { Important/ Very important } \\
\text { Not important/ Somewhat important/ } \\
\text { Important/ Very important }\end{array}$ \\
\hline \multicolumn{3}{|c|}{ What are the most important skills that you use (or think you will use) in your degree study? } & $\begin{array}{l}\text { VUW } \\
(2009)\end{array}$ & Rank skill list \\
\hline \multicolumn{3}{|c|}{ During your degree study, how certain are you that you will do/ are doing the following? } & $\begin{array}{l}\text { BUSSE } \\
(2009)\end{array}$ & $\begin{array}{l}\text { Not at all certain/ Somewhat certain/ } \\
\text { certain/ Very Certain }\end{array}$ \\
\hline \multirow{6}{*}{\begin{tabular}{|l|} 
Expected \\
Academic \\
Perseverance
\end{tabular}} & \multirow{6}{*}{$\begin{array}{l}\text { Student certainty } \\
\text { that they will } \\
\text { persist in the face } \\
\text { of academic } \\
\text { adversity. }\end{array}$} & Study when there are other interesting things to do & $\begin{array}{l}\text { BUSSE } \\
(2009)\end{array}$ & $\begin{array}{l}\text { Not at all certain/ Somewhat certain/ } \\
\text { certain/ Very Certain }\end{array}$ \\
\hline & & $\begin{array}{l}\text { Find additional information for course assignments when you } \\
\text { don't understand the material }\end{array}$ & $\begin{array}{l}\text { BUSSE } \\
(2009)\end{array}$ & $\begin{array}{l}\text { Not at all certain/ Somewhat certain/ } \\
\text { certain/ Very Certain }\end{array}$ \\
\hline & & $\begin{array}{l}\text { Participate regularly in course discussions, even when you don't } \\
\text { feel like it }\end{array}$ & $\begin{array}{l}\text { BUSSE } \\
(2009)\end{array}$ & $\begin{array}{l}\text { Not at all certain/ Somewhat certain/ } \\
\text { certain/ Very Certain }\end{array}$ \\
\hline & & $\begin{array}{l}\text { Ask instructors for help when you struggle with course } \\
\text { assignments }\end{array}$ & $\begin{array}{l}\text { BUSSE } \\
(2009)\end{array}$ & $\begin{array}{l}\text { Not at all certain/ Somewhat certain/ } \\
\text { certain/ Very Certain }\end{array}$ \\
\hline & & Finish something you have started when you encounter challenges & $\begin{array}{l}\text { BUSSE } \\
(2009)\end{array}$ & $\begin{array}{l}\text { Not at all certain/ Somewhat certain/ } \\
\text { certain/ Very Certain }\end{array}$ \\
\hline & & Stay positive, even when you do poorly on a test or assignment & $\begin{array}{l}\text { BUSSE } \\
(2009)\end{array}$ & $\begin{array}{l}\text { Not at all certain/ Somewhat certain/ } \\
\text { certain/ Very Certain }\end{array}$ \\
\hline \multicolumn{3}{|c|}{ To what extent did the preparation programme emphasise each of the following? } & $\begin{array}{l}\text { AUSSE } \\
(2008)\end{array}$ & Not at all/Some/Quite a bit/Very much \\
\hline \multirow{3}{*}{\begin{tabular}{|l|} 
Supportive \\
Learning \\
Environment
\end{tabular}} & \multirow{3}{*}{$\begin{array}{l}\text { Feelings of } \\
\text { legitimation within } \\
\text { the university } \\
\text { community }\end{array}$} & Providing the support you need to help you succeed academically & $\begin{array}{l}\text { AUSSE } \\
(2008)\end{array}$ & Not at all/Some/Quite a bit/Very much \\
\hline & & $\begin{array}{l}\text { Helping you cope with your non-academic responsibilities (e.g. } \\
\text { work, family, etc.) }\end{array}$ & $\begin{array}{l}\text { AUSSE } \\
(2008)\end{array}$ & Not at all/Some/Quite a bit/Very much \\
\hline & & $\begin{array}{l}\text { Received prompt written or verbal feedback from teachers/tutors } \\
\text { on your academic performance }\end{array}$ & $\begin{array}{l}\text { AUSSE } \\
(2008)\end{array}$ & Never/Sometimes/Often/Very often \\
\hline
\end{tabular}




\begin{tabular}{|c|c|c|c|c|}
\hline $\begin{array}{l}\text { Student and } \\
\text { Staff } \\
\text { Interactions }\end{array}$ & $\begin{array}{l}\text { Level and nature } \\
\text { of students' } \\
\text { contact with } \\
\text { teaching staff }\end{array}$ & Contacted tutor or lecturer outside of class time about your studies & $\begin{array}{l}\text { AUSSE } \\
\text { (2008) }\end{array}$ & Never/Sometimes/Often/Very often \\
\hline \multirow[t]{2}{*}{$\begin{array}{l}\text { Overall } \\
\text { Satisfaction }\end{array}$} & \multirow{2}{*}{$\begin{array}{l}\text { Students' overall } \\
\text { satisfaction with } \\
\text { their educational } \\
\text { experience }\end{array}$} & $\begin{array}{l}\text { How would you evaluate your entire educational experience on } \\
\text { the preparation programme? }\end{array}$ & $\begin{array}{l}\text { AUSSE } \\
(2008)\end{array}$ & Poor/Fair/Good/Excellent \\
\hline & & $\begin{array}{l}\text { If you could start over again, would you do the same } \\
\text { preparation programme? }\end{array}$ & $\begin{array}{l}\text { AUSSE } \\
(2008)\end{array}$ & $\begin{array}{l}\text { Definitely no/Probably no/Probably } \\
\text { yes/Definitely yes }\end{array}$ \\
\hline Advice & $\begin{array}{l}\text { Student Advice to } \\
\text { other students } \\
\text { about to begin the } \\
\text { programme }\end{array}$ & $\begin{array}{l}\text { What advice would you give to someone about to begin the } \\
\text { Certificate of University Preparation programme? }\end{array}$ & $\begin{array}{l}\text { VUW } \\
(2009)\end{array}$ & open ended \\
\hline Evaluation & & $\begin{array}{l}\text { What are the BEST ASPECTS of how the preparation programme } \\
\text { engaged students in learning? } \\
\text { What could be done to IMPROVE how the preparation } \\
\text { programme engages students? }\end{array}$ & $\begin{array}{l}\text { VUW } \\
(2009) \\
\text { VUW } \\
(2009)\end{array}$ & $\begin{array}{l}\text { Open ended } \\
\text { Open ended }\end{array}$ \\
\hline
\end{tabular}




\section{Appendix B. Participant Information Sheet}

\section{VICTORIA UNIVERSITY OF WELLINGTON (letterhead)}

Project title: Experience and Achievement of Undergraduate Students who Transitioned from the CUP Programme at VUW

Researcher:

Liz Chinlund, Faculty of Education, Victoria University of Wellington

E-mail: Liz.Chinlund@vuw.ac.nz

This study is designed to gather student responses to the preparation programme at Victoria University of Wellington (VUW), Certificate of University Preparation, and their achievement. The information gathered will be used to assess students' perceptions of the preparation programme in order to identify successful elements and areas that students felt were lacking.

The purpose of this study is to determine to what extent preparation and engagement relate to university academic achievement and progression as mediated by students' participation in the Certificate of University Preparation programme. The results will be analysed to further inform programme developments and provide advice for policy and practice.

Data will be collected through survey (online and print available), potentially interviews or focus groups, as well as student records and existing student databases. Participants are requested to fill out a response to each survey question by choosing a Likert Scale option and/or to give a brief written answer. This survey will take approximately 20 minutes to complete and all information will be kept confidential. The researcher will also gather students' achievement data. No identification of individual or of individuals' responses will be possible as only group responses will be included in the report.

Results from this study will be collated and reported to the University. The data could potentially be used for a conference or article, but individual confidentiality will be maintained. This data will also be used to fulfil the requirements of a Master's in Education and the finished thesis will be deposited in the University Library. Study information will be stored for three years at the University, after which all data will be destroyed.

Participation is on a voluntary, confidential basis and participation can be withdrawn at any point up to 1 July 2012.

\section{Liz Chinlund}

Signed: 


\section{Appendix C. Reports of Preliminary Analyses}

\section{Achievement Variables}

\section{Secondary school achievement.}

The distribution of the secondary school achievement scale locations (based on level 3 Achievement Standard results) appeared to be reasonably normal upon inspection of the histogram (Figure 4) and Normal Q-Q Plot (See Figure 5; $n=351, M=-1.86, s d=$ $1.062)$.

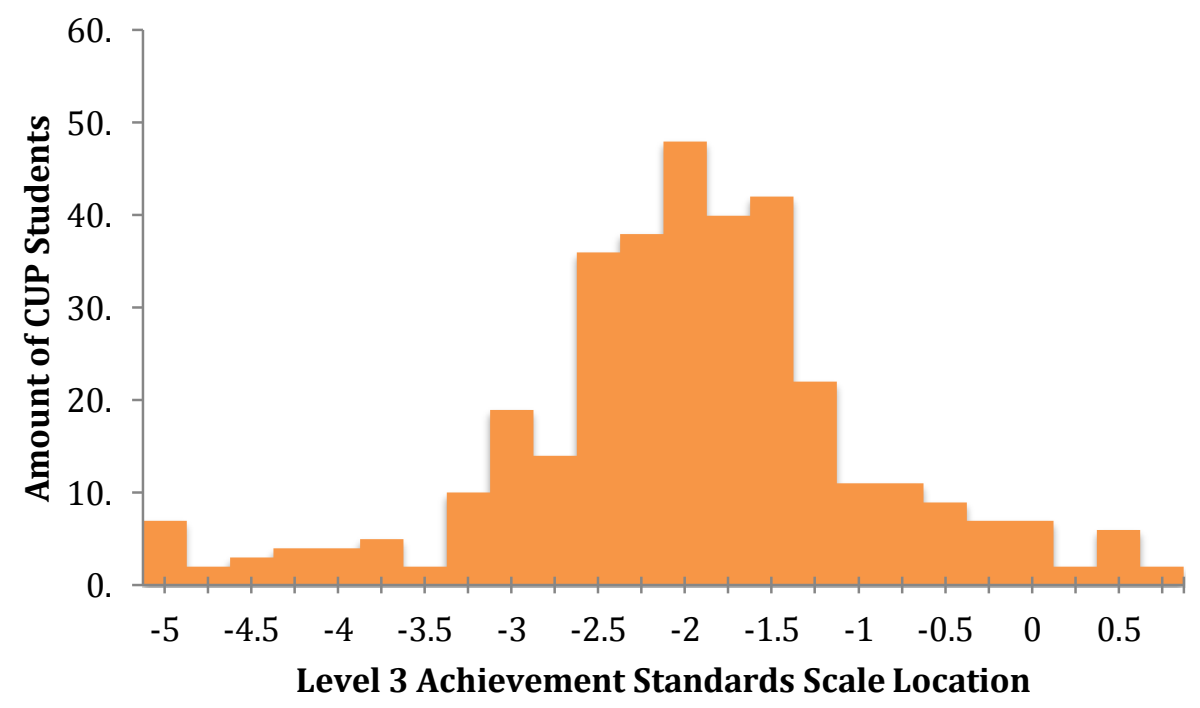

Figure 4. Histogram of CUP Students' Level 3 Achievement Standard Scale Locations

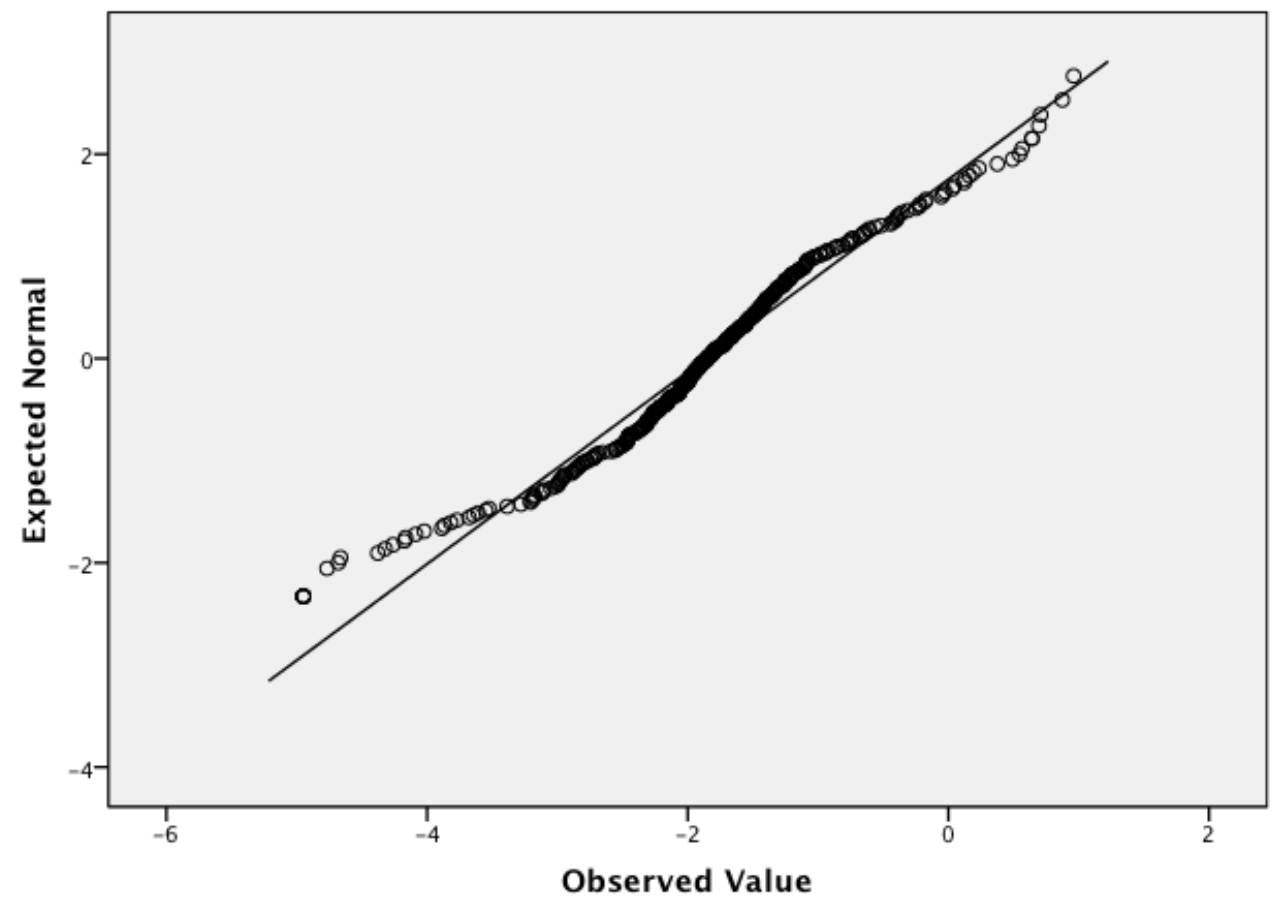

Figure 5. Q-Q Plot of CUP Students' Level 3 Achievement Standard Scale Location

No violations of normality were present in the achievement data. 
Certificate of University Preparation achievement.

The distribution of the CUP achieved scale location scores is relatively flat with a kurtosis value of -0.754 , as displayed in Figure $6(n=662, S E=0.190)$.

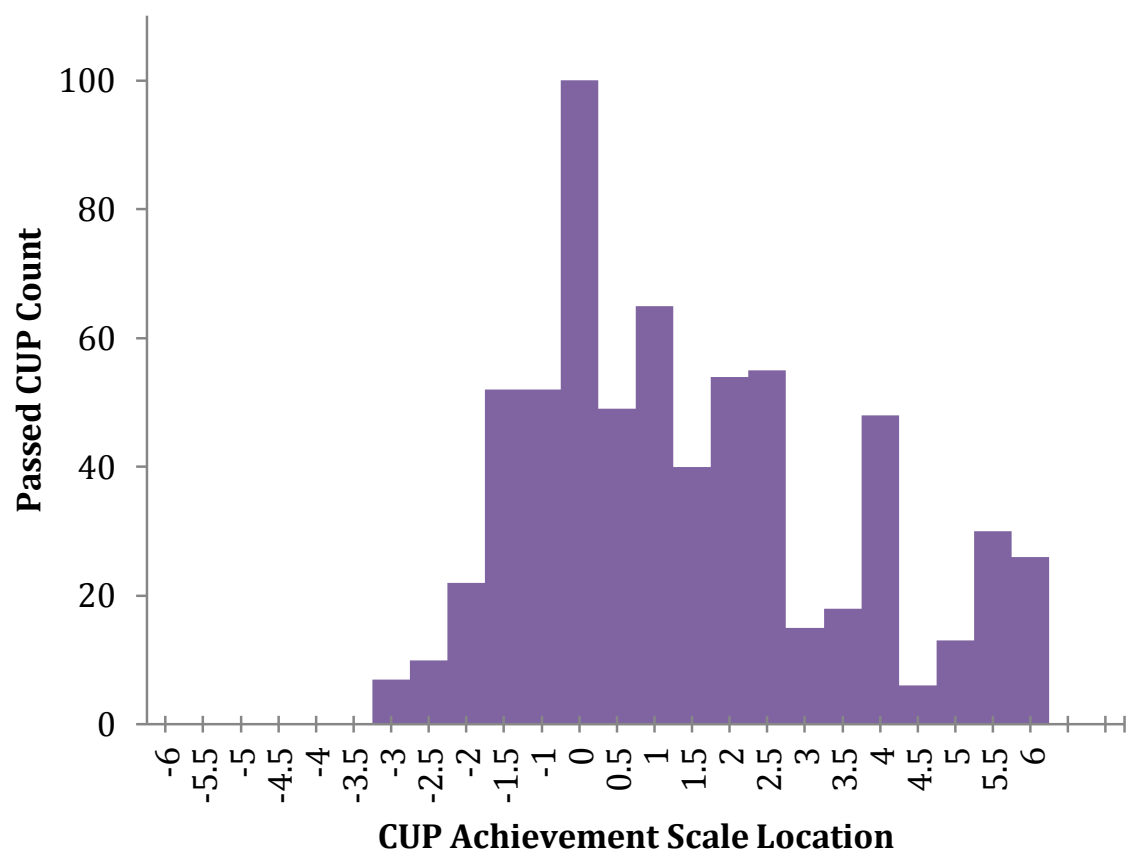

Figure 6. Histogram of CUP Awarded Achievement Scale Location

The scale locations seem to be relatively normally distributed, but slightly negatively skewed, upon examination of the histogram (See Figure 6; $n=662, M=1.03, s d=2.240$ ) and Q-Q Plot (See Figure 7). This is due to the fact that normally only students who passed the CUP programme were able to matriculate to university study.

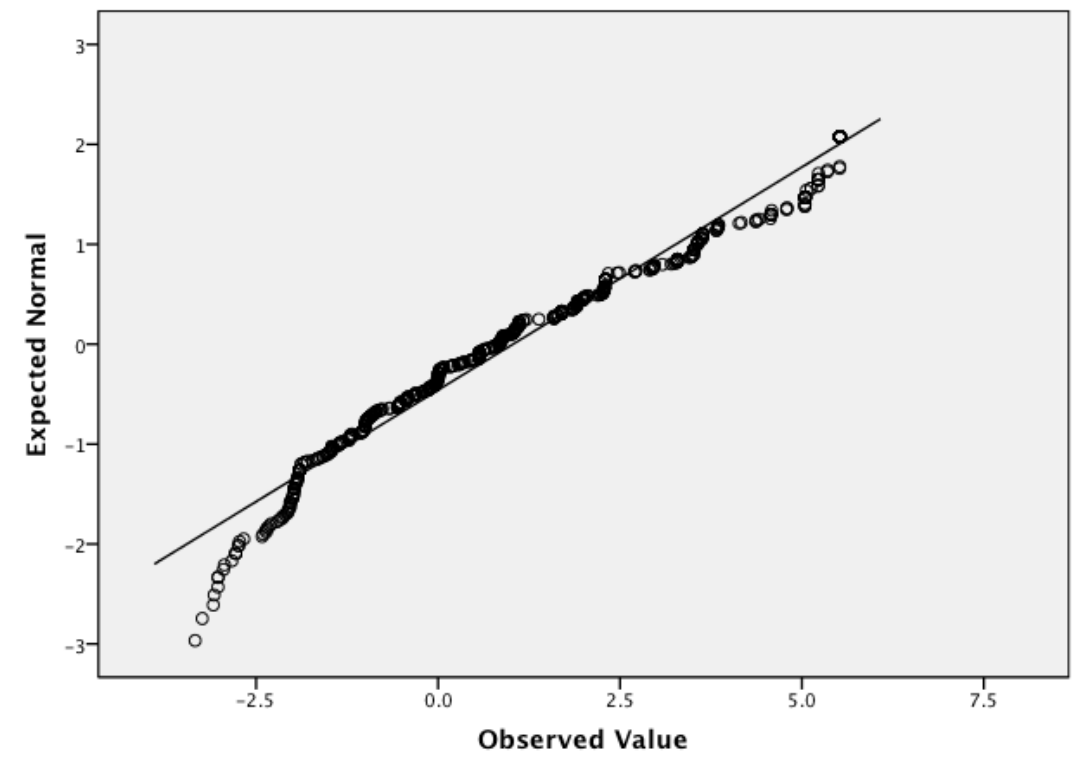

Figure 7. Q-Q Plot of CUP Awarded Achievement Scale Location 


\section{University achievement}

First-year university achievement scale locations appear to be reasonably distributed. Figure 8 shows the achievement scale locations from the students who earned the Certificate of University Preparation certificate $(n=483, M=-2.17, s d=2.979)$.

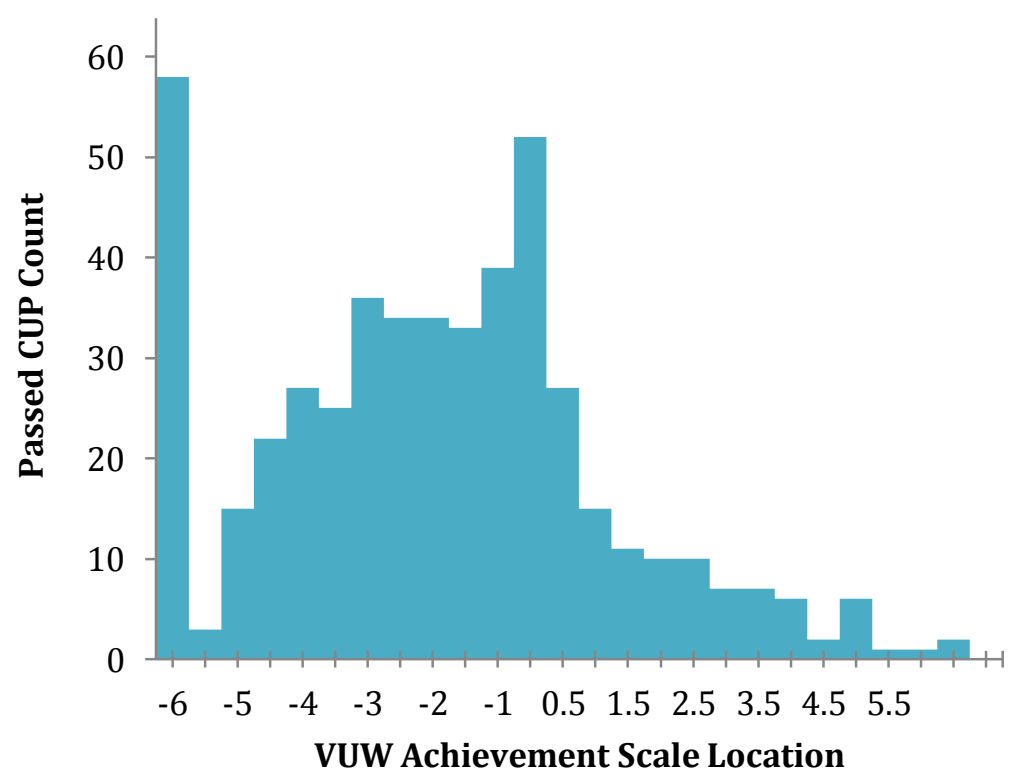

Figure 8. Histogram of CUP-Awarded Students' VUW First-year Achievement Scale Location

There are many scale locations clustered on the left indicating positive skewness, although the skewness value is $0.202(S E=.11)$, and according to Tabachnick and Fidell (2001, p. 74), skewness should not "make a substantive difference in analysis" with samples above 200. Inspection of the Normal Q-Q Plot (Figure 9) shows most scale locations cluster around the zero line indicating a normal distribution.

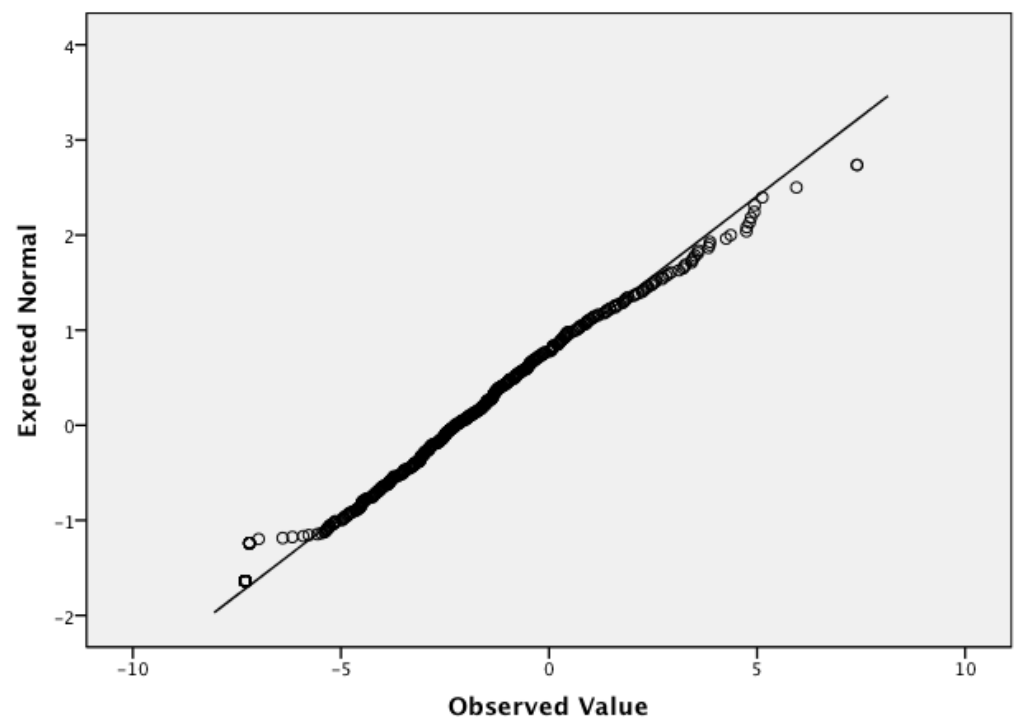

Figure 9. Q-Q Plot of CUP Awarded First-Year VUW Achievement Scale Location 
For students who did not pass CUP, but accessed first-year university, their achievement scale locations were comparably poor and positively skewed with scale locations clustered on the low values (See Figure 10; $n=53, M=-4.68, s d=2.73$ ).

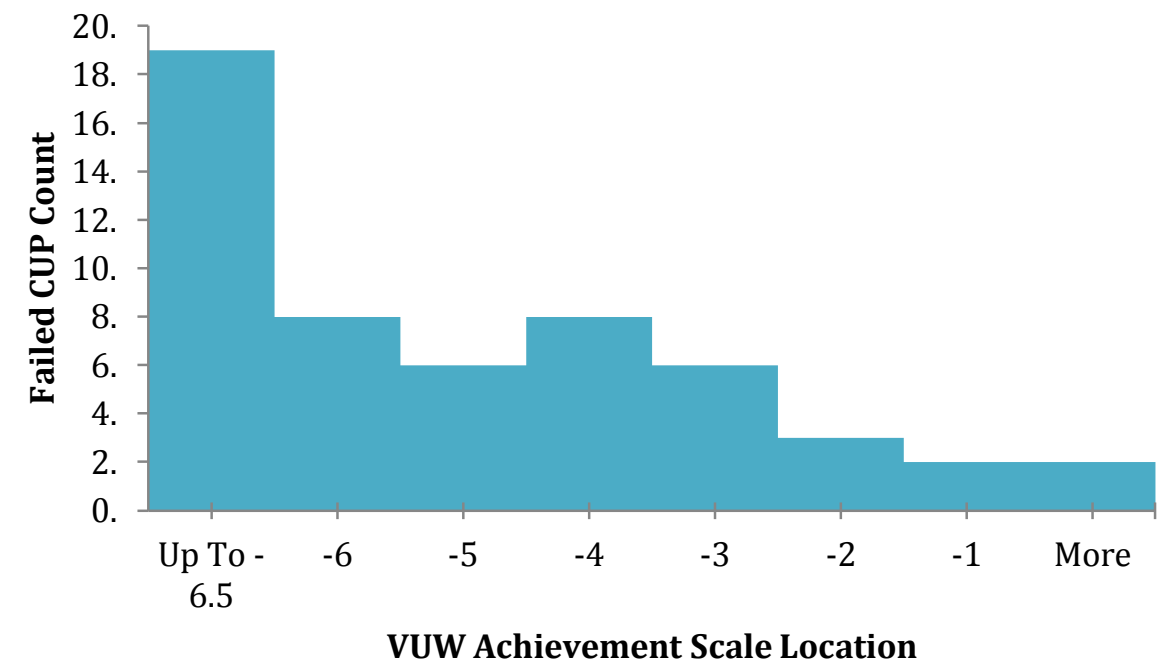

Figure 10. Histogram of CUP-Failed Students' VUW First-year Achievement Scale Location

First-year results from the students who failed CUP were not normally distributed, but the histogram (See Figure 10) appeared more linear in shape. The positive skewness of this distribution is not surprising given that prior underachievement tends to be associated with subsequent underachievement. To compensate for this distribution, the first-year achievement variables were collapsed into equal groups of high, medium, and low scoring results to perform an Analysis of Variance comparing first-year achievement results from those who passed and those who failed CUP. 


\section{Engagement Survey Variables.}

\section{Academic challenge.}

Academic challenge is defined as the extent to which expectations and assessments challenge students to learn. Students' rate:

- how often they worked hard to master difficult content

- how often they worked harder than they thought they could to meet a teacher's/tutor's standards or expectations

- To what extent CUP provided a challenging academic experience

- how academically challenging they found the CUP programme

One component was extracted from the Principle Components Analysis (PCA), which explained $63.34 \%$ of the variance (Total $=2.534$ ). Factor loadings suggest the subscale is unidimensional:

Table 11 .

Factor Loadings of Academic Challenge Subscale*

\begin{tabular}{llc}
\hline Item & Engagement Survey Descriptor & Loading \\
\hline AC1 & How often they worked hard to master difficult content & .812 \\
AC2 & $\begin{array}{l}\text { How often they worked harder than they thought they could to } \\
\text { meet a teacher's/tutor's standards or expectations }\end{array}$ & .753 \\
AC3_INC & $\begin{array}{l}\text { To what extent CUP provided a challenging academic experience } \\
\text { ACPrep }\end{array}$ & How academically challenging they found the CUP programme \\
\hline
\end{tabular}

Note. *Using Principle Component Analysis with Varimax Rotation procedure. Factor loadings > .40 are in boldface.

Therefore, total academic challenge scale locations were calculated using IRT based on 217 responses to the above four items. This interval scale did not appear to be normally distributed (See Figure 11; $n=210, M=.09, s d=2.837$ ). The kurtosis value was -3.794 $(S E=2.62)$, which indicates many of the academic challenge scale locations were extreme.

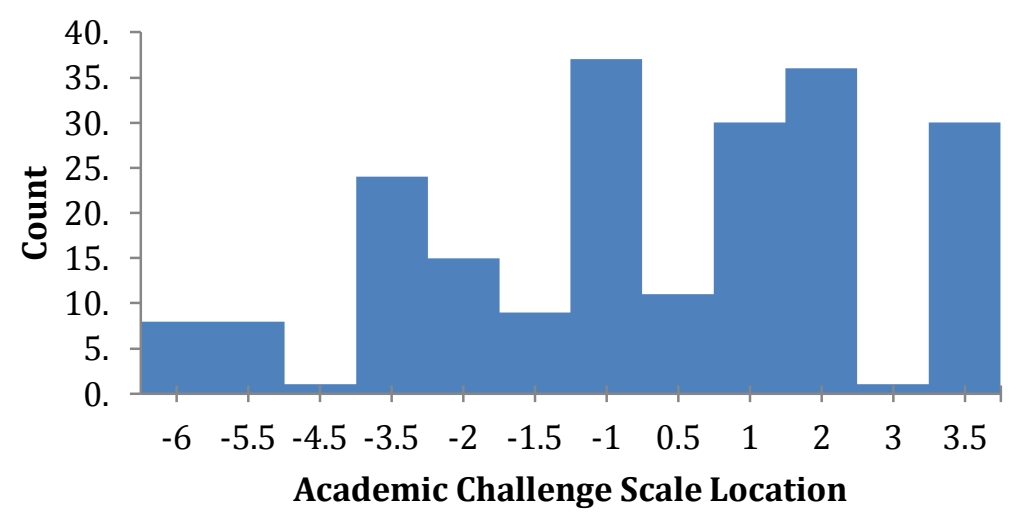

Figure 11. Histogram of Academic Challenge Scale Locations for CUP Survey Respondents 
This type of distribution precludes $t$-test analyses without transformation, but it should not impact on regressions or correlations; therefore distributions of academic challenge scale locations were not used in $t$-tests. 


\section{Academic perseverance.}

Academic perseverance is defined as students' certainty that they will persist in the face of academic adversity. This is based on students' rating the extent that they will:

- Study when there are other interesting things to do

- Find additional information for course assignments when you don't understand the material

- Participate regularly in course discussions, even when you don't feel like it

- Ask instructors for help when you struggle with course assignments

- Finish something you have started when you encounter challenges

- Stay positive, even when you do poorly on a test or assignment

One component was extracted from the PCA, which explained $49.438 \%$ of the variance $($ Total $=2.966)$. Factor loadings suggest the subscale is one-dimensional:

Table 12.

Factor Loadings of Expected Academic Perseverance Subscale

\begin{tabular}{|c|c|c|}
\hline Item & Expected Academic Perseverance Survey Descriptor & Loading \\
\hline PER1 & Study when there are other interesting things to do & .651 \\
\hline PER2 & $\begin{array}{l}\text { Find additional information for course assignments when you don't } \\
\text { understand the material }\end{array}$ & .744 \\
\hline PER3 & $\begin{array}{l}\text { Participate regularly in course discussions, even when you don't feel } \\
\text { like it }\end{array}$ & .728 \\
\hline PER4 & Ask instructors for help when you struggle with course assignments & 662 \\
\hline PER5 & Finish something you have started when you encounter challenges & .816 \\
\hline PER6 & Stay positive, even when you do poorly on a test or assignment & .596 \\
\hline
\end{tabular}

Note. *Using Principle Component Analysis with Varimax Rotation procedure. Factor loadings > .40 are in boldface.

Accordingly, students total academic perseverance scale locations were calculated using IRT based on 217 responses to the above six items. The distribution of this interval scale was relatively normal (See Figure $12 ; n=197, M=-.07, s d=1.863$ ). 


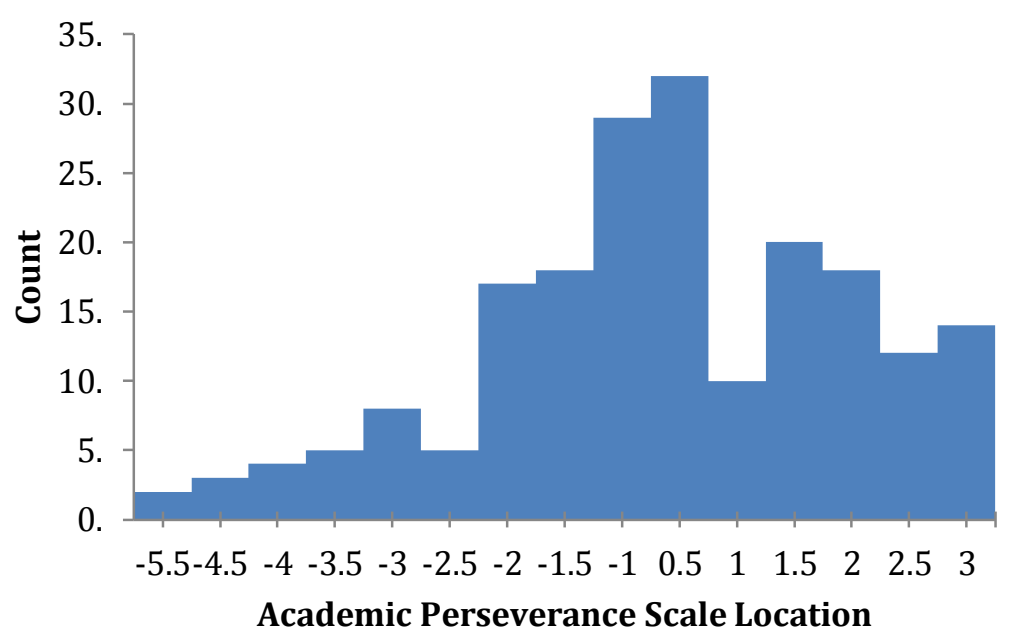

Figure 12. Histogram of Perseverance Scale Locations for CUP Survey Respondents

Although the scale locations for academic perseverance are somewhat negatively skewed $(-.973, S E=1.01)$ indicating that survey respondents generally measure higher on the academic perseverance construct, this should not impact on further analyses, therefore academic perseverance was included in the correlations and regressions. 
Academic readiness.

Academic readiness is measuring the extent that students feel prepared for their academic studies in the following areas:

- Using computers in academic work

- Reading and understanding academic material

- Comprehending instructions/information

- Taking notes

- Using the library for research

- Staying committed and motivated

- Managing your time

- Staying organised

One component was extracted from the PCA of the above items, which explained $57.199 \%$ of the variance (Total $=4.004)$. Factor loadings suggest the subscale is unidimensional:

Table 13.

Factor Loadings for Academic Readiness Engagement Subscale*

\begin{tabular}{lll}
\hline Item & Engagement Survey Descriptor & Loading \\
\hline AR2_PREP & Using computers in academic work & .722 \\
AR3_PREP & Reading and understanding academic material & .762 \\
AR4_PREP & Comprehending instructions/information & .753 \\
AR5_PREP & Taking notes & .620 \\
AR6_PREP & Using the library for research & .742 \\
AR7_PREP & Staying committed and motivated & .851 \\
AR8_PREP & Managing your time & .822 \\
\hline $\begin{array}{l}\text { Note. *Using Principle Component Analysis with Varimax Rotation procedure. Factor loadings > .40 are } \\
\text { in boldface. }\end{array}$ &
\end{tabular}

Therefore, total academic readiness scale locations were calculated using IRT based on 214 responses to the above seven items. The distribution of this interval scale was somewhat negatively skewed with many students with positive results, but still appeared reasonably normal (See Figure 13; $n=192, M=-.03, s d=2.229$ ). 


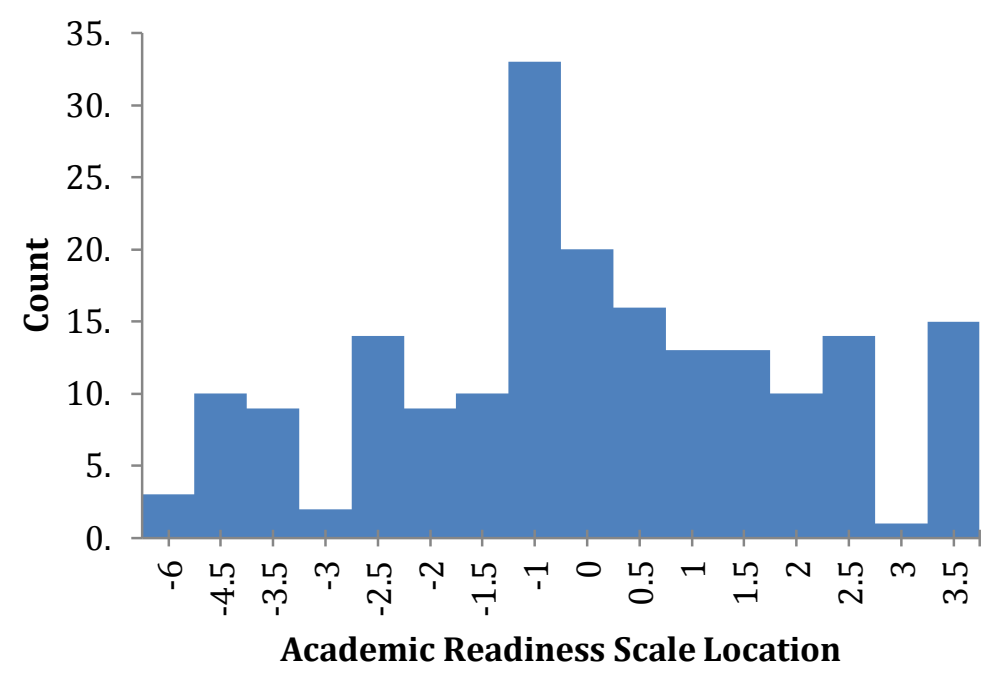

Figure 13. Histogram of Academic Readiness Scale Locations for CUP Survey Respondents

Accordingly, academic readiness scale locations were further analysed to examine their relationship with achievement. 


\section{Active learning.}

Active learning measures students' efforts to actively construct their knowledge, specifically how often they:

- Used student learning support services

- Came to class having completed readings or assignments

- Kept up to date with your studies

- Worked with other students on projects during class

- Worked with other students outside class to prepare assignments

Two components were extracted from the active learning subscale, suggesting that these items were multidimensional; therefore the active learning subscale was not totalled for any further analyses. Table 14 shows that two items load strongly on each component, which does not warrant full-scale calculations.

Table 14.

Factor Loadings for Active Learning Engagement Subscale*

Loading

Item Engagement Survey Descriptor $\quad$ Component 1 Component 2

\begin{tabular}{|c|c|c|c|}
\hline AL1 & Used student learning support services & .163 & .147 \\
\hline AL2 & $\begin{array}{l}\text { Came to class having completed readings or } \\
\text { assignments }\end{array}$ & -.085 & .874 \\
\hline AL3 & Kept up to date with your studies & .190 & .841 \\
\hline AL4 & $\begin{array}{l}\text { Worked with other students on projects during } \\
\text { class }\end{array}$ & .873 & .126 \\
\hline AL5 & $\begin{array}{l}\text { Worked with other students outside class to } \\
\text { prepare assignments }\end{array}$ & .882 & -.057 \\
\hline
\end{tabular}

Note. *Using Principle Component Analysis with Varimax Rotation procedure. Factor loadings > .40 are in boldface.

The construct validity of the active learning subscale did not seem to stand for this particular sample, most likely because the population sampled in this study is much smaller than the entire AUSSE cohort. However, it could be that the surveyed students differ from the general population on their active learning. Due to these limitations, this particular subscale was not calculated into an interval score. Yet, these individual ordinal items were checked for correlations with achievement on CUP and on degrees. 


\section{General development outcomes.}

General development outcomes subscale considers to what extent students develop general forms of individual and social development, particularly:

- Understanding yourself

- Understanding people of other cultural or ethnic backgrounds

- Contributing to the welfare of your community

One component was extracted from the PCA, which explained $65.610 \%$ of the variance $($ Total $=1.968)$. Factor loadings suggest the subscale is unidimensional, as presented in Table 15 below:

Table 15.

Factor Loadings for General Development Outcomes Engagement Subscale*

\begin{tabular}{lll}
\hline Item & Engagement Survey Descriptor & Loading \\
\hline DEV1_PREP & Understanding yourself & .799 \\
DEV2_PREP & $\begin{array}{l}\text { Understanding people of other cultural or ethnic } \\
\text { backgrounds }\end{array}$ & .847 \\
DEV3_PREP & $\begin{array}{l}\text { Contributing to the welfare of your community } \\
\text { Dent }\end{array}$ & .782
\end{tabular}

Note. *Using Principle Component Analysis with Varimax Rotation procedure. Factor loadings $>.40$ are in boldface.

Therefore, total general development outcome scale locations were calculated using IRT based on 210 responses to the above three items. The distribution of this interval scale seemed to be relatively normal (See Figure $14 ; n=187, M=-.04, s d=2.470$ ), and this construct was included in subsequent analyses.

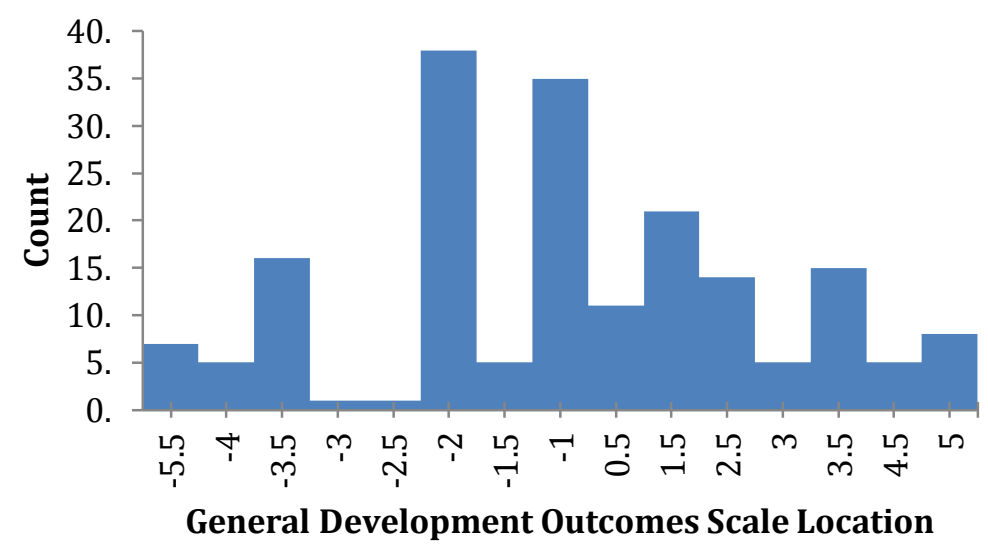

Figure 14. Histogram of General Development Outcomes Scale Locations for CUP Survey Respondents

The general development outcome scale locations were negatively skewed $(-1.98, S E=$ $1.01)$ with a positive kurtosis $(3.53, S E=2.62)$ with the peak in scores apparent on the -2 to -1 range. Due to a large enough sample size, the distribution of these scale location scores should not limit subsequent analyses. 


\section{General learning outcomes.}

General learning outcomes considered development of the following general competencies:

- Acquiring a broad general education

- Writing clearly and effectively

- Speaking clearly and effectively

- Thinking critically and analytically

- Using computing and information technology

- Working effectively with others

- Learning effectively on your own

One component was extracted from the PCA, which explained $52.199 \%$ of the variance $($ Total $=3.649)$. Factor loadings $($ See Table 16) indicated that the subscale is unidimensional.

Table 16.

Factor Loadings for General Learning Outcomes Engagement Subscale*

\begin{tabular}{lll}
\hline Item & Engagement Survey Descriptor & Loading \\
\hline LRN1_PREP & Acquiring a broad general education & .686 \\
LRN2_PREP & Writing clearly and effectively & .702 \\
LRN3_PREP & Speaking clearly and effectively & .763 \\
LRN4_PREP & Thinking critically and analytically & .764 \\
LRN5_PREP & Using computing and information technology & .641 \\
LRN6_PREP & Working effectively with others & .706 \\
LRN7_PREP & Learning effectively on your own & .782
\end{tabular}

Note. *Using Principle Component Analysis with Varimax Rotation procedure. Factor loadings > .40 are in boldface..

Therefore, total general learning outcome scale locations were calculated using IRT based on 218 responses to the above seven items. The distribution of this interval scale was reasonably normal (See Figure $15 ; n=195, M=-.08, s d=2.076$ ). 


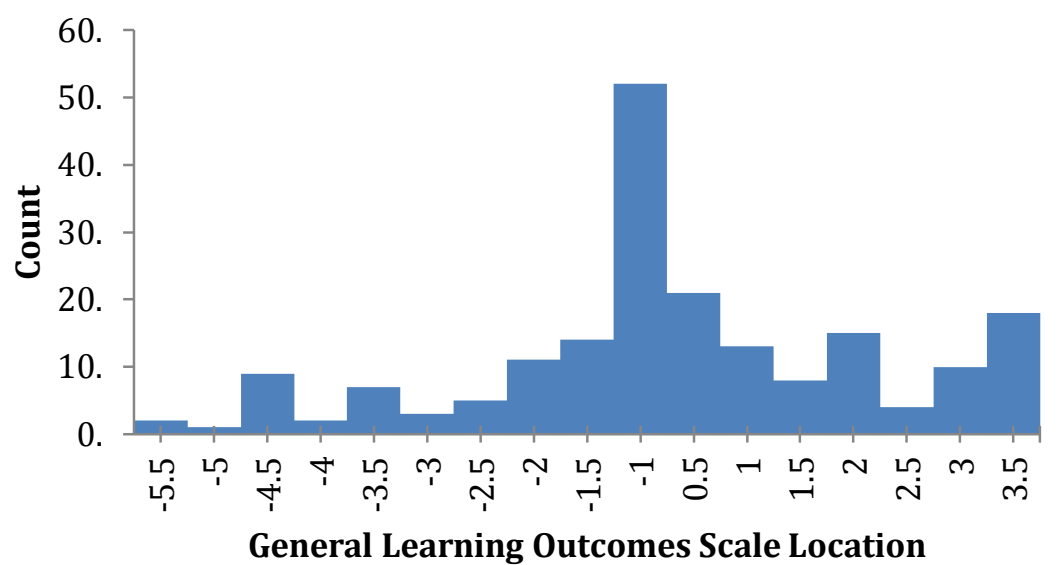

Figure 15. Histogram of General Learning Outcome Scale Locations for CUP Survey Respondents

The general learning outcomes histogram was somewhat negatively skewed $(-1.38, S E=$ 1.01) suggesting higher scale locations for the general learning outcome measure, although these results should not limit the ability to generate inferential statistics. 


\section{Supportive learning environment.}

Supportive learning environment considers students' feelings of legitimation within the university community, by measuring how much they perceived their programme provided:

- Support to help you succeed academically

- Assistance coping with your non-academic responsibilities (work, family, etc.)

- Support to help you thrive socially

- Opportunities to attend campus events and activities

One component was extracted from the factor analysis, which explained $56.622 \%$ of the variance $($ Total $=2.265)$. Factor loadings suggest the subscale was unidimensional:

Table 17.

Factor Loadings* for Supportive Learning Environment Engagement Subscale

\begin{tabular}{|c|c|c|}
\hline Item & Engagement Survey Descriptor & Loading \\
\hline SLE1_INC & Support to help you succeed academically & .574 \\
\hline SLE2_INC & $\begin{array}{l}\text { Assistance coping with your non-academic } \\
\text { responsibilities (work, family, etc.) }\end{array}$ & .810 \\
\hline SLE3_INC & Support to help you thrive socially & .807 \\
\hline SLE4_INC & $\begin{array}{l}\text { Opportunities to attend campus events and } \\
\text { activities }\end{array}$ & .792 \\
\hline
\end{tabular}

Therefore, total scale locations for supportive learning environment were calculated using IRT based on 210 responses to the above four items. The distribution of this interval scale seemed relatively normal (See Figure 16; $n=184, M=-.08, s d=2.323$ ).

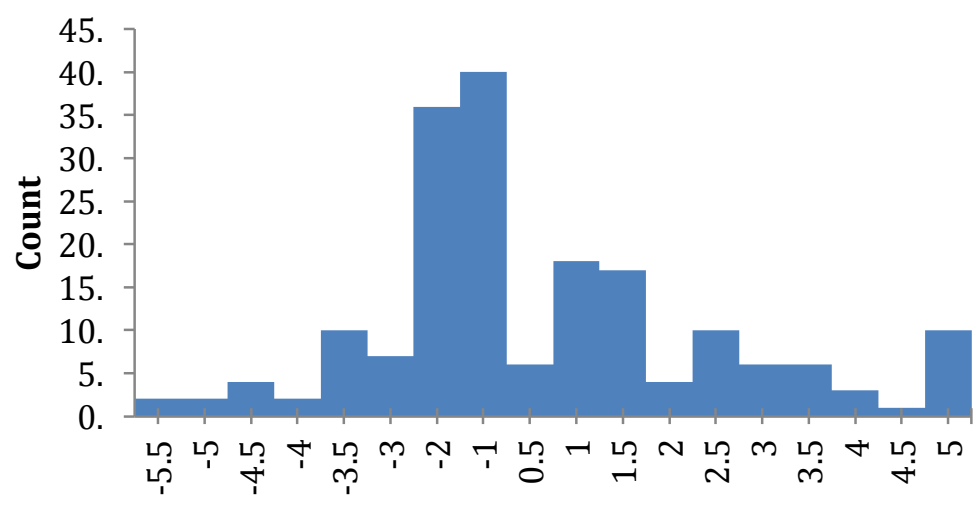

Supportive Learning Environment Scale Location

Figure 16. Histogram of Supportive Learning Environment Scale Locations for CUP Survey Respondents

Accordingly, scale locations for supportive learning environment were included in inferential analyses. 